\title{
Atrial fibrillation ablation: pitfalls and potential solutions
}

Citation for published version (APA):

Kumar, N. (2015). Atrial fibrillation ablation: pitfalls and potential solutions. [Doctoral Thesis, Maastricht University]. Maastricht University. https://doi.org/10.26481/dis.20151105nk

Document status and date:

Published: 01/01/2015

DOI:

10.26481/dis.20151105nk

Document Version:

Publisher's PDF, also known as Version of record

\section{Please check the document version of this publication:}

- A submitted manuscript is the version of the article upon submission and before peer-review. There can be important differences between the submitted version and the official published version of record.

People interested in the research are advised to contact the author for the final version of the publication, or visit the DOI to the publisher's website.

- The final author version and the galley proof are versions of the publication after peer review.

- The final published version features the final layout of the paper including the volume, issue and page numbers.

Link to publication

\footnotetext{
General rights rights.

- You may freely distribute the URL identifying the publication in the public portal. please follow below link for the End User Agreement:

www.umlib.nl/taverne-license

Take down policy

If you believe that this document breaches copyright please contact us at:

repository@maastrichtuniversity.nl

providing details and we will investigate your claim.
}

Copyright and moral rights for the publications made accessible in the public portal are retained by the authors and/or other copyright owners and it is a condition of accessing publications that users recognise and abide by the legal requirements associated with these

- Users may download and print one copy of any publication from the public portal for the purpose of private study or research.

- You may not further distribute the material or use it for any profit-making activity or commercial gain

If the publication is distributed under the terms of Article $25 \mathrm{fa}$ of the Dutch Copyright Act, indicated by the "Taverne" license above, 
Atrial fibrillation ablation:

\section{Pitfalls and potential solutions}


(C) Narendra Kumar, Maastricht 2015

No part of this book may be reproduced or transmitted in any form or by any means, without prior permission in writing by the author, or when appropriate, by the publishers of the publications.

Layout: Tiny Wouters

English editor: Judith Wilson; Bhojpuri translation: Translation India

Cover: Justus Watermann, Narendra Kumar, Freepix.com

Printed by: GVO drukkers \& vormgevers B.V. | Ponsen \& Looijen

ISBN: 978-90-6464-925-7

Financial support by the Dutch Heart Foundation and Stichting Hartsvrienden RESCAR is gratefully acknowledged.

Further financial support granted by Daiichi Sankyo Nederlands, Bayer HealthCare, St. Jude Medical and CardioFocus. 


\title{
Atrial fibrillation ablation: \\ Pitfalls and potential solutions
}

\author{
DISSERTATION
}

to obtain the degree of Doctor at Maastricht University, on the authority of the Rector Magnificus Prof. dr. L.L.G. Soete,

in accordance with the decision of the Board of Deans, to be defended in public on Thursday 5 november 2015, at 12:00 hours

by

Narendra Kumar 
Promotor

Prof. dr. J.G. Maessen

\section{Copromotor}

Dr. C.C.M.M. Timmermans

Prof. dr. S. Gelsomino

\section{Beoordelingscommissie}

Prof. dr. A.P.M. Gorgels (chairman)

Dr. Y. Blaauw, UMC Groningen

Dr. B. Kietselaer

Prof. dr. H.P.Brunner La Rocca

Prof. dr. J.L.R.M. Smeets, Radboud UMC 
"The woods are lovely, dark and deep,

But I have promises to keep,

And miles to go before I sleep, And miles to go before I sleep."

Robert Frost

Dedicated to my parents Prof. Sheo Jag Singh and Mrs. Kaushalya Devi 



\section{Contents}

$\begin{array}{lll}\text { Chapter } 1 & \text { Introduction } & 9\end{array}$

Chapter 2 Management of pulmonary vein stenosis following catheter $\quad 15$ ablation of atrial fibrillation.

Chapter 3 Hybrid approach to atrial fibrillation ablation using cryoballoon endocardially and bipolar RF clamp epicardially.

Chapter 4 Hemoptysis after cryoablation for atrial fibrillation ablation:

Truth or just a myth?

Chapter 5 Adenosine testing after second-generation balloon devices

(cryo and laser) pulmonary vein ablation for atrial fibrillation.

Chapter $6 \quad$ Impact of hybrid procedure on P-wave duration for atrial fibrillation ablation.

Chapter 7 Use of adenosine for testing of box lesion.

Chapter 8 The symbiosis of a contact force catheter use for hybrid ablation for atrial fibrillation.

Chapter 9 Atraumatic lung hernia: A rare complication of minimally invasive surgical atrial fibrillation ablation.

Chapter 10 Adenosine Testing after Second generation Cryoballoon Ablation (ATSCA) study improves clinical success rate for atrial fibrillation.

Chapter 11 General discussion

Summary

Samenvatting

Saaransh

Valorisation

Acknowledgements

Curriculum vitae 



\section{Chapter 1}

Introduction

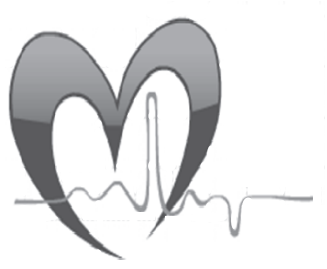


Chapter 1 


\section{The emerging global epidemic called atrial fibrillation}

In the $21^{\text {st }}$ century, atrial fibrillation (AF) is a worldwide epidemic affecting more than 33 million people, and over time its ever-rising prevalence is expected to account for increasing clinical and public health costs. Western countries and the rapidly developing countries such as Brazil, China, India, and Indonesia are facing an ageing population and more frequently recurring risk factors for $A F$, contributing to an increase in the prevalence and cost of AF. ${ }^{1-4}$ Several studies have shown a difference in AF incidence according to race. Among members of the Kaiser Permanente Southern California Health Plan who were aged $\geq 60$ years in 2008 , the prevalence of AF was significantly higher in white individuals (8.0\%) compared to Black (3.8\%), Hispanic (3.6\%), and Asian (3.9\%) ethnic groups. ${ }^{1,5-9}$ Similarly, data from the UK-based West Birmingham Atrial Fibrillation Project ${ }^{10}$ showed a low prevalence of AF among Indo-Asian participants aged $>50$ years $(0.6 \%)$, whereas the prevalence of $A F$ was $2.4 \%$ in the general study population aged $\geq 50$ years. Global studies support the findings of ethnic variation in the prevalence of AF in the Western world. Detailed analysis of data from the multinational ASSERT trial ${ }^{11}$ (in which patients had an implanted pacemaker or defibrillator) revealed a higher incidence of AF in individuals of European ancestry than in individuals of African, Chinese, or Japanese backgrounds. AF may cause associated morbidities such as stroke, ${ }^{12,13}$ myocardial infarction, ${ }^{14,15}$ heart failure, ${ }^{16}$ dementia, ${ }^{17,18}$ and chronic kidney disease, ${ }^{19,20}$ which are responsible for a high mortality of patients with AF. ${ }^{21,22}$

The exact number of AF-ablation procedures worldwide, as well as their complication rates is uncertain, in part owing to the lack of a global registry. ${ }^{23,24}$ However, the available data show that AF-ablation procedures are increasing, particularly in highincome countries. Surveys from arrhythmia centers around the globe, have reported more ablation procedures in the current decade compared to the last decade. ${ }^{23,25}$

\section{Aims and outline of this thesis}

In this thesis, we highlighted the various endocardial and epicardial ablation techniques using cryothermal, laser balloon, contact force catheters, and bipolar radiofrequency clamps. Various pitfalls are explained later such as hemoptysis after cryoablation and lung hernia after minimally invasive cardiac surgery that may be encountered by an ablationist be it a cardiac surgeon or an electrophysiologist while fighting the epidemic storm of AF. We also administered adenosine after pulmonary vein isolation using ablation catheter with different energy sources to reveal dormant reconduction. Ablating the reconducting veins significantly increases the success rate.

Chapter 2 summarizes the limited resources available for management of pulmonary vein stenosis following catheter ablation of atrial fibrillation. 
In chapter 3, endocardial cryoballoon ablation and epicardial bipolar radiofrequency ablation was combined for the first time as a hybrid approach to treat atrial fibrillation. In chapter 4, we observed hemoptysis as a complication of cryoablation. The purpose of this retrospective study was to report the incidence and characteristics of hemoptysis after cryoballoon ablation.

In chapter 5, we reported on the feasibility, safety, and clinical outcome up to 1 year after adenosine testing using second-generation cryo and laser balloon devices to treat atrial fibrillation.

To better predict the outcome of a hybrid procedure before procedure, we systematically analyzed, in chapter 6 , the changes of the $P$ wave obtained from the ECG, before and after a hybrid procedure- a systematic analysis.

In chapter 7 we observed the limitations of adenosine administration to test a box lesion.

Chapter 8 focuses on the safety and feasibility of use of a contact force catheter during a hybrid procedure for atrial fibrillation ablation and reports the annual success rate of the procedure.

For the first time, an atraumatic lung hernia as a complication of minimally invasive surgical atrial fibrillation ablation is reported in chapter 9.

The Adenosine Testing after Second generation Cryoballoon Ablation (ATSCA) study shows an improved clinical success rate for the treatment of atrial fibrillation in chapter 10.

The strength and weakness of both the endocardial catheter and epicardial surgical ablation approach were highlighted in chapter 11 .

We explained the rationale of combining new energy source for a hybrid procedure such as endocardial cryoballoon and epicardial bipolar radiofrequency clamp and we further improved success rates by using adenosine. Finally, current challenges and future developments are discussed in chapter 12 . 


\section{References}

1. Go AS, Hylek EM, Phillips KA, Chang Y, Henault LE, Selby JV, Singer DE. Prevalence of diagnosed atrial fibrillation in adults: national implications for rhythm management and stroke prevention: the AnTicoagulation and Risk Factors in Atrial Fibrillation (ATRIA) Study. JAMA 2001;285:2370-2375.

2. Moran A, Gu D, Zhao D, Coxson P, Wang YC, Chen CS, Liu J, Cheng J, Bibbins-Domingo K, Shen YM, He J, Goldman L. Future cardiovascular disease in china: markov model and risk factor scenario projections from the coronary heart disease policy model-china. Circ Cardiovasc Qual Outcomes 2010;3:243-252.

3. Miyasaka Y, Barnes ME, Gersh BJ, Cha SS, Bailey KR, Abhayaratna WP, Seward JB, Tsang TS. Secular trends in incidence of atrial fibrillation in Olmsted County, Minnesota, 1980 to 2000, and implications on the projections for future prevalence. Circulation 2006;114:119-125.

4. Kim MH, Johnston SS, Chu BC, Dalal MR, Schulman KL. Estimation of total incremental health care costs in patients with atrial fibrillation in the United States. Circ Cardiovasc Qual Outcomes 2011;4:313-320.

5. Hernandez MB, Asher CR, Hernandez AV, Novaro GM. African american race and prevalence of atrial fibrillation:a meta-analysis. Cardiol Res Pract 2012;2012:275624.

6. Shen AY, Contreras R, Sobnosky S, Shah AI, Ichiuji AM, Jorgensen MB, Brar SS, Chen W. Racial/ethnic differences in the prevalence of atrial fibrillation among older adults--a cross-sectional study. J Natl Med Assoc. 2010;102:906-913.

7. Alonso A, Agarwal SK, Soliman EZ, Ambrose M, Chamberlain AM, Prineas RJ, Folsom AR. Incidence of atrial fibrillation in whites and African-Americans: the Atherosclerosis Risk in Communities (ARIC) study. Am Heart J 2009;158:111-117.

8. Dewland TA, Olgin JE, Vittinghoff E, Marcus GM. Incident atrial fibrillation among Asians, Hispanics, blacks, and whites. Circulation 2013;128:2470-2477.

9. Jensen PN, Thacker EL, Dublin S, Psaty BM, Heckbert SR. Racial differences in the incidence of and risk factors for atrial fibrillation in older adults: the cardiovascular health study. Journal of the American Geriatrics Society Feb 2013;61:276-280.

10. Lip GY, Golding DJ, Nazir M, Beevers DG, Child DL, Fletcher RI. A survey of atrial fibrillation in general practice: the West Birmingham Atrial Fibrillation Project. Br J Gen Pract 1997;47:285-289.

11. Lau CP, Gbadebo TD, Connolly SJ, et al. Ethnic differences in atrial fibrillation identified using implanted cardiac devices. J Cardiovasc Electrophysiol 2013;24:381-387.

12. Stewart S, Hart CL, Hole DJ, McMurray JJ. A population-based study of the long-term risks associated with atrial fibrillation: 20-year follow-up of the Renfrew/Paisley study. Am J Med 2002;113:359-364.

13. Lip GY, Nieuwlaat R, Pisters R, Lane DA, Crijns HJ. Refining clinical risk stratification for predicting stroke and thromboembolism in atrial fibrillation using a novel risk factor-based approach: the euro heart survey on atrial fibrillation. Chest 2010;137:263-272.

14. Soliman EZ, Safford MM, Muntner P, Khodneva Y, Dawood FZ, Zakai NA, Thacker EL, Judd S, Howard VJ, Howard G, Herrington DM, Cushman M. Atrial fibrillation and the risk of myocardial infarction. JAMA intern Med 2014;174:107-114.

15. Miyasaka Y, Barnes ME, Gersh BJ, Cha SS, Bailey KR, Seward JB, Iwasaka T, Tsang TS. Coronary ischemic events after first atrial fibrillation: risk and survival. Am J Med 2007;120:357-363.

16. Miyasaka Y, Barnes ME, Gersh BJ, Cha SS, Bailey KR, Abhayaratna W, Seward JB, Iwasaka T, Tsang TS. Incidence and mortality risk of congestive heart failure in atrial fibrillation patients: a community-based study over two decades. Eur Heart J 2006;27:936-941.

17. Udompanich S, Lip GY, Apostolakis S, Lane DA. Atrial fibrillation as a risk factor for cognitive impairment: a semi-systematic review. QJM 2013;106:795-802.

18. Kwok CS, Loke YK, Hale R, Potter JF, Myint PK. Atrial fibrillation and incidence of dementia: a systematic review and meta-analysis. Neurology 2011;76:914-922.

19. Watanabe H, Watanabe T, Sasaki S, Nagai K, Roden DM, Aizawa Y. Close bidirectional relationship between chronic kidney disease and atrial fibrillation: the Niigata preventive medicine study. Am Heart J 2009;158:629-636.

20. Bansal N, Fan D, Hsu CY, Ordonez JD, Marcus GM, Go AS. Incident atrial fibrillation and risk of end-stage renal disease in adults with chronic kidney disease. Circulation 2013;127:569-574. 
21. Miyasaka Y, Barnes ME, Bailey KR, Cha SS, Gersh BJ, Seward JB, Tsang TS. Mortality trends in patients diagnosed with first atrial fibrillation: a 21-year community-based study. J Am Coll Cardiol 2007;49: 986-992.

22. Benjamin EJ, Wolf PA, D'Agostino RB, Silbershatz H, Kannel WB, Levy D. Impact of atrial fibrillation on the risk of death: the Framingham Heart Study. Circulation 1998;98:946-952.

23. Cappato R, Calkins H, Chen SA, et al. Updated worldwide survey on the methods, efficacy, and safety of catheter ablation for human atrial fibrillation. Circ Arrhythm Electrophysiol 2010;3:32-38.

24. Gupta A, Perera T, Ganesan A, Sullivan T, Lau DH, Roberts-Thomson KC, Brooks AG, Sanders P. Complications of catheter ablation of atrial fibrillation: a systematic review. Circ Arrhythm Electrophysiol 2013;6:1082-1088.

25. Cappato R, Calkins H, Chen SA, Davies W, lesaka Y, Kalman J, Kim YH, Klein G, Packer D, Skanes A. Worldwide survey on the methods, efficacy, and safety of catheter ablation for human atrial fibrillation. Circulation 2005;111:1100-1105. 


\section{Chapter}

Management of pulmonary vein stenosis following catheter ablation of atrial fibrillation

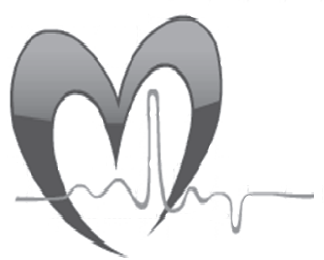

Narendra Kumar

Ismail Aksoy

Laurent Pison

Carl Timmermans

Jos Maessen

Harry Crijns

JAFIB: Journal of Atrial Fibrillation 2014;7(1) 


\section{Abstract}

There is limited literature available regarding PV (pulmonary vein) stenosis management. Starting from its incidence, subsequent follow up using imaging technologies to monitor the success and the way of management different groups pose varied opinions. However, with newer technological advancements and better understanding of mechanism of the atrial fibrillation ablation, the incidence of PV stenosis secondary to catheter ablation is declining. This paper highlights the current trends and future of management of PV stenosis secondary to catheter ablation for atrial fibrillation. 


\section{Introduction}

Atrial fibrillation (AF) concerns not only the medical community but also the society as a whole, due to increased risk of the morbidity, mortality, and also a reduced quality of life. The last few decades have seen better understanding of the pathophysiology of AF and the development of electrophysiological techniques. They allow for better catheter based ablation and electrical isolation of the pulmonary vein (PV) ostia for the treatment of AF. However, PV stenosis remains a potential complication of catheter ablation for $A F{ }^{1,2,3}$ The incidence rate is difficult to determine with current reported incidence varying from $1 \%$ to $21 \% .{ }^{4,5,6,7}$ Barrette et al. attributed it to multiple factors such as relating to the variability of patient symptoms, the discrepancy between PV stenosis and observed symptoms, the differences in enthusiasm for screening of PV stenosis following AF ablation and the different modalities that have been used to perform such screening. ${ }^{8} \mathrm{AF}$ catheter ablation as an etiology for PV stenosis was first described in 2000. ${ }^{9}$ Saad et al. observed left-sided PV stenosis more commonly after PV isolation for AF, attributing it to deeper movement of ablation catheter into a left-sided PV with respiration. When energy is delivered within the PV rather than in the preferred ostial location stenosis is more likely. ${ }^{5}$ The radiofrequency energy delivered during ablation procedure causes thermal injury to tissue surrounding the PV. At the local site, a scar leading to electrical isolation of the pulmonary venous musculature, replaces the healthy tissue. The location and volume of scar tissue formed may lead to PV narrowing or obstruction.

\section{Other causes of PV stenosis}

Before the advent of PV isolation, pulmonary venoocclusive disease was extremely rare. In most cases of naturally occurring pulmonary venoocclusive disease, the cause is unknown. However, this may occur secondary to conditions such as leukemia, lupus, lymphoma, or chemotherapy. The associated survival rates range from just a few weeks in infants to another few years in adults. $10 \mathrm{It}$ may also rarely lead to primary pulmonary hypertension.

PV stenosis has also been described as a rare complication of cardiac surgery. Among the pediatric population it is commonly described after complex congenital deformities repair in which the atria and PVs are directly manipulated, e.g. in atrial switch operations (the Mustard procedure) in D-transposition of the great vessels or anomalous pulmonary venous return. ${ }^{11,12}$ Booher and Bach et al. claim that "In adults who undergo cardiac surgery, PV stenosis has also been observed after autotransplantation for myxoma and inadvertent injury of the left atrium or PV". ${ }^{13-15}$ 


\section{Diagnosis before intervention and subsequent follow up}

The different imaging modalities assume significance for management of AF induced PV stenosis as they are not only decisive for choice of strategy. They also hold the key to a better follow up after intervention e.g. transesophageal echocardiography (TEE), computed tomography (CT), magnetic resonance imaging (MRI), and ventilationperfusion scans.

The echocardiography has a significant role in the diagnosis and follow-up of patients with acquired PV stenosis. ${ }^{15}$ TEE can be utilized for in- stent or in-vein restenosis intervention for such patients. ${ }^{16}$ However, post AF ablation induced PV stenosis without any intervention of stenting or angioplasty, CT or MRI should be preferred. ${ }^{8}$ De Piccoli et al. compared TEE and CT for follow up post AF ablation and observed CT was able to visualize more PVs than TEE; further the authors concluded that TEE provided additional functional data regarding the PV stenosis significance. ${ }^{17}$

As goes the sensible saying by Packer et al. "The best way to manage PV stenosis is to avoid it." It remains unclear, which is the best and most cost-effective way of detecting PV stenosis after ablation. However, on the basis of their experience, a staged approach starting with TEE and adding standard CT scanning if TEE gives insufficient results is proposed. Virtually every patient tolerated TEE first time, which was a prerequisite before PV ablation. However, not every PV could be assessed by peak Doppler flow velocity especially left inferior PV (in about 33\% of the patients studied). In addition, TEE was repeated in only $71 \%$ and $48 \%$ of patients during follow-up at 3 and 6 months respectively, usually because patients were unwilling to repeat this test just for routine screening. Consequently, data set of serial measurements was too small to draw any firm conclusions. Peak Doppler flow measurements of usually $>1 \mathrm{~m} / \mathrm{s}$ in stenosed PVs was observed. ${ }^{18}$

If an interventional procedure is planned, 3 dimensional reconstruction using acquired images gives edge to CT and MRI. The most common modality used for PV stenosis evaluation before and after ablation is CT. For CT to be used for assessing PV stenosis, a reading cardiologist or a radiologist should have an understanding of the anatomical details and the training required to diagnose.8

In the 21st century, with perfection of 3-dimensional mapping, CT and their integration can aid the treating electrophysiologists for better delivery of radiofrequency lesions and improving the safety profile of ablation procedures. ${ }^{19}$

Utmost, the highest care particularly in asymptomatic patients, when a high index of suspicion may not be present. CT tends to overestimate the PV stenosis. Pulmonary artery wedge angiography is a reliable option.20 Moreover, PV stenosis may be misdiagnosed in some patients. Yamaji et al. highlighted $50 \%$ overdiagnosis of PV stenosis at the level of the descending aorta/left aortic arch. The authors further concluded that to assess PV pseudostenosis especially left inferior PV, a prone position (rather than supine) should be used. 
The main advantage of CT over MRI is the quicker acquisition of images and the lower cost. Considering that MRI avoids radiation exposure, it should especially be considered for patients with long duration persistent AF who may need reinterventions. ${ }^{2}$

Tinte ra et al. used a semiautomatic measurement with contrast-enhanced MRI of PV cross-sectional areas to not only accurately assess, but also quantify the degree of proximal PV stenosis. $^{21}$

Ventilation-perfusion scans can reveal the perfusion defects of the affected lung segments in cases of severe stenosis and thus are extremely useful in showing the functional status. ${ }^{7,22}$ Perfusion values are less likely to be conclusive in patients with bilateral PV stenosis as the measured percent flow to each segment is, in turn, is dependent on the flow to other segments. ${ }^{20}$

There are several studies concluding that the use of intracardiac echo can lead to avoidance of such complications.

\section{Other techniques}

Recognizing the risk of PV stenosis, the next evolution in the treatment of AF was to perform wide area circumferential ablation (WACA), in which the encircling point-bypoint PV lesions were not performed at the ostia but at 1-2 cm away from the ostia of the PVs. This approach reduces the incidence of PV stenosis, but increases the risk of leaving gaps in the ablation lesions of a PV leading to arrythmias. Figure 2.1 summarizes the intra-procedural parameters during catheter ablation attributing to PV stenosis. ${ }^{23}$ Maeda et al. observed that the strategy of the local extensive encircling pulmonary vein isolation (EEPVI) is effective for preventing complications of severe PV stenosis. The strategy helps to determine the optimal ablation site and endpoint of the ablation procedure occurrence of stenosis using multidetector computed tomography (MDCT). Asymptomatic and mild PV stenosis was seen in 15 of 700 PVs (2.1\% of patients) who underwent significant narrowing after 12 months of follow up. ${ }^{24}$

\section{Role of energy sources}

Cryoballoon (Arctic Front ${ }^{\circledR}$, Medtronic, Minneapolis, MN, USA) ablation has been developed to provide a safe alternative for PV isolation. Compared to radiofrequency catheter ablation, the cryoballoon ablation causes lesser damage at histological level leading to PV shrinkage in preclinical assessment. Cryo ablation of a PV leading to its stenosis has been reported neither in animals ${ }^{25-28}$ nor in humans ${ }^{29-32}$ except STOP-AF trial where 7 (3.1\%) of the 228 cryoablated patients (10 PVs) developed stenosis that included 5 left inferior PVs, 4 left superior PVs, and 1 right inferior PV. Five patients were asymptomatic. The sixth patient became asymptomatic at the end of 1 year and 
the last patient refused further interventions. ${ }^{33}$ There was another case report of asymptomatic PV stenosis after cryoballoon ablation affecting left superior PV. ${ }^{34}$

There is a case report of left superior PV stenosis after using pulmonary vein ablation catheter (PVAC), Medtronic Inc. Limiting the total number and/or the number of 2:1 modus applications, avoiding ablations too close to the PV ostium, and improved imaging modalities to delineate the PV ostia are potential ways to minimize the risk of PV stenosis using PVAC. ${ }^{35}$ So, far there have been no clinical reports of PV stenosis with limited use of laser balloon. ${ }^{36,37}$

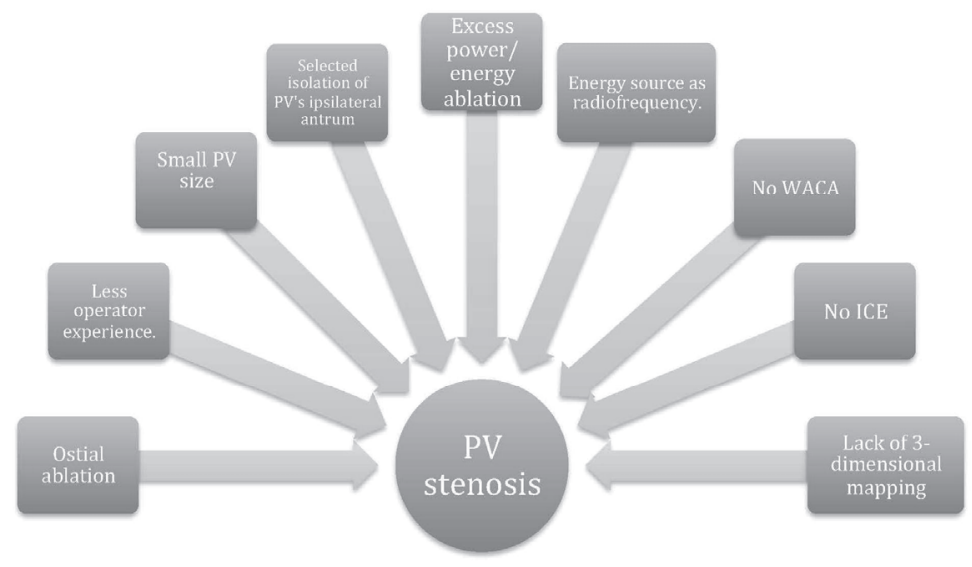

Figure 2.1 Intra procedural factors during catheter ablation associated with the development of pulmonary vein (PV) stenosis. WACA; wide area catheter ablation, ICE; intra-cardiac echocardiography.

\section{Classification of PV stenosis}

As stated in the consensus statement on catheter and surgical ablation of AF guidelines; according to the percentage reduction of the luminal diameter, the severity of PV stenosis is generally defined as mild $(<50 \%)$, moderate $(50-70 \%)$, or severe $(>70 \%){ }^{38}$ The amount of reduction in luminal diameter of PV is not related to clinical symptoms. The patients with mild and moderate stenosis can be asymptomatic. Respiratory symptoms for example coughing, hemoptysis and dyspnea are associated with severe stenosis of single or multiple PVs. ${ }^{39}$ In contrast, even patients with severe PV stenosis or even complete occlusion can be asymptomatic too. ${ }^{2,5,40,41}$ 


\section{Maastricht experience}

Currently cryoablation is commonly used for paroxysmal AF at Maastricht university medical center. Since January 2009, cryoballoon has been used for more than 450 patients who have been mostly paroxysmal and some persistent type of AF. Hybrid ablation combining simultaneous thoracoscopic surgical bipolar radiofrequency devices (Atricure, West Chester, OH, USA) and transvenous catheter AF ablation is preferred for failed previously ablated paroxysmal $A F$ (and dilated left atrium), persistent $A F$, and long standing persistent AF patients. ${ }^{42,43}$ Due to simultaneous use of videoscope during hybrid procedure PV fibrosis secondary to previous catheter ablation may also be visualized. ${ }^{44}$

At our center, irrigated tip radiofrequency catheters are used for endocardial touchups for re-do cases of AF recurrence. The power settings are limited as per the targeted area for ablation e.g. for posterior wall $>25$ watt and ablation deeper in PV is deliberately avoided.45 Recently past more than 2 year, irrigated tip radiofrequency catheters with contact force sensors (SmartTouch ${ }^{\mathrm{TM}}$, Biosense Webster Inc.) are being used. So far, we have never identified any symptomatic PV stenosis secondary to these AF ablation procedures yet. ${ }^{46}$

We have also performed a limited amount of PV isolation using laser balloon CardioFocus, Inc., Marlborough, Massachusetts) for 96 PVs (24 patients) with follow up data of 15 months and yet to see any symptomatic PV stenosis case. ${ }^{47}$ Several symptomatic patients whose PV isolation was done at other center were referred here, but were managed medically without any need for any interventions. (Figure 2.2a and $2.2 b)$
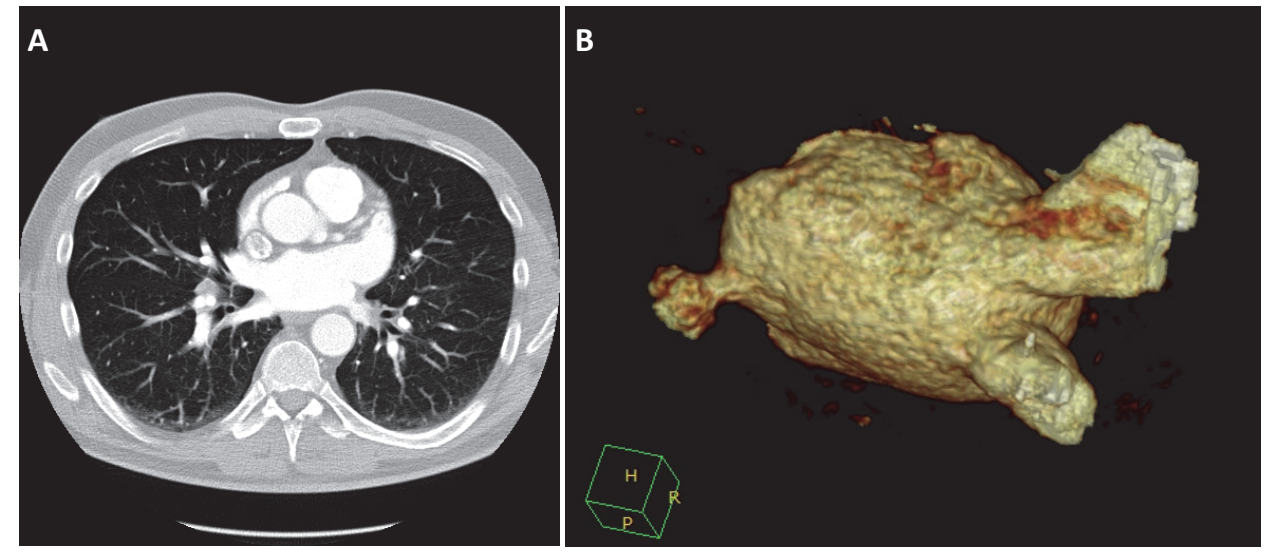

Figure 2.2 High-resolution computerized tomography scans of a patient with complete occlusion of left superior pulmonary vein secondary to previous radiofrequency catheter ablation. A) Axial view B) 3-dimensional reconstruction. 


\section{Management of PV stenosis}

There is limited literature on post procedural PV stenosis management secondary to catheter ablation of $A F$, in which the follow up is organized and according to standards of ESC or AHA.

The general consensus is that patients with symptomatic severe PV stenosis should be treated with PV angioplasty with or without stenting. ${ }^{2,5}$ For a single PV with severe stenosis but an asymptomatic case, there is no uniform opinion on whether or not intervention is warranted. However, the available evidence suggests that an early intervention in such patients translates to clinical benefit. Di Biase et al. also concluded single vessel PV occlusion is frequently asymptomatic if there is no ipsilateral PV stenosis.

In the last decade, several studies have demonstrated that PV angioplasty and stenting are feasible and successful for a majority of patients, resulting in symptomatic improvement. $^{20,32,48-51}$ However, their follow up revealed the susceptibility of such patients to high rates of in-segment or in-stent restenosis. ${ }^{8}$ Polytetrafluoroethylene covered stents have been used for congenital and acquired PV stenosis. Balloon expandable covered stents have better success rates in comparison to bare expandable stents for PV stenosis intervention. ${ }^{52-55}$ An isolated report of 2 cases successfully treated with endovascular conventional stenting and adjuvant oral Sirolimus provides an interesting point of view on this issue. ${ }^{56}$ De Potter et al. showed implantation of drug eluting stents (DES) for PV stenosis with an excellent stent patency rate during follow up of $12 \pm 14$ months. They further claimed that for monitoring stent patency, TEE Doppler measurements provide a viable way. ${ }^{57}$ Jariwala et al. who used bifurcation DESs also confirmed such an approach for PV stenosis post AF ablation. The patient neither had any instant restenosis confirmed by CT angiography after 12 months nor any arrhythmia or hemoptysis at 24 month follow up. Notably, during the 12 months following the angioplasty patient was taking Clopidogrel $75 \mathrm{mg} /$ day, AAS $75 \mathrm{mg} /$ day, and warfarin. Clopidogrel and warfarin were stopped after almost 1 year. ${ }^{58}$

Dragulescu et al. reported Paclitaxel to be particularly appropriate as it is highly lipophilic and hydrophobic and may increase vascular absorption in surrounding tissue. $^{56,59}$ Neointimal proliferation can lead to narrowing of the orifice or distal branches of the PV.60 For PV in-stent stenosis, cutting balloon angioplasty appears to improve the intermediate results of repeat angioplasty compared with standard angioplasty. ${ }^{61}$ Furukawa et al. implanted 3 bare metal stents and 3 Sirolimus-eluting stents (SESs) in pigs. The neointimal thickness, calculated using injury score after 8 weeks, was lesser in the SES group compared with the other group. ${ }^{62}$

There are several surgical procedures to treat the PV stenosis, for example, reimplantation of the PV with direct anastomosis, ${ }^{63}$ excision of the stenosis, ${ }^{64}$ patchplasty, ${ }^{64}$ and finally a sutureless technique. ${ }^{65,66}$ The sutureless technique has been used successfully to treat PV stenosis secondary to catheter ablation of an adult 
patient. ${ }^{67}$ Especially for redo cases after failure of conventional patchplasty, this technique effectively prevents reactive hyperplasia of the intima over the left atrium and the PV junction.

If a "wait and watch policy" strategy is employed, regular follow up is a must. The treating physician needs to reinvestigate even the slightest sign of symptoms. For PV stenosis patients, an "earlier the better" approach seem more realistic. Late intervention, even if associated with good restoration of venous patency, is not associated with significant improvement in affected lung-segments perfusion.

\section{Anticoagulation}

This is another area that definitely needs attention due to lack of optimal anticoagulation strategy following PV intervention. Considering the high rate of restenosis in treated PV segments, oral anticoagulation should be continued, in an effort to avoid thrombotic occlusion of the vein. The delay or failure in recognizing PV stenosis may lead to interruption of the anticoagulation after the procedure in asymptomatic patients. This tends to affect the pulmonary perfusion and attenuates the risk of the developing respiratory infections, pulmonary hypertension, pulmonary infarction and even thrombotic occlusion of the PV. ${ }^{2}$ If patients have no evidence of instent restenosis or AF recurrence after 12 months, patients with larger stents (9-10 $\mathrm{mm}$ ) can be discontinued with warfarin and started on aspirin therapy henceforth. ${ }^{20}$ Baranowski and Saliba et al. also advocate that the size of the stent used should be decisive in determining the duration of warfarin therapy. Due to the higher risk of occlusion in patients receiving smaller stents $(<1 \mathrm{~cm})$, warfarin is typically continued indefinitely. On the other hand, warfarin should be continued for at least a year for a patient receiving a larger stent $(\geq 1 \mathrm{~cm})$. They did not use Clopidogrel therapy routinely following a PV intervention. ${ }^{68}$ Similarly, Prieto et al. continued prescribing warfarin indefinitely for patients with small stents and/or diffusely hypoplastic veins.

Potter et al. initiated dual antiplatelet therapy with aspirin and clopidogrel for patients on an empirical basis giving due weightage to stents being placed in a low-flow system (PVs) and the lack of clinical data on venous DES thrombosis. ${ }^{56,57,69}$ This approach cannot be recommended as general practice and must be exercised with extreme caution. 


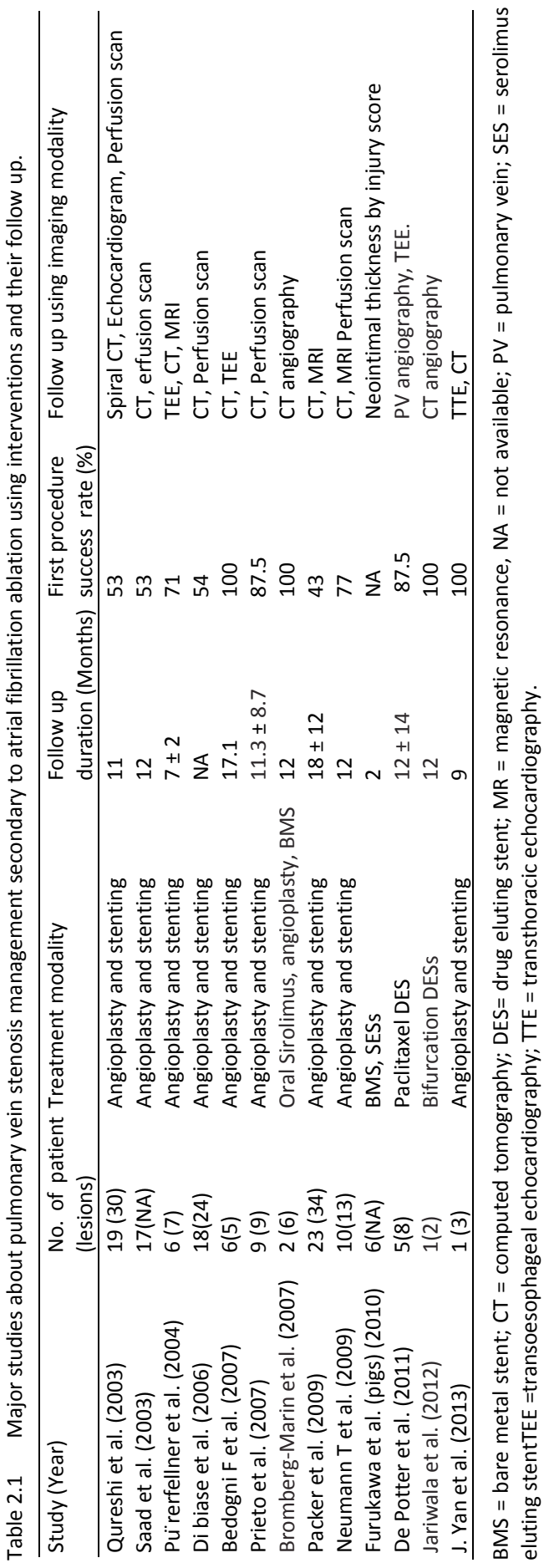




\section{Future perspectives}

Ever evolving techniques in AF ablation and increasing operator experience will reduce the incidence of PV stenosis in the future. Full proof technology complemented by suitable techniques which can withstand the test of time to prevent PV stenosis are yet to be developed. Anticoagulation strategy in spite of its importance in preventing any reocclusion still has to become a standard guideline. There is a need for large randomized studies to demonstrate the reduced restenosis and safety of using stents (bare metal and or drug eluted) in the setting of PV stenosis, and also regarding the use of imaging modality for follow up of patients after intervention.

\section{Conclusion}

Even though catheter ablation for symptomatic drug refractory AF is a safe technique, complications such as PV stenosis may still occur. With growing awareness of such complications and their improved management, its incidence should continue to decrease which is in the best interests of not only the patients but physicians too. Ultimately, "Prevention is better than cure." 


\section{References}

1. Saad EB, Rossillo A, Saad CP, Martin DO, Bhargava M, Erciyes D, Bash D, Williams-Andrews M, Beheiry S, Marrouche NF, Adams J, Pisano E, Fanelli R, Potenza D, Raviele A, Bonso A, Themistoclakis S, Brachmann J, Saliba WI, Schweikert RA, Natale A. Pulmonary vein stenosis after radiofrequency ablation of atrial fibrillation: Functional characterization, evolution, and influence of the ablation strategy. Circulation 2003;108:3102-3107.

2. Di Biase L, Fahmy TS, Wazni OM, Bai R, Patel D, Lakkireddy D, Cummings JE, Schweikert RA, Burkhardt JD, Elayi CS, Kanj M, Popova L, Prasad S, Martin DO, Prieto L, Saliba W, Tchou P, Arruda M, Natale A. Pulmonary vein total occlusion following catheter ablation for atrial fibrillation: Clinical implications after long-term follow-up. J Am Coll Cardiol 2006;48:2493-2499.

3. Dong J, Vasamreddy CR, Jayam V, Dalal D, Dickfeld T, Eldadah Z, Meininger G, Halperin HR, Berger R, Bluemke DA, Calkins $\mathrm{H}$. Incidence and predictors of pulmonary vein stenosis following catheter ablation of atrial fibrillation using the anatomic pulmonary vein ablation approach: Results from paired magnetic resonance imaging. J Cardiovasc Electrophysiol 2005;16:845-852.

4. Holmes DR, Jr., Monahan KH, Packer D. Pulmonary vein stenosis complicating ablation for atrial fibrillation: Clinical spectrum and interventional considerations. JACC Cardiovasc Interv 2009;2:267-276.

5. Saad EB, Marrouche NF, Saad CP, Ha E, Bash D, White RD, Rhodes J, Prieto L, Martin DO, Saliba WI, Schweikert RA, Natale A. Pulmonary vein stenosis after catheter ablation of atrial fibrillation: Emergence of a new clinical syndrome. Ann Intern Med 2003;138:634-638.

6. Cappato R, Calkins H, Chen SA, Davies W, lesaka Y, Kalman J, Kim YH, Klein G, Natale A, Packer D, Skanes A, Ambrogi F, Biganzoli E. Updated worldwide survey on the methods, efficacy, and safety of catheter ablation for human atrial fibrillation. Circ Arrhythm Electrophysiol 2010;3:32-38.

7. Arentz T, Jander N, von Rosenthal J, Blum T, Furmaier R, Gornandt L, Josef Neumann F, Kalusche D. Incidence of pulmonary vein stenosis 2 years after radiofrequency catheter ablation of refractory atrial fibrillation. Eur Heart J 2003;24:963-969.

8. Barrett CD, Di Biase L, Natale A. How to identify and treat patient with pulmonary vein stenosis post atrial fibrillation ablation. Curr Opin Cardiol 2009;24:42-49.

9. Scanavacca MI, Kajita L, Vieira M, Sosa EA. Pulmonary vein stenosis complicating catheter ablation of focal atrial fibrillation. J Cardiovasc Electrophysiol 2000;11:677-681.

10. Kojodjojo P, Wong T, Wright AR, Kon OM, Oldfield W, Kanagaratnam P, Davies DW, Peters NS. Pulmonary venous stenosis after treatment for atrial fibrillation. BMJ 2008;336:830-832.

11. Ussia G, Marasini M, Zannini L, Pongiglione G. Acquired pulmonary vein obstruction after open-heart surgery. Eur J Cardiothorac Surg 2002;22:465-467.

12. Devaney EJ, Ohye RG, Bove EL. Pulmonary vein stenosis following repair of total anomalous pulmonary venous connection. Seminars in thoracic and cardiovascular surgery. Semin Thorac Cardiovasc Surg Pediatr Card Surg Annu. 2006:51-55.

13. Anh D, Dudar B, Ananthasubramaniam K. Acquired isolated left pulmonary vein stenosis: A complication of bronchogenic cyst removal diagnosed by transesophageal echocardiography. Echocardiography (Mount Kisco, N.Y.). 2006;23:73-74.

14. Rosetti M, Tighe DA, Chandok D, Gammie JS, Griffith BP, Folland ED. An unusual cause of pulmonary vein stenosis: A case report and review of the literature. Echocardiography (Mount Kisco, N.Y.). 2006;23:685-688.

15. Booher AM, Bach DS. Acquired pulmonary vein stenosis: One problem, two mechanisms. J Am Soc Echocardiogr. 2010;23:904 e901-903.

16. Schneider C, Ernst S, Malisius R, Bahlmann E, Lampe F, Broemel T, Krause K, Boczor S, Antz M, Kuck KH. Transesophageal echocardiography: A follow-up tool after catheter ablation of atrial fibrillation and interventional therapy of pulmonary vein stenosis and occlusion. J Interv Card Electrophysiol 2007;18:195-205.

17. De Piccoli B, Rossillo A, Zanella C, Bonso A, Themistoclakis S, Corrado A, Raviele A. Role of transoesophageal echocardiography in evaluating the effect of catheter ablation of atrial fibrillation on anatomy and function of the pulmonary veins. Europace 2008;10:1079-1084. 
18. Purerfellner H, Aichinger J, Martinek M, Nesser HJ, Cihal R, Gschwendtner M, Dierneder J. Incidence, management, and outcome in significant pulmonary vein stenosis complicating ablation for atrial fibrillation. Am J Cardiol 2004;93:1428-1431, A1410.

19. Martinek M, NESSER HJ, Aichinger J, Boehm G, Purerfellner H. Impact of integration of multislice computed tomography imaging into three-dimensional electroanatomic mapping on clinical outcomes, safety, and efficacy using radiofrequency ablation for atrial fibrillation. Pacing Clin Electrophysiol 2007;30:1215-1223.

20. Prieto LR, Kawai Y, Worley SE. Total pulmonary vein occlusion complicating pulmonary vein isolation: Diagnosis and treatment. Heart Rhythm 2010;7:1233-1239.

21. Tintera J, Porod V, Cihak R, Mlcochova H, Rolencova E, Fendrych P, Kautzner J. Assessment of pulmonary venous stenosis after radiofrequency catheter ablation for atrial fibrillation by magnetic resonance angiography: A comparison of linear and cross-sectional area measurements. Eur Radiol 2006;16:2757-2767.

22. Nanthakumar K, Mountz JM, Plumb VJ, Epstein AE, Kay GN. Functional assessment of pulmonary vein stenosis using radionuclide ventilation/perfusion imaging. Chest 2004;126:645-651.

23. Sarabanda AVL, Beck LC, Ferreira LGG, Gali WL, Melo Netto F, Monte GU. Treatment of pulmonary vein stenosis after percutaneous ablation of atrial fibrillation. Arq Bras Cardiol 2010;94:e7-e10.

24. Maeda S, lesaka Y, Otomo K, Uno K, Nagata Y, Suzuki K, Hachiya H, Goya M, Takahashi A, Fujiwara H, Isobe $M$. No severe pulmonary vein stenosis after extensive encircling pulmonary vein isolation: $12-$ month follow-up with 3d computed tomography. Heart Vessels. 2011;26:440-448.

25. Avitall B, Urboniene D, Rozmus G, Lafontaine D, Helms R, Urbonas A. New cryotechnology for electrical isolation of the pulmonary veins. J Cardiovasc Electrophysiol 2003;14:281-286.

26. Feld GK, Yao B, Reu G, Kudaravalli R. Acute and chronic effects of cryoablation of the pulmonary veins in the dog as a potential treatment for focal atrial fibrillation. J Interv Card Electrophysiol 2003;8: 135-140.

27. Avitall B, Lafontaine D, Rozmus G, Adoni N, Le KM, Dehnee A, Urbonas A. The safety and efficacy of multiple consecutive cryo lesions in canine pulmonary veins-left atrial junction. Heart Rhythm 2004;1: 203-209.

28. Sarabanda AV, Bunch TJ, Johnson SB, Mahapatra S, Milton MA, Leite LR, Bruce GK, Packer DL. Efficacy and safety of circumferential pulmonary vein isolation using a novel cryothermal balloon ablation system. J Am Coll Cardiol 2005;46:1902-1912.

29. Tse HF, Reek S, Timmermans C, Lee KL, Geller JC, Rodriguez LM, Ghaye B, Ayers GM, Crijns HJ, Klein HU, Lau CP. Pulmonary vein isolation using transvenous catheter cryoablation for treatment of atrial fibrillation without risk of pulmonary vein stenosis. J Am Coll Cardiol 2003;42:752-758.

30. Chun KR, Schmidt B, Metzner A, Tilz R, Zerm T, Koster I, Furnkranz A, Koektuerk B, Konstantinidou M, Antz $\mathrm{M}$, Ouyang $\mathrm{F}$, Kuck $\mathrm{KH}$. The 'single big cryoballoon' technique for acute pulmonary vein isolation in patients with paroxysmal atrial fibrillation: A prospective observational single centre study. Eur Heart J 2009;30:699-709.

31. Schmidt B, Chun KR, Metzner A, Ouyang F, Kuck KH. Balloon catheters for pulmonary vein isolation. Herz 2008;33:580-584.

32. Neumann T, Vogt J, Schumacher B, Dorszewski A, Kuniss M, Neuser H, Kurzidim K, Berkowitsch A, Koller M, Heintze J, Scholz U, Wetzel U, Schneider MA, Horstkotte D, Hamm CW, Pitschner HF. Circumferential pulmonary vein isolation with the cryoballoon technique results from a prospective 3-center study. J Am Coll Cardiol 2008;52:273-278.

33. Packer DL, Kowal RC, Wheelan KR, Irwin JM, Champagne J, Guerra PG, Dubuc M, Reddy V, Nelson L, Holcomb RG, Lehmann JW, Ruskin JN, Investigators SAC. Cryoballoon ablation of pulmonary veins for paroxysmal atrial fibrillation: First results of the north american arctic front (stop af) pivotal trial. J Am Coll Cardiol 2013;61:1713-1723.

34. Thomas D, Katus HA, Voss F. Asymptomatic pulmonary vein stenosis after cryoballoon catheter ablation of paroxysmal atrial fibrillation. J Electrocardiol 2011;44:473-476.

35. De Greef Y, Schwagten B, De Keulenaer G, Stockman D. Pulmonary vein stenosis after pulmonary vein ablation catheter-guided pulmonary vein isolation. Heart Rhythm 2010;7:1306-1308. 
36. Bordignon S, Chun KR, Gunawardene M, Fuernkranz A, Urban V, Schulte-Hahn B, Nowak B, Schmidt B. Comparison of balloon catheter ablation technologies for pulmonary vein isolation: The laser versus cryo study. J Cardiovasc Electrophysiol 2013;24:987-994.

37. Dukkipati SR, Kuck KH, Neuzil P, Woollett I, Kautzner J, McElderry HT, Schmidt B, Gerstenfeld EP, Doshi SK, Horton R, Metzner A, d'Avila A, Ruskin JN, Natale A, Reddy VY. Pulmonary vein isolation using a visually guided laser balloon catheter: The first 200-patient multicenter clinical experience. Circulation Arrhythm Electrophysiol 2013;6:467-472.

38. Calkins H, Brugada J, Packer DL, Cappato R, Chen SA, Crijns HJ, Damiano RJ, Jr., Davies DW, Haines DE, Haissaguerre $M$, lesaka $Y$, Jackman $W$, Jais $P$, Kottkamp $H$, Kuck KH, Lindsay BD, Marchlinski FE, McCarthy PM, Mont JL, Morady F, Nademanee K, Natale A, Pappone C, Prystowsky E, Raviele A, Ruskin JN, Shemin RJ. Hrs/ehra/ecas expert consensus statement on catheter and surgical ablation of atrial fibrillation: Recommendations for personnel, policy, procedures and follow-up. A report of the heart rhythm society (hrs) task force on catheter and surgical ablation of atrial fibrillation developed in partnership with the european heart rhythm association (ehra) and the european cardiac arrhythmia society (ecas); in collaboration with the american college of cardiology (acc), american heart association (aha), and the society of thoracic surgeons (sts). Endorsed and approved by the governing bodies of the american college of cardiology, the american heart association, the european cardiac arrhythmia society, the european heart rhythm association, the society of thoracic surgeons, and the heart rhythm society. Europace 2007;9:335-379.

39. Demelo-Rodriguez P, Del Toro-Cervera J, Andres-Del Olmo B. Haemoptysis and pulmonary vein stenosis after ablation for atrial fibrillation: Pathophysiology and therapeutic options. Arch Bronconeumol 2013;49:366-367.

40. Neumann T, Kuniss M, Conradi G, Sperzel J, Berkowitsch A, Zaltsberg S, Wojcik M, Erkapic D, Dill T, Hamm CW, Pitschner HF. Pulmonary vein stenting for the treatment of acquired severe pulmonary vein stenosis after pulmonary vein isolation: Clinical implications after long-term follow-up of 4 years. J Cardiovasc Electrophysiol 2009;20:251-257.

41. Sarabanda AV, Beck LC, Ferreira LG, Gali WL, Melo Netto F, Monte GU. [treatment of pulmonary vein stenosis after percutaneous ablation of atrial fibrillation]. Arq Bras Cardiol 2010;94:e7-e10.

42. Pison L, La Meir M, van Opstal J, Blaauw Y, Maessen J, Crijns HJ. Hybrid thoracoscopic surgical and transvenous catheter ablation of atrial fibrillation. J Am Coll Cardiol 2012;60:54-61.

43. Kumar N, Pison L, M. la Meir, J. Maessen, H. Crijns. Hybrid Approach to Atrial Fibrillation Ablation Using Bipolar Radiofrequency Devices Epicardially and Cryoballoon Endocardially.DOI:10.1093/icvts/ivu189.

44. Kumar N, Pison L, la Meir M, Maessen J. Direct visualization of pulmonary vein stenosis after previous catheter ablation. Heart Rhythm 2014;11:1602.

45. Baman TS, Jongnarangsin K, Chugh A, Suwanagool A, Guiot A, Madenci A, Walsh S, Ilg KJ, Gupta SK, Latchamsetty R, Bagwe S, Myles JD, Crawford T, Good E, Bogun F, Pelosi F, Jr., Morady F, Oral H. Prevalence and predictors of complications of radiofrequency catheter ablation for atrial fibrillation. J Cardiovasc Electrophysiol 2011;22:626-631.

46. Moreira W, Manusama R, Timmermans C, Ghaye B, Philippens S, Wellens HJ, Rodriguez L-M. Long-term follow-up after cryothermic ostial pulmonary vein isolation in paroxysmal atrial fibrillation. J Am Coll Cardiol 2008;51:850-855.

47. Kumar N, Blaauw Y, Timmermans C, Laurent Pison, Vernooy K, Harry Crijns. Adenosine testing after second-generation balloon devices (cryo and laser) pulmonary vein ablation for atrial fibrillation. J Interv Card Electrophysiol 2014;41:91-7.

48. Driscoll DJ, Hesslein PS, Mullins CE. Congenital stenosis of individual pulmonary veins: Clinical spectrum and unsuccessful treatment by transvenous balloon dilation. Am J Cardiol 1982;49:1767-1772.

49. Mendelsohn AM, Bove EL, Lupinetti FM, Crowley DC, Lloyd TR, Fedderly RT, Beekman RH, 3rd. Intraoperative and percutaneous stenting of congenital pulmonary artery and vein stenosis. Circulation 1993;88:II210-217.

50. Lock JE, Bass JL, Castaneda-Zuniga W, Fuhrman BP, Rashkind WJ, Lucas RV, Jr. Dilation angioplasty of congenital or operative narrowings of venous channels. Circulation 1984;70:457-464.

51. Qureshi AM, Prieto LR, Latson LA, Lane GK, Mesia Cl, Radvansky P, White RD, Marrouche NF, Saad EB, Bash DL, Natale A, Rhodes JF. Transcatheter angioplasty for acquired pulmonary vein stenosis after radiofrequency ablation. Circulation 2003;108:1336-1342. 
52. Tehrani S, Lipkin D. Angioplasty of acquired pulmonary vein stenosis using covered stent. Catheter Cardiovasc Interv2013;82:E617-620.

53. Gordon BM, Moore JW. Treatment of pulmonary vein stenosis with expanded polytetrafluoroethylene covered stents. Catheter Cardiovasc Interv 2010;75:263-267.

54. Mwipatayi BP, Thomas S, Wong J, Temple SE, Vijayan V, Jackson M, Burrows SA. A comparison of covered vs bare expandable stents for the treatment of aortoiliac occlusive disease. J Vasc Surg 2011; 54:1561-1570.

55. Matsumoto T, Zahn EM, Kar S. Percutaneous pulmonary vein stenosis angioplasty complicated by rupture: Successful stenting with a polytetrafluoroethylene-covered stent. Catheter Cardiovasc Interv 2014;83:E292-5.

56. Bromberg-Marin G, Tsimikas S, Mahmud E. Treatment of recurrent pulmonary vein stenoses with endovascular stenting and adjuvant oral sirolimus. Catheter Cardiovasc Interv 2007;69:362-368.

57. De Potter TJ, Schmidt B, Chun KR, Schneider C, Malisius R, Nuyens D, Ouyang F, Kuck KH. Drug-eluting stents for the treatment of pulmonary vein stenosis after atrial fibrillation ablation. Europace 2011;13: 57-61.

58. Jariwala P, Seitz J, Bouvier E, Piechaud JF. Bifurcation angioplasty using drug eluting stents of post-af ablation severe pulmonary vein stenosis. Pacing Clin Electrophysiol 2012;35:e330-333.

59. Dragulescu A, Ghez O, Quilici J, Fraisse A. Paclitaxel drug-eluting stent placement for pulmonary vein stenosis as a bridge to heart-lung transplantation. Pediatr Cardiol 2009;30:1169-1171.

60. Wax DF, Rocchini AP. Transcatheter management of venous stenosis. Pediatr Cardiol 1998;19:59-65; discussion 66.

61. Cook AL, Prieto LR, Delaney JW, Rhodes JF. Usefulness of cutting balloon angioplasty for pulmonary vein in-stent stenosis. Am J Cardiol 2006;98:407-410.

62. Furukawa T, Kishiro M, Fukunaga H, Ohtsuki M, Takahashi K, Akimoto K, Shimizu T, Kawasaki S, Kumasaka T. Drug-eluting stents ameliorate pulmonary vein stenotic changes in pigs in vivo. Pediatr Cardiol 2010;31:773-779.

63. Pacifico AD, Mandke NV, McGrath LB, Colvin EV, Bini RM, Bargeron LM, Jr. Repair of congenital pulmonary venous stenosis with living autologous atrial tissue. J Thorac Cardiovasc Surg 1985;89: 604-609.

64. van Son JA, Danielson GK, Puga FJ, Edwards WD, Driscoll DJ. Repair of congenital and acquired pulmonary vein stenosis. Ann Thorac Surg 1995;60:144-150.

65. Viola N, Alghamdi AA, Perrin DG, Wilson GJ, Coles JG, Caldarone CA. Primary pulmonary vein stenosis: The impact of sutureless repair on survival. J Thorac Cardiovasc Surg 2011;142:344-350.

66. Hickey EJ, Caldarone CA. Surgical management of post-repair pulmonary vein stenosis. Seminars in thoracic and cardiovascular surgery. Semin Thorac Cardiovasc Surg Pediatr Card Surg Annu 2011;14:101-108.

67. Hirota M, Hoshino J, Fukada $\mathrm{Y}$, Isomura T. Sutureless technique for recurrent pulmonary vein stenosis after pericardial patchplasty in an adult. J Thorac Cardiovasc Surg 2012;144:1264-1266.

68. Baranowski B, Saliba W. Our approach to management of patients with pulmonary vein stenosis following af ablation. J Cardiovasc Electrophysiol 2011;22:364-367.

69. Ernst S, Ouyang F, Goya M, Lober F, Schneider C, Hoffmann-Riem M, Schwarz S, Hornig K, Muller KM, Antz M, Kaukel E, Kugler C, Kuck KH. Total pulmonary vein occlusion as a consequence of catheter ablation for atrial fibrillation mimicking primary lung disease. J Cardiovasc Electrophysiol 2003;14: 366-370. 


\section{Chapter}

Hybrid approach to atrial fibrillation ablation using bipolar radiofrequency devices epicardially and cryoballoon endocardially

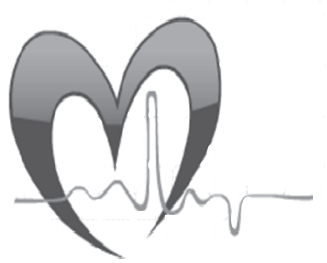

Narendra Kumar

Laurent Pison

Mark La Meir

Jos Maessen

Harry Crijns

Interactive CardioVascular and Thoracic Surgery, doi:10.1093/icvts/ivu189 


\section{Abstract}

\section{Objective}

Bipolar radiofrequency (RF) devices are used epicardially by cardiac surgeons and cryoballoon endocardially by cardiac electrophysiologists for atrial fibrillation (AF) ablation, but in separate entities. The study's objective was to evaluate the feasibility and safety of combining an endocardial cryoballoon with epicardial bipolar RF ablation for the treatment of AF.

\section{Methods}

A cohort of 7 patients with AF underwent a hybrid thoracoscopic surgical and endocardial ablation. To prevent bilateral sequential lung deflation in these patients with severe chronic obstructive pulmonary disease, the right pulmonary veins (PVs) were isolated using an epicardial bipolar RF clamp and the contralateral veins with an endocardial cryoballoon. A box lesion set was made epicardially using a bipolar RF pen.

\section{Results}

Acutely, pacing manoeuvres proved a bidirectional block in all PVs in all patients. No complications were seen. A box lesion was made in 5 patients. During follow-up, 2 of them had AF recurrence: 1 was treated successfully with sotalol and another underwent redo RF catheter ablation with reisolation of the right inferior PV. At present, 6 of 7 patients are in sinus rhythm without any anti-arrhythmic drugs during a follow-up of more than $40 \pm 3$ months.

\section{Conclusion}

A hybrid approach to AF ablation using a cryoballoon endocardially and a bipolar RF device epicardially is feasible and safe. 


\section{Introduction}

Atrial fibrillation (AF) is the most common arrhythmia with an incidence of 6 million patients in the USA alone. ${ }^{1} \mathrm{AF}$ is a major cause of stroke and an independent risk factor for mortality. ${ }^{2,3}$ Despite recent advances, medications have only been effective in restoring sinus rhythm (SR) in only almost half of all the patients with AF., ${ }^{4,5}$ Pulmonary vein (PV) isolation is the cornerstone of AF ablation. In patients with symptomatic AF, refractory to Class I and III anti-arrythmic drugs (AADs), who have undergone one or more failed attempts at catheter ablation or are not candidates for catheter ablation,

the European Society of Cardiology suggests considering standalone surgical ablation. ${ }^{6,7}$ Transmural atrial ablation is an effective way of curing this arrhythmia and bipolar ablation tools have been demonstrated to create better transmural lesions. ${ }^{8}$ However, these bipolar tools can only be used epicardially. This limits the use of such tools as only certain parts of the atrium allow clamping.

A combination of catheter and surgical ablation and also a simultaneous combination of radiofrequency (RF) with cryoablation have promising results. ${ }^{9,10}$ Cardiac surgeons consider the maze procedure as the gold standard for AF ablation, and a 'box lesion' around the PVs is the most important part of this procedure. ${ }^{11}$ In patients with paroxysmal and (long-standing) persistent AF with a dilated left atrium (LA) where an otherwise low success rate is expected by epicardial or endocardial ablation alone, the hybrid approach is a suitable option. ${ }^{12,13}$ However, lung deflations during a surgical approach may have deleterious consequences in subjects with a history of chronic obstructive pulmonary disease (COPD). In addition, phrenic nerve paralysis, which is the most common complication of endocardial cryoballoon ablation near the right superior $\mathrm{PV}$, can have severe negative effects on lung function in those patients. We aimed to study the feasibility of a hybrid approach using an endocardial cryoballoon with epicardial bipolar RF devices for the treatment of AF.

\section{Materials and methods}

From May 2008 to February 2011, 34 patients underwent a thoracoscopic surgical and transvenous catheter ablation of AF. In this group, epicardial ablation of PVs and endocardial touch-ups using radiofrequency catheters (if needed) were carried out for 27 patients. ${ }^{12}$ Endocardial cryoballoon and epicardial RF clamp were used for PV isolation in only 7 patients. All of them had recurrent, symptomatic paroxysmal AF and failed at least one AAD or catheter ablation.

The patients included had symptomatic paroxysmal AF, dilated LA $\geq 29 \mathrm{ml} / \mathrm{m}_{2}$ and/or history of failing at least one AAD or previous catheter ablation. These patients also had a Global Initiative for Chronic Obstructive Lung Disease (GOLD) spirometric classification, with a Class 4 category. According to the 2011 strategy document, Class 4 
category COPD patients have $<30 \%$ of predicted post-bronchodilator forced expiratory volume in 1 second. ${ }^{14}$ Table 3.1 summarizes the baseline characteristics of the selected patient group.

Table 3.1 Baseline characteristics of all included patients.

\begin{tabular}{lcccccccc}
\hline Patient number & Age & AF type & Gender & LVEF & CAD & LA Volume & AF duration & BMI \\
\hline 1 & 57 & Parox. & M & 62 & No & 99 & 48 & 31 \\
2 & 60 & Parox. & M & 62 & Yes & 90 & 108 & 28 \\
3 & 66 & Parox. & M & 57 & Yes & 84 & 120 & 24 \\
4 & 66 & Parox. & M & 63 & No & 82 & 120 & 32 \\
5 & 59 & Parox. & F & 70 & Yes & 80 & 72 & 26 \\
6 & 73 & Parox. & M & 50 & Yes & 94 & 102 & 24 \\
7 & 68 & Parox & F & 50 & No & 84 & 118 & 29 \\
\hline
\end{tabular}

$\mathrm{BMI}=$ body mass index; $\mathrm{M}=$ male; $\mathrm{LA}$ volume= left atrial volume $(\mathrm{ml}) ; \mathrm{CAD}=$ coronary artery disease; Parox. = paroxysmal; $\mathrm{LVEF}=$ left ventricular ejection fraction (\%); $\mathrm{AF}=$ atrial fibrillation; $\mathrm{AF}$ duration = in months.

\section{Hybrid procedure}

Under general anaesthesia, patients were ventilated using a double-lumen endotracheal tube for selective lung ventilation.

Transoesophageal echocardiography was used to rule out thrombus in the LA. The patient was laid in the supine position with arms parallel to the body. In the right thorax, after placing a 12-mm video port in the fifth intercostal space, carbon dioxide was insufflated in the thoracic cavity. Two working ports of 5 and $12 \mathrm{~mm}$ were inserted along the anterior axillary line in the third and sixth or seventh intercostal spaces, respectively, on the right side (Figure 3.1). The pericardium was opened posterior to the phrenic nerve and extended up to the diaphragm and superior vena cava on opposite sides. Stay sutures were placed for a better view of the PV and to facilitate dissection in transverse and oblique sinuses. A His Catheter (St. Jude Medical, St. Paul, MN, USA) and coronary sinus catheter (Medtronic, Minneapolis, MN, USA) were placed in the heart under fluoroscopic guidance through the groin venous puncture. A single trans-septal puncture was performed via a venous puncture in the right groin, and a 8-F long sheath (SLO, St. Jude Medical) was advanced into the LA. A heparin bolus of 1000 units per $10 \mathrm{~kg}$ of bodyweight followed by infusion with target activated clotting time above $300 \mathrm{~s}$ was given to heparinize the patient. To visualize the PVs and the LA, contrast was injected through the long sheath during rapid ventricular pacing. A wellsized circular mapping catheter (Lasso, Biosense Webster, Inc., Diamond Bar, CA, USA) was placed ostially to assess the presence of PV potentials. In the patient with a previous catheter ablation procedure, none of the PVs was isolated. No scars were visible on the epicardial surface of the ostium or antrum of the PVs that would be suggestive of transmural lesions. 


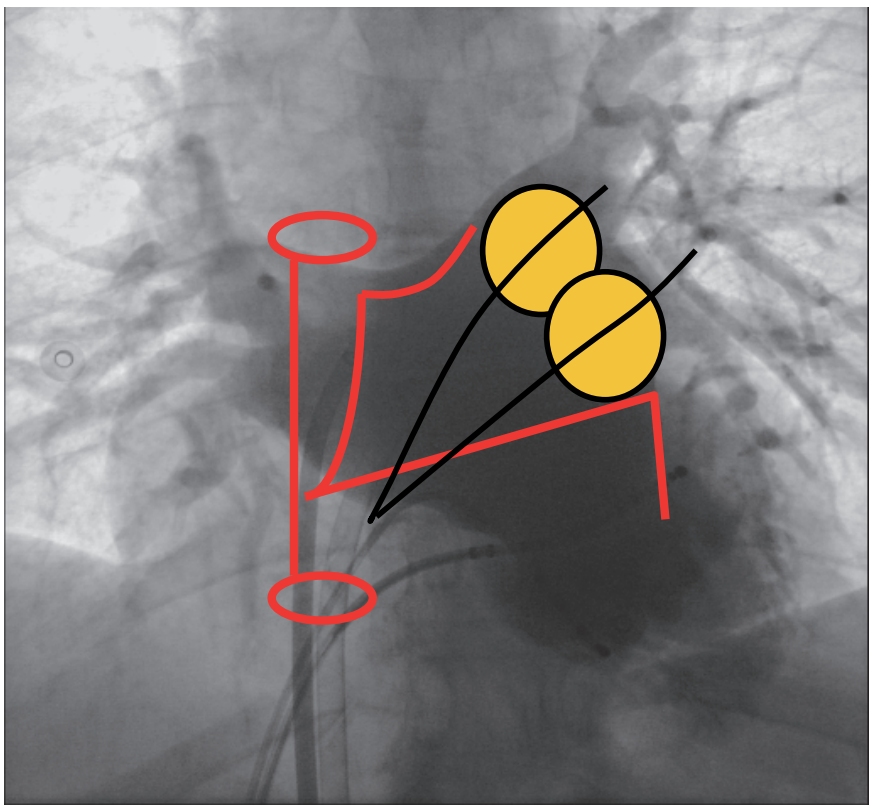

Figure 3.1 Red line indicates the epicardial bipolar radiofrequency application and big yellow circles represent the cryoballoon application to complete the left side of the box lesion.

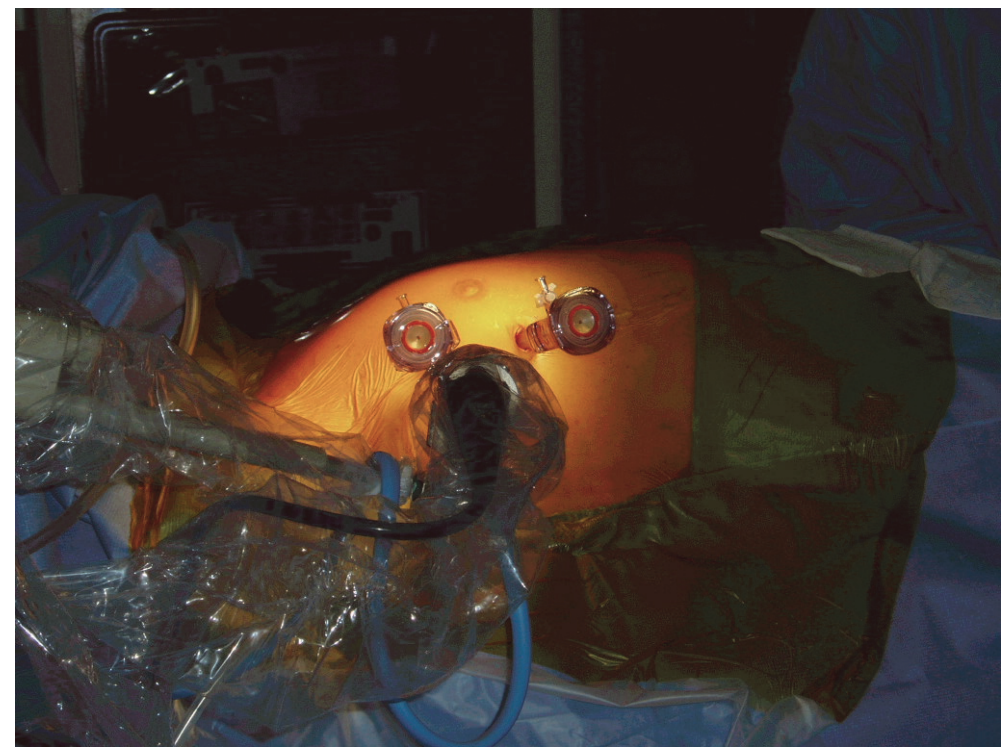

Figure 3.2 Placement of the working ports and a video port on the right side of the patient. 
A bipolar RF clamp (Atricure, West Chester, OH, USA) was placed at the antrum of the right PVs. Four to six applications of $\sim 15 \mathrm{~s}$ with a median output of 10-15 W were performed. After each application, the bipolar RF clamp was opened and closed again to prevent folding of atrial tissue that would cause incomplete transmural lesions. Systematic ablation of the ganglionated plexi was not attempted. Both roof line (connecting both superior PVs) and an inferior line (connecting both inferior PVs) were made epicardially using a bipolar RF pen or a linear pen device (Coolrail, Atricure). A diagram of the ablation lines made during the procedure is shown in Figure 3.2.

A cryoballoon was advanced into the LA through the transseptal puncture. This balloon was placed at the ostium of the left superior PV and left inferior PV respectively. Contrast injections showed complete occlusion (Figure 3.3). The freezing cycle was applied twice for $5 \mathrm{~min}$. Endocardial pacing manoeuvres proved a bidirectional block for each of the four PVs. The endpoints followed were same as those of the standard procedure for the cohort. ${ }^{12}$ Two additional ablation lines: one encircling the superior caval vein using the clamp, and the other connecting both caval veins using the linear pen were created for patients with a dilated right atrium that is, for patient 1 and 4.

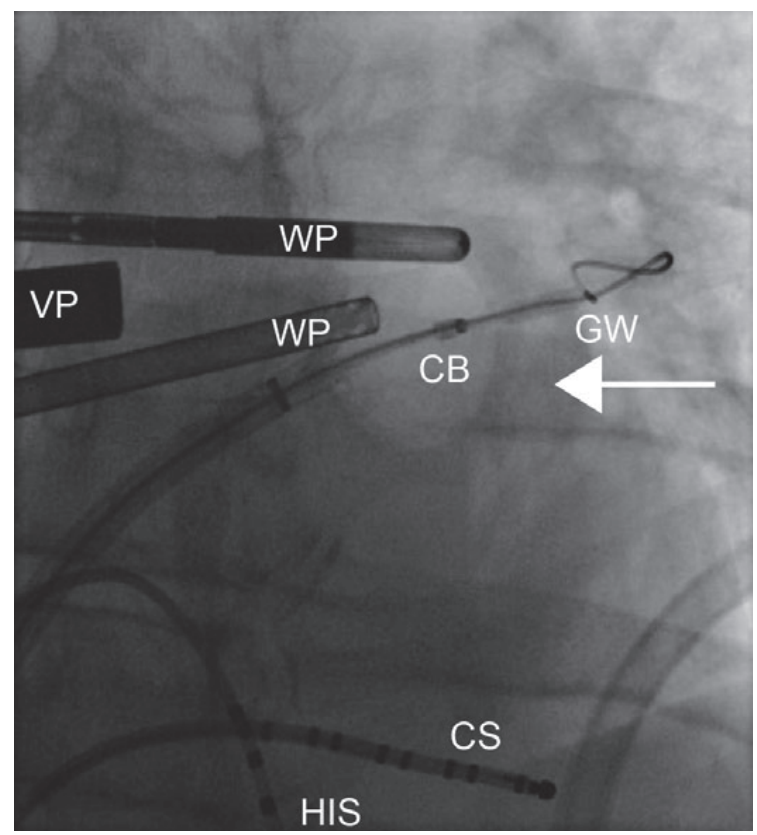

Figure 3.3 Fluoroscopic view of a cryoballoon (CB) with a guidewire (GW) occluding the left superior pulmonary vein with impending contrast (arrow), His (HIS) and coronary sinus (CS) catheters, working ports (WPs) and video port (VP) placed in the pericardial space. 
A stapling device was used to remove the LA appendage in all patients after widening the space for an interport. The bipolar RF pen device was used for 1 patient to create a mitral isthmus line from the ablation line on the antrum of the left inferior PV towards and crossing the coronary sinus. Cavo-tricuspid isthmus ablation was performed endocardially with an irrigated tip RF catheter. The endpoint at cavo-tricuspid isthmus ablation was demonstration of a bidirectional block.

After finishing the endocardial ablation, the pericardium was approximated with a stitch. Bilateral chest tubes were inserted in pleural cavities, without any drain in the pericardial space. Patients were extubated in the operating room before being transferred to the post-surgical care unit. Low-molecular-weight heparin was started within $6 \mathrm{~h}$ and bridged with acenocoumarol in the next 2 days. The patients were restarted on AADs as soon as possible. However, after 6 months, after confirming the absence of atrial arrhythmias, anti-coagulation and AADs were discontinued.

\section{Follow-up}

Follow-up was conducted in our outpatient clinic at the 3rd, 6th, 9th and 12th month after the procedure using $48 \mathrm{~h}$ or 7-day continuous Holter monitoring. Any episode of AF, atrial flutter or atrial tachycardia lasting more than $30 \mathrm{~s}$ detected after the 3-month blanking period was considered an arrhythmia recurrence. After 1 year of regular follow-up, visits were scheduled every 6th month henceforth with minimum 24-48 $\mathrm{h}$ or a 7-day Holter recording.

\section{Statistical analysis}

Continuous variables are expressed as mean \pm standard deviation. Data were retrospectively entered into a database. Statistical analysis was performed using SPSS 16.0 (SPSS, Inc., Chicago, IL, USA).

\section{Perioperative results}

None of the patients demonstrated phrenic nerve paralysis. No deaths or conversion to cardiopulmonary bypass were encountered. There were no signs of infection. The 7 patients who underwent this modality of treatment were all male with a mean age of $61.6 \pm 4.16$ years and AF duration of $98.3 \pm 27.9$ months. One patient had undergone catheter PV isolation. The remaining 6 patients were attempted twice with both pharmacological and electrical cardioversions, respectively. They opted for a hybrid procedure as the first procedure, without undergoing prior catheter ablation considering the longer AF duration. The median length of the hybrid procedure from initial skin incision to skin closure was $280 \pm 84 \mathrm{~min}$ (195-505 $\mathrm{min}$ ), attributed to the learning curve of the initial 3 cases. The patients had a mean left atrial size of $87.6 \pm 7$ 
$\mathrm{ml}$, right atrial volume of $70.2 \pm 20.6 \mathrm{ml}$ and a mean left ventricular ejection fraction of $59.1 \pm 7.3 \%$. A 28-mm cryoballoon was used for all 7 patients (100\%).

Acute PV isolation was obtained in $7 / 7$ (100\%) patients. The mean number of applications per patient was 2 per vein. The basal metabolic index was $27.7 \pm 3.2$. For 5 patients, PV isolation with a box lesion was made epicardially. One patient with a prior history of typical atrial flutter underwent additional cavo-tricuspid isthmus ablation and another one needed mitral isthmus ablation due to induction of mitraldependent atrial flutter during burst pacing to test arrhythmia induction. Further details of lesion sets and the follow-up are given in Table 3.2. Two patients among the group of 7 patients had AF recurrence. One was subsequently started on sotalol due to refusal for any further redo procedure. Another patient underwent a redo catheter ablation for symptomatic AF recurrence. During this procedure, reconduction of the right inferior PV was demonstrated. The other PVs were still isolated. The other ablation lines were intact too. The lung function improved to GOLD class 2 for all patients during subsequent follow-up. All patients except 1 remained in SR at the end of 3 years (Table 3.2). At present after $40 \pm 3$ months, 6 of 7 patients are in SR without any AADs.

Table 3.2 The lesions set and follow up results of patients. No patients had previous cardiac surgery or cerebrovascular accident.

\begin{tabular}{llll}
\hline Patient number & AAD & Lesion set & Follow up \\
\hline 1 & Sotalol & PVI, box, bicaval line & 3 year, AF. \\
2 & - & $P V I$, box & 3 year, NSR. \\
3 & - & $P V I$, box & 3 Year, NSR after redo CA, \\
4 & - & $P V I$, CTI line & 3 year, NSR. \\
5 & - & $P V I$, box & 3 year, NSR. \\
6 & - & $P V I$, box & 3 year, NSR. \\
7 & - & $P V I$, mitral isthumus line, bicaval line & 3 year, NSR. \\
\hline
\end{tabular}

$\mathrm{NSR}=$ normal sinus rhythm; $\mathrm{AF}=$ atrium fibrillation; $\mathrm{AAD}=$ anti arrhythmic drug; $\mathrm{CTI}=$ cavo-tricuspid isthumus line; $C A=$ catheter ablation; $P V I=$ pulmonary vein isolation.

\section{Discussion}

AF is the most common heart arrhythmia, and COPD is one of the leading causes of death. Their concomitant presence is a challenge to physicians. Several authors have reported positive results in terms of safety and freedom from AF on follow-up, after using different devices and methodologies including energy sources as RF and cryo, but separately. ${ }^{15,16}$ COPD in AF patients is associated with higher recurrence of arrhythmia after single-catheter ablation; however, significant improvements in quality of life have been observed in the post-ablation follow-up. ${ }^{17}$ With pre-existent compromised lung function, the most common side effect of use of cryoballoon for right superior PV, 
phrenic nerve paralysis (even though transient), may worsen the breathing difficulty of a patient. Cryoablation alone does not allow for completion of the box lesion. Ligation/stapling of the LA appendage could also not be part of an endocardial cryoablation procedure. Obesity can predispose a person to develop AF up to 2.4 times more. ${ }^{18}$ Considering the operative risks in COPD and overweight patients as well as the in-house availability of both energy sources and the clinical expertise, a combination of endocardial cryoballoon for left-sided PVs and minimally invasive epicardial bipolar RF clamp application on the contralateral side was decided for AF ablation.

New balloon-based technologies aim to perform PV isolation with one single application of energy unlike conventional RF catheters. ${ }^{19,20}$ This has shown good success rates for patients with paroxysmal AF. Cryoablation needs longer time for application with an inability to drag the catheter during ablation due to its inherent property of adherence to tissue. To overcome these limitations, a combined approach has been described using a cryoballoon for PV isolation and a focal RF catheter for LA substrate modification with a favourable outcome compared with that of cryoballoon $\mathrm{PV}$ isolation alone for persistent $\mathrm{AF} .^{21}$ Surgical ablation procedures need bilateral lung deflation after general anaesthesia is administered. Because of the history of COPD (GOLD class 4 ) in our patients, bilateral lung deflation could have been deteriorative. ${ }^{22}$

Cryoenergy helps to achieve stability by distinct freeze mediated catheter adhesion. It causes less thrombus formation and less risk for embolization and stroke. ${ }^{23}$ Its most common side effect being right phrenic nerve paralysis, ${ }^{24,25}$ cryoablation was reserved for the left side. Moreover, during an epicardial approach, the surgeon can directly visualize the phrenic nerve during ablation to prevent any damage. Considering the different advantages associated with cryoballoon and RF, this combination was preferred.

There are several studies that have concluded that RF and cryoenergy can be synergistic, however, this has been proved with regard to other organ(s). ${ }^{9}$ This procedure uniquely combines the advantages of epicardial and endocardial ablation, doing away with their disadvantages, ensuring the transmurality of lesions and preventing long-term recurrence. It is a minimally invasive technique, with shorter operating time and fewer complications. This leads to shorter hospital stay, finally ensuring a high cure rate for paroxysmal patients with dilated LA when compared with individual techniques alone. In the future, this may be used as a distinct therapeutic option following one or more unsuccessful catheter ablations especially in patients with higher LA volume and deteriorated lung function.

After PV isolation, only if AF was still inducible, a box lesion set was considered. Owing to organization into mitral isthmus-dependent atrial flutter, an epicardial mitral isthmus line was created for 1 patient at the end of the procedure. However, the endocardial touch-up ablation was needed to reach a bidirectional block, starting from the mitral annulus towards or inside the coronary sinus. The efficacy of the index procedure in $5 / 7$ patients is $71.4 \%$ and after a single redo of another patient $6 / 7$ is 
$80.6 \%$ following 3-year follow-up is comparable to most of high-volume centres of catheter ablation and minimally invasive AF ablation.

\section{Limitations}

Our experience is based on a limited number of patients undergoing minimally invasive surgical ablation of paroxysmal AF. Moreover, in the majority of patients, the intensity of monitoring was higher during the period of pharmacological support and lower when AADs were stopped, thus introducing a potential bias in the results. Minimally invasive PV epicardial ablation requires appropriate initial training and guidance, but can quickly be mastered by surgeons with minimally invasive procedural experience. Multicentre randomized studies with more investigations are required in order to determine whether the risk/benefit ratio and the costs of this new technique are acceptable.

\section{Conclusions}

A hybrid approach to AF ablation using a cryoballoon endocardially and bipolar RF devices epicardially appears feasible, safe and successful. 


\section{References}

1. Cameron A, Schwartz MJ, Kronmal RA, Kosinski AS. Prevalence and significance of atrial fibrillation in coronary artery disease (CASS Registry). Am J Cardiol 1988;61:714-717.

2. Miyasaka Y, Barnes ME, Gersh BJ, Cha SS, Bailey KR, Abhayaratna WP et al. Secular trends in incidence of atrial fibrillation in Olmsted County, Minnesota, 1980 to 2000, and implications on the projections for future prevalence. Circulation 2006;114:119-125.

3. Kannel WB, Abbott RD, Savage DD, McNamara PM. Epidemiologic features of chronic atrial fibrillation: the Framingham study. N Engl J Med 1982;306:1018-1022.

4. Roy D, Talajic M, Dorian P, Connolly S, Eisenberg MJ, Green M et al. Amiodarone to prevent recurrence of atrial fibrillation. N Engl J Med 2000;342:913-920.

5. Corley SD, Epstein AE, DiMarco JP, Domanski MJ, Geller N, Greene HL et al. Relationships between sinus rhythm, treatment, and survival in the Atrial Fibrillation Follow-Up Investigation of Rhythm Management (AFFIRM) Study. Circulation 2004;109:1509-1513.

6. Calkins H, Brugada J, Packer DL, Cappato R, Chen SA, Crijns HJ et al. HRS/EHRA/ECAS expert consensus statement on catheter and surgical ablation of atrial fibrillation: recommendations for personnel, policy, procedures and follow-up. A report of the Heart Rhythm Society (HRS) Task Force on Catheter and Surgical Ablation of Atrial Fibrillation developed in partnership with the European Heart Rhythm Association (EHRA) and the European Cardiac Arrhythmia Society (ECAS); in collaboration with the American College of Cardiology (ACC), American Heart Association (AHA), and the Society of Thoracic Surgeons (STS). Endorsed and approved by the governing bodies of the American College of Cardiology, the American Heart Association, the European Cardiac Arrhythmia Society, the European Heart Rhythm Association, the Society of Thoracic Surgeons, and the Heart Rhythm Society. Europace 2007;9:335-379.

7. Verma A, Kilicaslan F, Pisano E, Marrouche NF, Fanelli R, Brachmann J et al. Response of atrial fibrillation to pulmonary vein antrum isolation is directly related to resumption and delay of pulmonary vein conduction. Circulation 2005;112:627-635.

8. La Meir M, Gelsomino S, Luca F, Lorusso R, Gensini GF, Pison L et al. Minimally invasive thoracoscopic hybrid treatment of lone atrial fibrillation: early results of monopolar versus bipolar radiofrequency source. Interact Cardiovasc Thorac Surg 2012;14:445-450.

9. Hines-Peralta A, Hollander CY, Solazzo S, Horkan C, Liu ZJ, Goldberg SN. Hybrid radiofrequency and cryoablation device: preliminary results in an animal model. J Vasc Interv Radiol 2004;15:1111-1120.

10. Sternik L, Ghosh P, Luria D, Glikson M, Shpigelshtein D, Malachy A et al. Mid-term results of the 'hybrid maze': a combination of bipolar radiofrequency and cryoablation for surgical treatment of atrial fibrillation. J Heart Valve Dis 2006;15:664-670.

11. Henry L, Durrani S, Hunt S, Friehling T, Tran H, Wish M et al. Percutaneous catheter ablation treatment of recurring atrial arrhythmias after surgical ablation. Ann Thorac Surg 2010;89:1227-1231.

12. Pison L, La Meir M, van Opstal J, Blaauw Y, Maessen J, Crijns HJ. Hybrid thoracoscopic surgical and transvenous catheter ablation of atrial fibrillation. J Am Coll Cardiol 2012;60:54-61.

13. Kumar N, Pison L, la Meir M, Maessen J. Direct visualization of pulmonary vein stenosis after previous catheter ablation. Heart Rhythm 2013.

14. Vestbo J, Hurd SS, Agusti AG, Jones PW, Vogelmeier C, Anzueto A et al. Global strategy for the diagnosis, management, and prevention of chronic obstructive pulmonary disease: GOLD executive summary. Am J Respir Crit Care Med 2013;187:347-365.

15. Balk EM, Garlitski AC, Alsheikh-Ali AA, Terasawa T, Chung M, Ip S. Predictors of atrial fibrillation recurrence after radiofrequency catheter ablation: a systematic review. J Cardiovasc Electrophysiol 2010;21:1208-1216.

16. Neumann T, Vogt J, Schumacher B, Dorszewski A, Kuniss M, Neuser H et al. Circumferential pulmonary vein isolation with the cryoballoon technique results from a prospective 3-center study. J Am Coll Cardiol 2008;52:273-278.

17. Gu J, Liu X, Tan H, Zhou L, Jiang W, Wang $Y$ et al. Impact of chronic obstructive pulmonary disease on procedural outcomes and quality of life in patients with atrial fibrillation undergoing catheter ablation. J Cardiovasc Electrophysiol 2013;24:148-154. 
18. Magnani JW, Hylek EM, Apovian CM. Obesity begets atrial fibrillation: a contemporary summary. Circulation 2013;128:401-405.

19. Reddy VY, Neuzil P, d'Avila A, Laragy M, Malchano ZJ, Kralovec S et al. Balloon catheter ablation to treat paroxysmal atrial fibrillation: what is the level of pulmonary venous isolation? Heart Rhythm 2008;5:353-360.

20. Pappone C, Oral H, Santinelli V, Vicedomini G, Lang CC, Manguso F et al. Atrio-esophageal fistula as a complication of percutaneous transcatheter ablation of atrial fibrillation. Circulation 2004;109: 2724-2726.

21. Mansour M, Forleo GB, Pappalardo A, Barrett C, Heist EK, Avella A et al. Combined use of cryoballoon and focal open-irrigation radiofrequency ablation for treatment of persistent atrial fibrillation: results from a pilot study. Heart Rhythm 2010;7:452-458.

22. Abe K, Oka J, Takahashi H, Funatsu T, Fukuda H, Miyamoto Y. Effect of high-frequency jet ventilation on oxygenation during one-lung ventilation in patients undergoing thoracic aneurysm surgery. J Anesth 2006;20:1-5.

23. Khairy P, Chauvet $\mathrm{P}$, Lehmann J, Lambert J, Macle L, Tanguay JF et al. Lower incidence of thrombus formation with cryoenergy versus radiofrequency catheter ablation. Circulation 2003;107:2045-2050.

24. Kuhne M, Knecht S, Altmann D, Kawel N, Ammann P, Schaer B et al. Phrenic nerve palsy during ablation of atrial fibrillation using a 28-mm cryoballoon catheter: predictors and prevention. J interv Card Electrophysiol 2013;36:47-54; discussion 54.

25. Kuck KH, Furnkranz A. Cryoballoon ablation of atrial fibrillation. J Cardiovasc Electrophysiol 2010; 21:1427-1431. 


\section{Chapter 4}

Hemoptysis after cryoablation for atrial fibrillation ablation: Truth or just a myth?

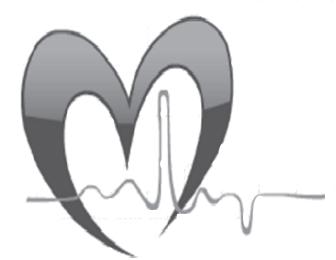

Narendra Kumar

Carl Timmermans

Marco Das

Willem Daessen

Suzanne Philippens

Jos Maessen

Harry Crijns

DOI: 10.1378/chest.14-1600

Part of manuscript is published as a correspondence to editor 


\section{Abstract}

\section{Background}

There have been few reports about hemoptysis after cryoballoon ablation for atrial fibrillation (AF). This retrospective study reports the incidence and characteristics of hemoptysis after cryoballoon ablation.

\section{Methods and results}

This retrospective single center study included patients undergoing PV isolation for symptomatic and drug-refractory AF. To investigate the etiology of hemoptysis a chest radiograph, contrastenhanced spiral computed tomography (CT) scan of the thorax, and/or a bronchoscopy were performed. Patients were followed at 3, 6, 9 and 12 months using Holter recording, transtelephonic telemetry, and/or when patients had symptoms. A random control group of 20 patients, having similar clinical characteristics, was selected to compare the procedural parameters that might predict the etiology of hemoptysis. Hemoptysis occurred in $6 / 283$ patients (200 men; 58 \pm 10 years) who underwent PV isolation for symptomatic AF. Right diaphragmatic paralysis was observed in $2 / 5$ patients undergoing chest radiography. CT scans did not reveal any PV stenosis but ground glass opacification (GGO) in the right inferior PV of 5 subjects and in the right superior PV of 2 patients presenting with hemoptysis. Further, the right superior PV showed ostial induration in 2 patients. Hyperemic mucosa and erosion were respectively discovered using bronchoscopy in 2 patients. Statistical analysis revealed lower temperature of the right inferior PV and deeper positioning of a smaller cryoballoon among hemoptysis patients compared to the control group.

\section{Conclusion}

Hemoptysis is an uncommon side effect and was associated with cryoballoon ablation for AF in $2.1 \%$ patients. This may be attributed to colder temperature during application of a cryoballoon. 


\section{Introduction}

Atrial fibrillation (AF) is the most common heart rhythm disorder and may lead to significant morbidity and mortality. Catheter ablation studies have reported a higher efficacy rate with a lower rate of complications compared to studies of anti-arrhythmic drug (AAD) therapy for $A F{ }^{1}$ Pulmonary vein (PV) isolation is regarded as the cornerstone in AF ablation. A cryoballoon is a novel tool for PV isolation having unique advantages compared to conventional radiofrequency (RF) catheter ablation. Complications of cryoenergy ablation may be due to damage of structures close to the site of application and may result in the phrenic nerve paralysis, gastroparesis, atrioesophageal fistula or esophageal lesions. ${ }^{6-9}$ Until now, only a few authors have reported on hemoptysis after cryoballoon ablation but without regular follow-up or identifying the etiology. ${ }^{10-13}$ The purpose of this retrospective study was to report the incidence and characteristics of hemoptysis after cryoballoon ablation.

\section{Methods}

\section{Patient population}

The study population consisted of 283 consecutive patients who underwent PV isolation for symptomatic drug refractory paroxysmal (88\%) or persistent (12\%) AF from January 2009 till April 2012. Holter monitors and 12 lead electrocardiograms (ECG) were used for documenting AF before admission to the hospital. The Heart Rhythm Society, European Heart Rhythm Association, and European Cardiac Arrhythmia Society consensus statement was followed for defining paroxysmal and persistent AF, success, and failure of cryoablation, and follow-up monitoring. ${ }^{4}$ IRB (Institutional Review Board) approval was not needed. Informed consent was obtained for all patients. For comparison the groups were labelled 'hemoptysis' and 'no hemoptysis'.

\section{Cryoballoon procedure}

The patients were brought to the electrophysiology laboratory in a fasting and nonsedated state. All patients were - at least one month before the procedure - treated with oral anticoagulants. Three days before the procedure, the oral anticoagulation was replaced by low molecular weight heparin. The administration of subcutaneous heparin was interrupted 12 hours before the intervention. After using local anesthesia under sterile technique, femoral venous access was obtained via a percutaneous approach. Decapolar and quadripolar catheters were placed in the coronary sinus and the His region respectively. Transesophageal echocardiography was performed to rule out a thrombus in the LA and to guide the transseptal punctures. After the first transseptal puncture, a 8.5-F sheath (SLO, St. Jude Medical, St. Paul, MN, USA) was inserted into the 
LA. Through a second transseptal puncture, a 15-F sheath (FlexCath, Cryocath, Medtronic, Minneapolis, MN, USA) was placed in the LA. After the transseptal punctures, an intravenous heparin bolus of $100 \mathrm{IU} / \mathrm{kg}$ were given, followed by a heparin infusion to maintain an activated clotting time (ACT) $300 \mathrm{~s}$.

During rapid ventricular pacing from the His bundle catheter, LA angiography was performed to visualize the ostia and major branches of the PVs. Through the $8.5 \mathrm{~F}$ sheath a circular mapping catheter (Lasso, Biosense Webster, Diamond Bar, USA) was inserted to map the PVs for the presence of potentials. A cryoballoon (Arctic Front ${ }^{\circledR}$, Medtronic, Minneapolis, MN, USA) was advanced into the LA through the 15-F sheath. Before every cryo application, occlusion of PV by the cryoballoon was fluoroscopically occluded by injecting contrast through the catheter in the PV. Patients underwent ostial isolation of all PVs using cryoballoon application cycles of 4 minutes. Continuous phrenic nerve stimulation was performed during right superior PV cryoballoon ablation. The procedural endpoint was complete electrical isolation of all PVs based on abolition of ostial PV potentials and bidirectional conduction block. If PV isolation could not be obtained using several cryoballoon applications, a regular cryocatheter (Freezer Max ${ }^{\circledR}$ Medtronic Cryocath LP, Canada) was used for point-by-point ablation. In case of documented typical atrial flutter, cryoablation of the cavotricuspid isthmus (CTI) was also performed during the same procedure. The evening of the procedure, oral anticoagulation and AADs were restarted and continued for all patients for at least 3 months. Thereafter, it was at the discretion of the referring physician. A random control group of 20 patients without hemoptysis with similar demographic characteristics as patients with hemoptysis was selected out of the study population to compare.

\section{Follow-Up}

Follow-up was conducted in our outpatient clinic at 3, 6 and 12 months. For those patients living outside the region of Maastricht, follow-up was obtained from the referring cardiologist. Any episode of AF, AFL, or AT lasting more than 30 seconds detected after the 3-month post-procedural period by electrocardiography or 7-day, 24-48 hour continuous Holter monitoring performed at 6, 9, and 12 months was considered failure. Every patient was instructed to contact our center or the referring cardiologist in case of symptoms suggestive of arrhythmia recurrence.

\section{Statistical analysis}

Continuous variables are expressed as mean \pm standard deviation and were compared with the Mann Whitney U-test as appropriate. The significance level was set at $p<0.05$. Statistical analysis using the Mann Whitney test was applied in the control group of 20 patients without hemoptysis. The intra-procedural parameters during cryoballoon PV isolation that may predict hemoptysis, such as lowest temperature, position (deep 
or ostial), the size of the cryoballoon and also grade of occlusion using contrast injection before every application were compared.

\section{Results}

\section{Ablation results}

There were 200 men and 83 women with a mean age of $58 \pm 10(22-83)$ years. The patients had a mean left atrium size of $41 \pm 5 \mathrm{~mm}$ and a mean LVEF of $60 \pm 7 \%$. A $28 \mathrm{~mm}$ cryoballoon was used for 179 patients (63\%) and a $23 \mathrm{~mm}$ for 97 patients (34\%). Both cryoballoon sizes were used for 7 patients (3\%). A regular cryoablation catheter was needed for 15 patients (5.3\%) for point-by-point ablation. Acute PV isolation was obtained in 279/283 patients (98.6\%). The mean minimum temperature of the cryoballoon applications was $-48.15 \pm 20.97$ (LSPV $=-48.7 \pm 22.4$, LIPV $=-47.9 \pm 20.5$, RSPV= $-49.6 \pm 19.7, \mathrm{RIPV}=-46.4 \pm 21.3)^{\circ} \mathrm{C}$. The mean number of applications per patient was $1.83 \pm 0.94$ (LSPV= 1.96 $\pm 0.88, \mathrm{LIPV}=1.92 \pm 1.25, \mathrm{RSPV}=1.78 \pm 0.89, \mathrm{RIPV}=1.67 \pm 0.75)$. The mean procedure and fluoroscopy time was $175 \pm 22$ and $38 \pm 8$ minutes, respectively. CTI cryoablation for typical AF was performed in 43 patients (14\%).

\section{Hemoptysis}

Hemoptysis occurred in $6 / 283$ patients (2.1\%). One of the hemoptysis patients described previously was excluded. ${ }^{14}$ There were 5 men and 1 woman with a mean age of 58.5 \pm 5.5 (51-63) years. Four patients had a history of hypertension. All patients had paroxysmal AF with a duration of $3.5 \pm 2$ years and diameter of LSPV was 19.5 \pm 1.22 , LIPV=17.5 \pm 1.05 , RSPV $20.3 \pm 1.5$, and $R I P V=18.2 \pm 2.56 \mathrm{~mm}$ calculated from CT scans. Their mean LA size was $40 \pm 1 \mathrm{~mm}$. Table 4.1 shows the procedural parameters of these patients. A $23 \mathrm{~mm}$ cryoballoon was used for 4 patients and a $28 \mathrm{~mm}$ for 2 patients. None of the procedural cryoablation parameters of the two balloon sizes of hemoptysis patients (e.g., grade of occlusion, ostial vs deeper placement, temperature) were statistically significant while comparing the hemoptysis group with the no hemoptysis control group. The ACT was $\geq 300 \mathrm{~s}$ and $\leq 400 \mathrm{~s}$ during the procedure. The mean minimum temperature of the cryoballoon application was $-58.6 \pm 2.0$ (LSPV $=-61.2 \pm 6.9$, $\mathrm{LIPV}=-56.6 \pm 8.8, \quad \mathrm{RSPV}=-57.5 \pm 6.0, \quad \mathrm{RIPV}=-59.0 \pm 10.1)^{\circ} \mathrm{C}$. The mean number of applications per patient was $1.65 \pm 0.1$ (LSPV= $1.5 \pm 0.5, \mathrm{LIPV}=1.7 \pm 0.5, \mathrm{RSPV}=1.7 \pm 0.5$, RIPV= 1.7 \pm 0.5 ). The cryoballoon was located towards the PV antrum during cryoablation in all patients. In patients 5 and 6 , a cryoballoon was placed deep in the PV (Figure 4.1). PNP occurred in patients 1 and 3 during cryoablation of the RSPV and resolved during the subsequent follow-up. 
Table 4.1 Procedural parameters of the 6 patients with hemoptysis.

\begin{tabular}{lcccccccc}
\hline $\begin{array}{l}\text { Patient } \\
\text { No. }\end{array}$ & Age & Gender & $\begin{array}{c}\text { Balloon } \\
\text { size }\end{array}$ & $\begin{array}{c}\text { LSPV } \\
\text { D/ T }\end{array}$ & $\begin{array}{c}\text { LIPV } \\
\text { D/ T }\end{array}$ & $\begin{array}{c}\text { RSPV } \\
\text { D/ T }\end{array}$ & $\begin{array}{c}\text { RIPV } \\
\text { D/ T }\end{array}$ & Culprit vessel \\
\hline 1 & 53 & M & 28 & $21 /-61$ & $17 /-75,-45$ & $22 /-57,-60$ & $16 /-65$ & RSPV, RIPV \\
2 & 51 & F & 23 & $19 /-64$ & $16 /-59$ & $22 /-67$ & $19 /-50,-45$ & RSPV \\
3 & 63 & M & 23 & $21 /-71$ & $18 /-64$ & $19 /-55$ & $14 /-71$ & LIPV, RSPV \\
4 & 60 & M & 28 & $19 /-55,-47$ & $19 /-47,-48$ & $19 /-47,-54$ & $20 /-45,-53$ & RIPV \\
5 & 63 & M & 23 & $18 /-66,-64$ & $17 /-57,-57$ & $19 /-56,-63$ & $20 /-70,-64$ & not clear \\
6 & 63 & M & 23 & $19 /-62,-65$ & $18 /-56,-58$ & $21 /-52,-64$ & $20 /-68,-59$ & RIPV \\
\hline
\end{tabular}

PV indicates pulmonary vein; $\mathrm{M}$, male; $\mathrm{F}$; female, LS, left superior; $\mathrm{LI}$, left inferior; RS, right superior; RI, right inferior; $\mathrm{D}$, diameter (in $\mathrm{mm}$ ); $\mathrm{T}$, minimum temperature during a cryoballoon application of the pulmonary vein (in degree Celsius), 1 number indicates 1 application and 2 numbers indicate 2 applications.

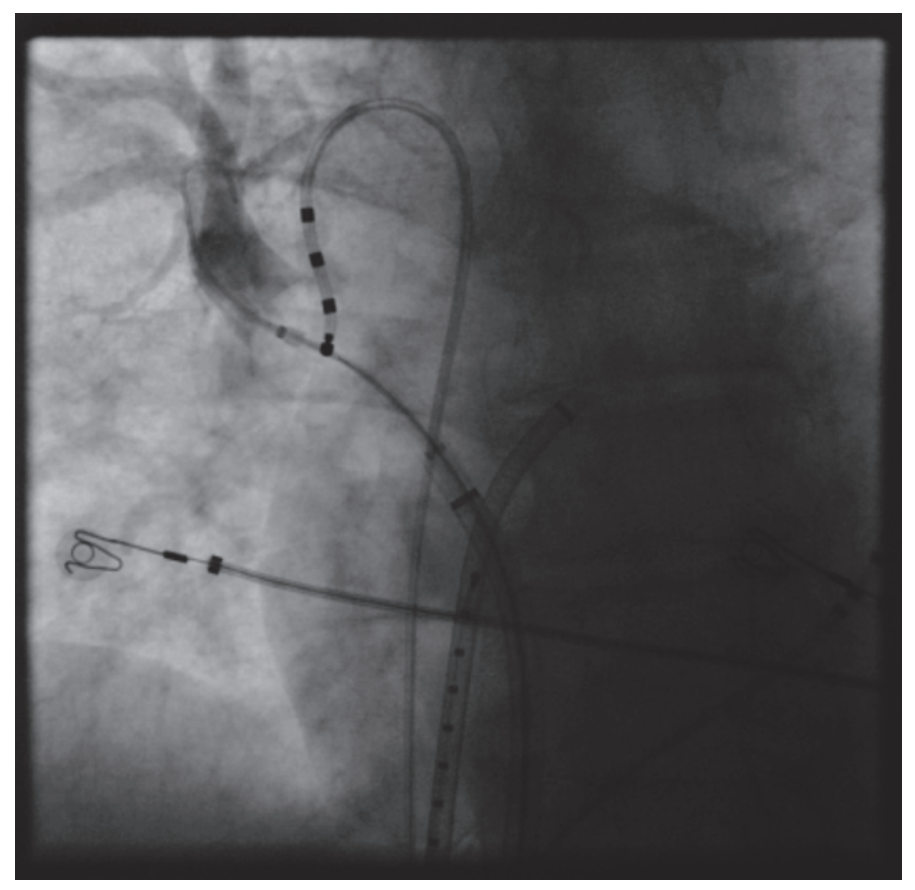

Figure 4.1 Fluoroscopy image showing deeper placement of cryoballoon in right superior pulmonary vein. His catheter is positioned in superior vena cava for phrenic nerve pacing.

Figure 4.2 shows the time course of hemoptysis in the 6 patients. Hemoptysis occurred only during the procedure in patient 2 and for 2 patients (numbers 1 and 5) hemoptysis started the day after the procedure (day 1) and continued for 2 and 7 days, respectively. In patient 1 , acenocaumarol was immediately stopped on the day of hemoptysis and restarted 7 days after the procedure. In patient 5, oral anticoagulation was not interrupted. Patient 3 developed hemoptysis continuing for a period of 7 days, after the 3 days of cryoablation. Acenocaumarol was interrupted only 5 days after the 
ablation for a period of 7 days and replaced by low molecular weight heparin (LMWH). Patient 4 presented the next day after the ablation due to hemoptysis. The same day, acenocaumarol was intervened but restarted the next day. The last patient developed hemoptysis on day 5 after PV ablation, which continued for the next 2 days.

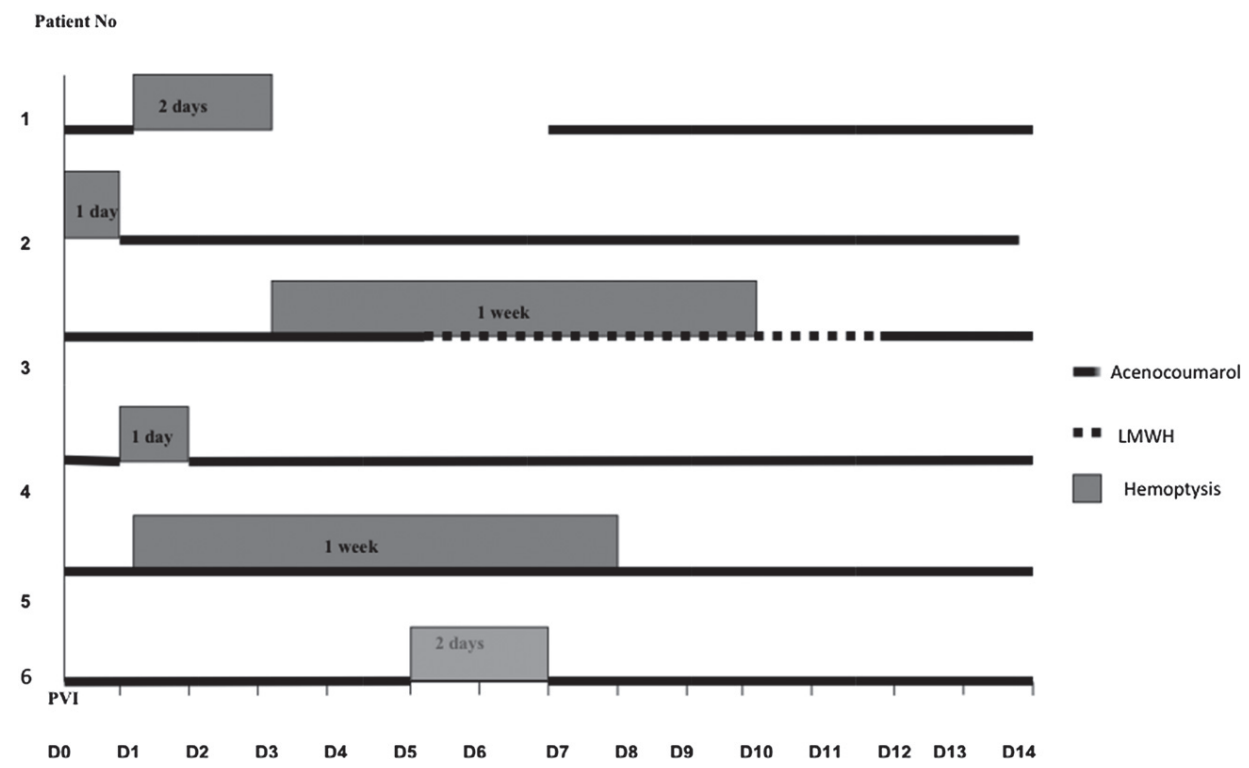

Figure 4.2 Time course of hemoptysis in 6 patients. LMWH indicates low molecular weight heparin; PVI, pulmonary vein isolation procedure day; D, days post procedure.

Hemoptysis episodes were mild type i.e., mostly blood streaked sputum, and the expectoration volume was $<50 \mathrm{ml}(20-40 \mathrm{ml})$ of blood in 24 hours. High resolution (HR) CT was performed for the first patient on the same day of presentation of hemoptysis. As the hemoptysis had stopped for the second patient, only bronchoscopy was performed. HRCT was performed for the next 2 patients on the fifth day post procedure. However, due to late presentation of patient 5 to the hospital, it was done on day 6 after the procedure.

\section{Other complications}

Despite continuous phrenic nerve stimulation during right superior PV cryoballoon ablation, phrenic nerve paralysis (PNP) occurred in 18/283 patients (6\%). PNP only presented during the ablation procedure in 11 Patients; 5 patients recovered within 1 year but PNP was still present after 1 year follow-up in 2 patients (0.7\%). In 11/18 patients (61\%) with PNP, a $23 \mathrm{~mm}$ cryoballoon was used. Pericardial effusion occurred 
in $2 / 283$ patients $(0.7 \%)$, and pericardial tamponade necessitating pericardiocentesis in $3 / 283$ patients $(1.1 \%)$. One patient $(0.3 \%)$ had a transient ischemic attack during the procedure. A groin hematoma developed in 5 patients (2.1\%) requiring firm compression.

\section{Control group}

A random control group of 20 patients with similar clinical characteristics was selected so as to compare the cryoballoon ablation parameters e.g., grade of occlusion, minimum temperature, number of ablation cycles and place of cryoballoon application (ostial vs deep) which may predict hemoptysis etiology, and or occurrence during the procedure. Statistical analysis (using Mann Whitney test) for $28 \mathrm{~mm}$ cryoballoon temperature of application in the control group versus the hemoptysis patients was not significantly different ( $p>0.05$ ). However, the $23 \mathrm{~mm}$ cryoballoon group revealed lower temperatures in the right PV of hemoptysis patients $\left(-65 \pm 7^{\circ} \mathrm{C}\right)$ compared with those of the control group $\left.\left(-57.5 \pm 21.0^{\circ} \mathrm{C}\right) ; \mathrm{p}=0.025\right]$.

\section{Follow up}

After a 3-month blanking period, 191 of 283 patients (72\%) were free of recurrent AF, with a single procedure at the end of 1-year follow-up. Of these 191 patients, 64 (24\%) were on AAD.

\section{Discussion}

This study describes hemoptysis as an acute extracardiac side effect of cryoballoon use for PV isolation. The temporal course of signs and symptoms clearly indicate that this adverse effect results due to the cryoballoon ablation. Diagnostic investigations revealed ostial induration and ground glass opacification of the respective PVs (Table 4.2).

Cryoballoon is considered safe for PV isolation during AF ablation. Thrombus formation is less likely, as there is no disruption of the endocardial surface and a lack of char formation. Severe PV stenosis after RF catheter ablation for AF is associated with respiratory symptoms [including hemoptysis and dyspnea], which frequently mimic more common diseases, often leading to erroneous diagnostic and therapeutic procedures. ${ }^{15}$ Cryoablation causes vascular injury through multiple factors including ice formation within the vasculature. ${ }^{16}$ The ice during expansion causes the formation of tears, clefts, leakage, and stasis post-reperfusion. ${ }^{17}$ Interruption of the vascular integrity is the reason for the intramyocardial hemorrhage as well as the hemoptysis associated with cryoinjury to the lung tissues. 
In an earlier publication, ${ }^{18}$ we summarized the relationship of cryoablation to hemoptysis with evidence ranging from several animal studies which can be traced earliest to $1974^{19,20,21}$ and later finding evidence clinically as well. A series of a few reports described acute injury to the lung, thought to be due to cytokine release, on the effects of freezing in about $35 \%$ of the liver in rats and sheep. ${ }^{26-29}$

Table 4.2 Investigations of patients after hemoptysis.

\begin{tabular}{|c|c|c|c|c|}
\hline \multicolumn{2}{|c|}{ Patient X-ray } & \multirow{2}{*}{$\begin{array}{l}\text { Bronchoscopy } \\
\text { NA }\end{array}$} & \multirow{2}{*}{$\begin{array}{l}\text { CT-scan } \\
\text { [PV with respective findings] } \\
\mathrm{RS}, \mathrm{RI}=\text { Ostial induration + GGO }\end{array}$} & \multirow{2}{*}{$\begin{array}{l}\text { Cryoballoon in } \\
\text { RS, LS, LI }\end{array}$} \\
\hline 1 & $\begin{array}{l}\text { R.D.P. } \\
\text { Atelectasis RIL }\end{array}$ & & & \\
\hline 2 & $\mathrm{NL}$ & Hyperemic mucosa RSB & NA & RS \\
\hline 3 & R.D.P. & $\begin{array}{l}\text { Erosion + blood effusion } \\
\text { at division LSB / LIB }\end{array}$ & $\mathrm{RS}, \mathrm{RI}=$ Ostial induration $+\mathrm{GGO}$ & LI, RS \\
\hline 4 & $\mathrm{NL}$ & NA & $\mathrm{RI}=$ Ostial induration $+\mathrm{GGO}$ & $\mathrm{RI}$ \\
\hline 5 & NA & NA & RI faint peripheral GGO & $\mathrm{NL}$ \\
\hline 6 & $\mathrm{NL}$ & NA & $\mathrm{RI}=$ Ostial induration + GGO & $\mathrm{RI}$ \\
\hline
\end{tabular}

RDP indicates right diaphragmatic paralysis; RI, right inferior; RS, right superior pulmonary vein [PV]; GGO, ground glass opacification; NL, normal; RSB, right superior bronchus; LSB, left superior bronchus; NA, not done; Echo, echocardiography.

Our study has shown that hemoptysis in humans can occur due to percutaneous cryoballoon application in the PVs. Statistical analysis of the $23 \mathrm{~mm}$ cryoballoon group showed a significant association of the lower temperature of ablation with hemoptysis. As extra cardiac dispersion of the endocardial delivery of cryoablation is the etiology for this, careful observation and control of temperature of application is advisable. None of the incidents was life threatening. They occurred a few days after the ablation procedure and resolved spontaneously with conservative medical management. The additive factors like anticoagulation (by heparin, warfarin etc.) and local trauma to lung tissue (by guide wire or deep ostial cryoballoon application) should be carefully monitored. Like any other complication, avoiding the above risk factors and interruption of anticoagulation can prevent it. INR should be carefully monitored; especially during post procedural time to avoid over treatment with anticoagulation and subsequent dose adjustment or symptomatic treatment should be done.

Bhagwandian et al. reported on 6 patients who developed hemoptysis after cryoballoon ablation. Initially, 2 patients developed symptomatic hemoptysis and needed prolonged hospital admission within a few days post procedure. Finally, 4 patients were seen during 3- month follow-up with short lasting hemoptysis resolving with discontinuation of anticoagulation medications. There are several important parameters that can result in hemoptysis. The definitive etiology of hemoptysis was not clear e.g., number and time of complete occlusions that result in cryo injury to adherent tissue and vasculature or pulmonary infarction. Local trauma by guide wire 
was not ruled out. Interaction of pre-existing pathology such as bronchiectasis with intra procedure, e.g., anticoagulation parameters were left unanswered.

In a similar series, CT documented how frozen lung complications occurred, leading to coughing and hemoptysis for a maximum of 1 week in 3 patients, and how avoiding very deep cryoballoon ablation temperatures may prevent this. ${ }^{12}$ In our series we had a similar observation that a lower temperature is associated with a higher incidence of hemoptysis.

HRCT results can be related to the severity of bleeding. The extent of lobar involvement as a severity factor was determined fter consulting a radiologist at our center. ${ }^{32} \mathrm{CT}$ scans showed GGO in all patients who developed hemoptysis and underwent CT scan (Figures 4.3 and 4.4). Bronchoscopy revealed bronchial erosion in the second patient; hence a CT scan was not performed. We also observed that the intensity of GGO is also related to the temporal delay for scan. ${ }^{33} \mathrm{PV}$ stenosis was ruled out (for all patients) by comparing the PV dimension before and after the procedure during regular follow-up. Moreover, GGO was not seen in any patient without hemoptysis. Necessitating the need of fine balance between efficacy and safety which requires careful observation

Significant cooling is associated with second-generation cryoballoon (CB-2G, Arctic Front Advance ${ }^{\mathrm{TM}}$, Medtronic, Inc.) necessitating the need of fine balance between efficacy and safety that requires careful observation. ${ }^{34}$ The need for continuous monitoring for ACT, grade of occlusion, the lowest temperature of cryoballoon ablation, number and time of complete occlusion of PV as important determinants for hemoptysis should not be ignored in post cryoballoon ablation for AF.

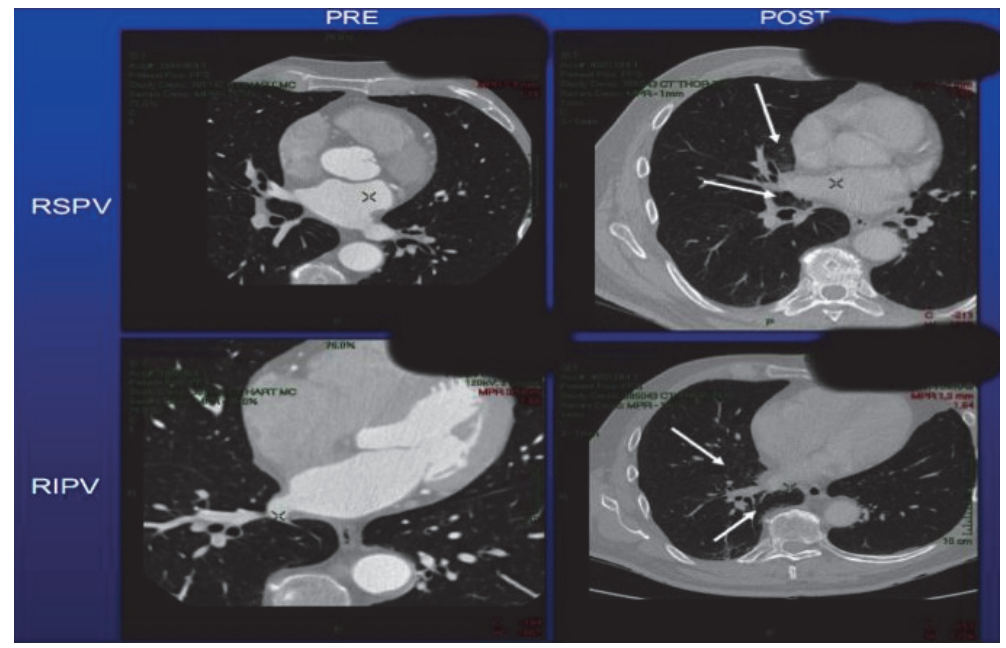

Figure 4.3 CT scan of thorax of patient 3 before and after cryoablation procedure. Right superior and right inferior pulmonary vein showing ground glass opacification due to hemoptysis. 


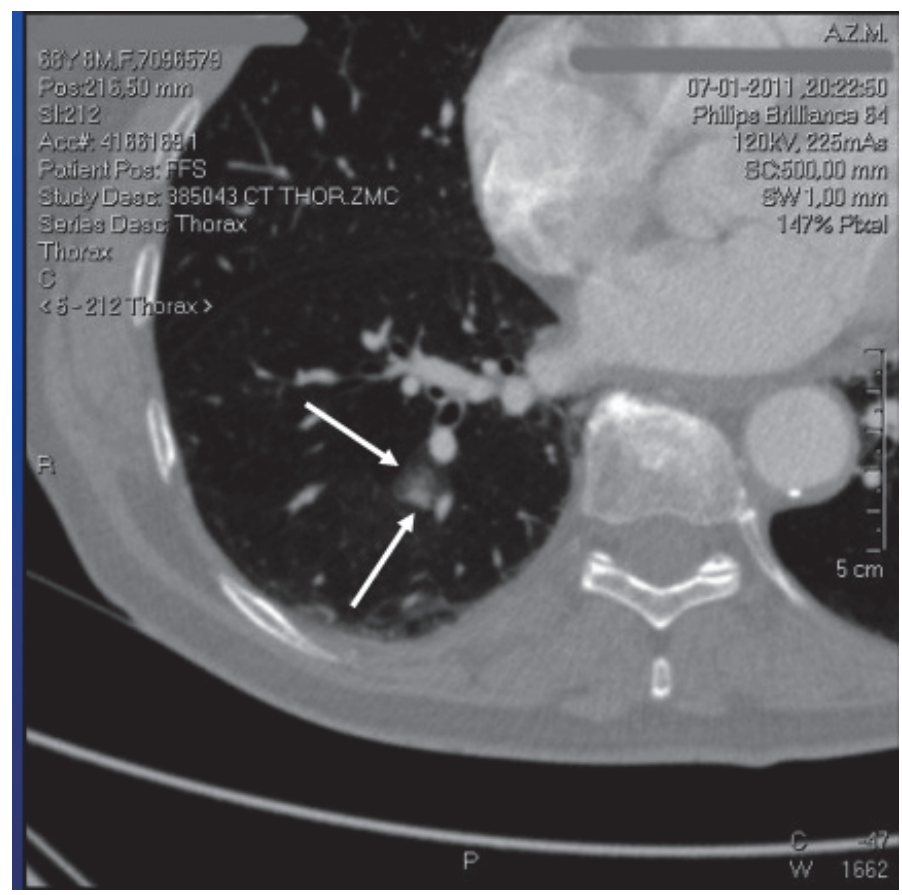

Figure 4.4 CT thorax of a hemoptysis patient showing ground glass opacification.

\section{Limitations}

Our study and observation is based on a limited number of patients who developed this complication after undergoing cryoballoon ablation for AF. The small size of this study $(n=283)$ may not reflect the true incidence of complications after cryoballoon ablation. Any subclinical hemoptysis could not be ruled out. Being a retrospective study, the need for additional follow-up CT scan was felt to predict the duration of lung's structural deformity. Multicenter randomized studies with more investigations may be needed to determine whether the risk/benefit ratio is acceptable.

\section{Conclusions}

Cryoballoon is a safe and effective therapy for paroxysmal AF. Along with other complications, physicians must keep hemoptysis in mind. It had a maximum incidence during and up to 3 days after the procedure in $2.1 \%$ of patients and was independent of other complications like phrenic nerve paralysis, gastroparesis. Dexterity of PV location does not influence the incidence. However, a $23 \mathrm{~mm}$ balloon has a more frequent 
association. A high degree of suspicion is necessary to avoid misleading diagnostic procedures and to allow proper and prompt management. Hemoptysis is indeed a valid side effect when using a cryoballoon for PV isolation during AF rather than a myth. 


\section{References}

1. Calkins H, Reynolds MR, Spector P, Sondhi M, Xu Y, Martin A, Williams CJ, Sledge I. Treatment of atrial fibrillation with antiarrhythmic drugs or radiofrequency ablation: two systematic literature reviews and meta-analyses. Circ Arrhythm Electrophysiol 2009;2:349-361.

2. Haïssaguerre M, Jaïs P, Shah DC, Takahashi A, Hocini M, Quiniou G, Garrigue S, Le Mouroux A, Le Métayer $\mathrm{P}$, Clémenty J. Spontaneous initiation of atrial fibrillation by ectopic beats originating in the pulmonary veins. N Engl J Medi 1998;339:659-666.

3. Chen SA, Hsieh MH, Tai CT, Tsai CF, Prakash VS, Yu WC, Hsu TL, Ding YA, Chang MS. Initiation of atrial fibrillation by ectopic beats originating from the pulmonary veins: electrophysiological characteristics, pharmacological responses, and effects of radiofrequency ablation. Circulation 1999;100:1879-1886.

4. Calkins H, Kuck KH, Cappato R, Brugada J, Camm AJ, Chen SA, Crijns HJ, Damiano RJ Jr, Davies DW, DiMarco J, Edgerton J, Ellenbogen K, Ezekowitz MD, Haines DE, Haissaguerre M, Hindricks G, lesaka $Y$, Jackman W, Jalife J, Jais P, Kalman J, Keane D, Kim YH, Kirchhof P, Klein G, Kottkamp H, Kumagai K, Lindsay BD, Mansour M, Marchlinski FE, McCarthy PM, Mont JL, Morady F, Nademanee K, Nakagawa H, Natale A, Nattel S, Packer DL, Pappone C, Prystowsky E, Raviele A, Reddy V, Ruskin JN, Shemin RJ, Tsao HM, Wilber D; Heart Rhythm Society Task Force on Catheter and Surgical Ablation of Atrial Fibrillation. 2012 HRS/EHRA/ECAS expert consensus statement on catheter and surgical ablation of atrial fibrillation: recommendations for patient selection, procedural techniques, patient management and follow-up, definitions, endpoints, and research trial design: a report of the Heart Rhythm Society (HRS) Task Force on Catheter and Surgical Ablation of Atrial Fibrillation. Developed in partnership with the European Heart Rhythm Association (EHRA), a registered branch of the European Society of Cardiology (ESC) and the European Cardiac Arrhythmia Society (ECAS); and in collaboration with the American College of Cardiology (ACC), American Heart Association (AHA), the Asia Pacific Heart Rhythm Society (APHRS), and the Society of Thoracic Surgeons (STS). Endorsed by the governing bodies of the American College of Cardiology Foundation, the American Heart Association, the European Cardiac Arrhythmia Society, the European Heart Rhythm Association, the Society of Thoracic Surgeons, the Asia Pacific Heart Rhythm Society, and the Heart Rhythm Society. Heart Rhythm 2012;9:632-696 e621.

5. Neumann T, Vogt J, Schumacher B, Dorszewski A, Kuniss M, Neuser H, Kurzidim K, Berkowitsch A, Koller M, Heintze J, Scholz U, Wetzel U, Schneider MA, Horstkotte D, Hamm CW, Pitschner HF. Circumferential pulmonary vein isolation with the cryoballoon technique results from a prospective 3-center study. J Am Coll Cardiol 2008;52:273-278.

6. Kuck KH, Furnkranz A. Cryoballoon ablation of atrial fibrillation. J Cardiovasc Electrophysiol 2010;21:1427-1431.

7. Guiot A, Savoure A, Godin B, Anselme F. Collateral nervous damages after cryoballoon pulmonary vein isolation. J Cardiovasc Electrophysiol 2012;23:346-351.

8. Stockigt F, Schrickel JW, Andrie R, Lickfett L. Atrioesophageal fistula after cryoballoon pulmonary vein isolation. J Cardiovasc Electrophysiol 2012;23:1254-1257.

9. Fürnkranz A, Bordignon S, Schmidt B, Böhmig M, Böhmer MC, Bode F, Schulte-Hahn B, Nowak B, Dignaß $A U$, Chun JK. Luminal esophageal temperature predicts esophageal lesions after second-generation cryoballoon pulmonary vein isolation. Heart Rhythm 2013;10:789-793.

10. Bhagwandien R, Van Belle Y, De Groot N, Jordaens L. Hemoptysis after pulmonary vein isolation with a cryoballoon: an analysis of the potential etiology. J Cardiovasc Electrophysiol 2011;22:1067-1069.

11. Vogt J, Heintze J, Muntean B, Scholz U, Luong LT, Horstkotte D. Long-term success and side effects of antral isolation of pulmonary veins with cryoballoon technique in a large patient cohort with atrial fibrillation. Paper presented at: J Am Coll Cardiol 2009.

12. Weig $\mathrm{H}$, Weretka $\mathrm{S}$, Parade $\mathrm{U}$, et al. Cryo-specific complications using the single big cryoballoon technique for pulmonary vein isolation in patients with paroxysmal atrial fibrillation. Paper presented at: Eur Heart J 2010.

13. Defaye P, Kane A, Chaib A, Jacon P. Efficacy and safety of pulmonary veins isolation by cryoablation for the treatment of paroxysmal and persistent atrial fibrillation. Europace 2011;13:789-795.

14. van Opstal JM, Timmermans C, Blaauw Y, Pison L. Bronchial erosion and hemoptysis after pulmonary vein isolation by cryoballoon ablation. Heart Rhythm 2011;8:1459. 
15. Saad EB, Marrouche NF, Saad CP, Ha E, Bash D, White RD, Rhodes J, Prieto L, Martin DO, Saliba WI, Schweikert RA, Natale A. Pulmonary vein stenosis after catheter ablation of atrial fibrillation: emergence of a new clinical syndrome. Ann Intern Med 2003;138:634-638.

16. Rabb JM, Renaud ML, Brandt PA, Witt CW. Effect of freezing and thawing on the microcirculation and capillary endothelium of the hamster cheek pouch. Cryobiology 1974;11:508-518.

17. Hoffmann NE, Bischof JC. The cryobiology of cryosurgical injury. Urology 2002;60:40-49.

18. Kumar N, Timmermans C, Pison L, Crijns HJ. Hemoptysis: déjà vu for cryoballoon use for pulmonary vein isolation for atrial fibrillation ablation. Chest 2014;145:1435.

19. Neel HB, 3rd, Farrell KH, Payne WS, DeSanto LW. Cryosurgery of respiratory structures. II. Cryonecrosis of the lung. Laryngoscope 1974;84:417-426.

20. Avitall B, Lafontaine D, Rozmus G, Adoni N, Le KM, Dehnee A, Urbonas A. The safety and efficacy of multiple consecutive cryo lesions in canine pulmonary veins-left atrial junction. Heart Rhythm 2004;1:203-209.

21. Avitall B, Urboniene D, Rozmus G, Lafontaine D, Helms R, Urbonas A. New cryotechnology for electrical isolation of the pulmonary veins. J Cardiovasc Electrophysiol 2003;14:281-286.

22. Tuesday, 1 September 2009. Eur Heart J 2009;30(suppl 1):587-843.

23. Monday, 30 August 2010. Eur Heart J 2010;31(suppl 1):297-587.

24. Conte G, Chierchia GB, Casado-Arroyo R, Ilsen B, Brugada P. Pulmonary vein intramural hematoma as a complication of cryoballoon ablation of paroxysmal atrial fibrillation. J Cardiovasc Electrophysiol 2013;24:830-831.

25. Ferrero-de Loma-Osorio A, Izquierdo-de Francisco M, Martínez-Brotons A, Sánchez-Gómez JM, Mascarell-Gregori B, Ruiz-Ros V, Cuenca-Romero I, García-Civera R, Chorro-Gascó FJ, Ruiz-Granell R. Medium-term results of cryoballoon ablation of the pulmonary veins in patients with paroxysmal and persistent atrial fibrillation. First experience of a Spanish center. J Interv Card Electrophysiol 2013;37(2):189-196.

26. Chapman WC, Debelak JP, Blackwell TS, Gainer KA, Christman JW, Pinson CW, Brigham KL, Parker RE. Hepatic cryoablation-induced acute lung injury: pulmonary hemodynamic and permeability effects in a sheep model. Arch Surg 2000;135:667.

27. Sadikot RT, Wudel L, Jansen DE, Debelak JP, Yull FE, Christman JW, Blackwell TS, Chapman WC. Hepatic cryoablation-induced multisystem injury: Bioluminescent detection of NF-KB activation in a transgenic mouse model. J Gastrointest Surg. 2002;6:264-270.

28. Washington K, Debelak JP, Gobbell C, Sztipanovits DR, Shyr Y, Olson S, Chapman WC. Hepatic cryoablation-induced acute lung injury: histopathologic findings. The J Surg Res 2001;95:1-7.

29. Blackwell TS, Debelak JP, Venkatakrishnan A, Schot DJ, Harley DH, Pinson CW, Williams P, Washington K, Christman JW, Chapman WC. Acute lung injury after hepatic cryoablation: correlation with NF-kappa B activation and cytokine production. Surgery 1999;126:518-526.

30. Jean-Baptiste E. Clinical assessment and management of massive hemoptysis. Crit Care Med 2000;28: 1642-1647.

31. Fartoukh M, Khalil A, Louis L, Carette MF, Bazelly B, Cadranel J, Mayaud C, Parrot A. An integrated approach to diagnosis and management of severe haemoptysis in patients admitted to the intensive care unit: a case series from a referral centre. Respir Res 2007;8:11.

32. Khalil A, Soussan M, Mangiapan G, Fartoukh M, Parrot A, Carette MF. Utility of high-resolution chest CT scan in the emergency management of haemoptysis in the intensive care unit: severity, localization and aetiology. Br J Radiol 2007;80:21-25.

33. Kumar N, Timmermans C, Das M, Pison L, Maessen J, Crijns HJ. Re: CT imaging of complications of catheter ablation for atrial fibrillation. Clin Radiol 2014;69:e367-8.

34. Martí-Almor J, Jauregui-Abularach ME, Benito B, Vallès E, Bazan V, Sánchez-Font A, Vollmer I, Altaba C, Guijo MA, Hervas M, Bruguera-Cortada J. Pulmonary hemorrhage after cryoballoon ablation for pulmonary vein isolation in the treatment of atrial fibrillation. Chest 2014;145:156-157. 


\section{Chapter}

Adenosine testing after second-generation balloon devices (cryothermal and laser) mediated pulmonary vein ablation for atrial fibrillation

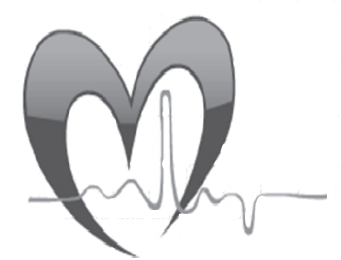

Narendra Kumar

Yuri Blaauw

Carl Timmermans

Laurent Pison

Kevin Vernooy

Harry Crijns

J Interv Card Electrophysiol 2014;41:91-7. 


\section{Abstract}

Aims

Adenosine administration after pulmonary vein (PV) isolation using radiofrequency and cryoablation can cause acute recovery of conduction to the PVs and predicts atrial fibrillation (AF) recurrence. This study evaluated whether adenosine testing after second-generation balloon devices (cryothermal and laser) could reveal dormant PVreconduction and recurrence rate of AF.

\section{Methods}

Out of total 60 patients, 20 patients underwent PV isolation using laser balloon and for the remaining patients, the cryoballoon was used. Following PVI, waiting period of 30 min was obtained. Thereafter, a bolus 15-21 mg of adenosine was injected followed by rapid saline flush. The subsequent response was assessed for each vein using an in situ lasso catheter. Further ablation (if needed) using laser balloon and cryocatheter respectively was done, until no reconduction occurred after repeat adenosine.

\section{Results}

Acute PV isolation was achieved in all 80 PVs of 20 patients (100\%) using laser device and in 151 PVs (96.2\%) of 38 patients (95\%) using cryoballoon. However, in seven patients (35\%), 11 PVs (13.7\%) (4 LSPV, 2 LIPV, 4 RSPV, and 1 RIPV) showed dormant PV potentials after adenosine administration in laser group. Cryoballoon group showed dormant reconduction in four patients (10\%), four PVs (5\%) [one LSPV, one LIPV, and two RIPV]. The follow-up of $337 \pm 92.4$ days for cryoballoon and $267 \pm 76.9$ days for laser balloon group demonstrated similar success rates (85\%).

\section{Conclusion}

Adenosine testing after PV isolation using second-generation balloon based energy devices (laser and cryothermal) reveals dormant conduction in initially isolated PVs with similar long-term success rate. 


\section{Introduction}

Achievement of pulmonary vein (PV) isolation is considered the cornerstone of atrial fibrillation (AF) ablation; ${ }^{1,2}$ however, the majority of recurrent atrial arrhythmias result from reconnection of $\mathrm{PV}^{3,4}$ Several balloon catheter based ablation technologies are widely used for PV isolation. The US FDA approved the cryoballoon several years ago, and recently, the second-generation cryoballoon (CB-2G) was introduced. This balloon has more cooling points, thereby delivering more uniform circumferential lesions around a PV. ${ }^{5}$ The endoscopic ablation system (EAS) is a recently introduced device and uses a laser energy source for ablation. ${ }^{6-9}$ The second-generation catheter uses a compliant balloon and has better balloon/tissue contact thus improving the energy delivery subsequently translating to durable PV isolation. ${ }^{10}$ Adenosine testing is a useful technique to predict acute $\mathrm{PV}$ reconnection during the index AF ablation procedure, as it can reveal dormant PV conduction. ${ }^{11-13}$ Adenosine activates adenosine-sensitive potassium channels, causing depolarization of resting membrane potential beyond the critical threshold value. ${ }^{14,15}$ Adenosine has been used previously for testing PV isolation after using cryoablation (old balloon) and radiofrequency ablation only, ${ }^{16,17}$ and targeting them may increase procedure success rate. The objective of this study was to determine whether adenosine could reveal PV reconduction after EAS and CB-2G ablation, subsequently to compare and study the mid-term recurrence of AF.

\section{Methods}

\section{Study population}

Sixty consecutive patients underwent PVI using EAS (HeartLight ${ }^{\mathrm{TM}}$, CardioFocus Inc.; LB, CardioFocus Inc., Marlborough, MA, USA) and CB-2G (Arctic Front ${ }^{\mathrm{TM}}$, Medtronic; CB, Medtronic, Minneapolis, MN, USA) for symptomatic paroxysmal and persistent AF from November 2012 until July 2013 at Maastricht University Medical Center. Patients were candidates for ablation if AF was refractory to at least one antiarrhythmic drug (AAD). AF had to be documented on Holter monitors or 12-lead electrocardiogram (ECG). Exclusion criteria in this study were as follows: patients with previous left atrial (LA) procedures, LA diameter $>50 \mathrm{~mm}$, obstructive pulmonary disease, left ventricular ejection fraction $<30 \%$, presence of intracardiac thrombus, moderate or severe valvular heart disease, myocardial infarction or cardiac surgery within the prior 3 months, and stroke or transient ischemic attack in the prior 6 months. Informed written consent was obtained in all patients after discussion of potential risks and benefit of the procedure. Before PV isolation, transesophageal echocardiography, and/or cardiac computed tomography scan was performed in all patients not only to rule out intracardiac thrombi but also to assess PV morphology and LA geometry. 
Paroxysmal and persistent AF was defined according to Heart Rhythm Society/European Heart Rhythm Association/European Cardiac Electrophysiology Society (HRS/EHRA/ECAS) consensus statement, updated in $2012 .^{18}$ Procedural success is defined as freedom from any left or right atrial arrhythmia lasting more than $30 \mathrm{~s}$ after the procedure and without the use of AADs. The first 3 months were considered as blanking period and subsequently the follow-up of patients was done using 24-48 $\mathrm{h}$ Holter monitor every 3 months. AADs were stopped 3 months after the procedure, only if there was no arrhythmia during follow-up. Patients without AF recurrence but still on AADs, irrespective of clinical status, are classified as failures. Procedural endpoints were PV isolation, demonstrated by entry block (the inability of an LA impulse to reach the PV muscle) and/or exit block (the inability of a PV potential to reach the LA).

\section{Electrophysiological procedure}

All procedures were performed under conscious sedation and analgesia using appropriate boluses of midazolam and morphine. Blood pressure and oxygen saturation were continuously monitored. The components of EAS and CB-2G procedure were performed as published elsewhere. ${ }^{9,10,19,20}$ Briefly, a coronary sinus catheter (Medtronic, Minneapolis, Minnesota) and a His catheter (St. Jude Medical, St. Paul, Minnesota) were placed via the femoral route and under fluoroscopic guidance. Following transseptal puncture, patients were heparinized (1,000 $\mathrm{U}$ heparin per $10 \mathrm{~kg}$ body weight and a heparin infusion) to maintain activated clotting time more than $\mathbf{3 0 0}$ $\mathrm{s}$ throughout the procedure. During rapid ventricular pacing (S1S1 $300 \mathrm{~ms}$ ), contrast was injected through the long sheath to visualize LA and PV anatomy.

\section{Endoscopic ablation system}

Double transseptal puncture was performed with a long 8-F sheath (SLO, St. Jude Medical) into the LA using a modified Brockenbrough technique. One of the sheaths was exchanged for a $12 \mathrm{~F}$ (TS; CardioFocus) sheath that was used for advancing the EAS balloon.

The compliant EAS balloon was filled with heavy water (D2O), and it can be inflated/deflated in accordance with PV size to the range of 9-35 $\mathrm{mm}$. The operator's view to the venous tissue is limited due to the endoscope's eccentric position on the catheter shaft. Therefore, a sequential catheter rotation is needed for complete visualization of the PVostium.

The catheter shaft is equipped with a radiopaque Z-shaped marker for correlating the orientation of the endoscopic with the fluoroscopic view as shown in Figure 5.3. The laser energy (5.5-10 W, 20-30 s) was delivered around the PV ostium in contiguous manner with approximately $50 \%$ lesion overlap.

The lowest dose of $5.5 \mathrm{~W} / 30 \mathrm{~s}$ was used in areas that were adjacent to or were overlapping with blood. For other areas, 7-W minimum was used. If PVs were not 
isolated, then higher watt was used. The PVs were mapped with a circular mapping catheter (Lasso, Biosense Webster, Diamond Bar, CA). The His catheter was repositioned to superior vena cava during ablation at right superior PV for continuous pacing of the right phrenic nerve (PN) to monitor the diaphragmatic function. An esophageal temperature probe was used for all patients and inserted for through nostrils to monitor and avoid excessive esophageal heating and thermal injury. The alarm was set at $39^{\circ} \mathrm{C}$, and the application was discontinued if this temperature was reached.

\section{Cryoballoon ablation procedure}

After single transseptal puncture (SLO, St. Jude), a guide wire was advanced to left superior PV, and the sheath was exchanged for the FlexCath sheath. The CB-2G balloon was advanced to the ostium of PV with Achieve catheter. After twice 4-min application of each PV and their electrical isolation, we proceeded with following steps. His catheter was also used for stimulating PN as like EAS procedure.

\section{Adenosine testing}

After isolating the PVs, they were individually checked to demonstrate entrance and exit blocks. The decapolar catheter (Lasso) was placed at PV ostia as shown in flowchart of Figure 5.1. Following awaiting time of $30 \mathrm{~min}$ of the last energy application, adenosine was administered followed by a rapid saline flush. Initially, $12 \mathrm{mg}$ adenosine was injected, and if atrioventricular (AV) block was not seen, then $3 \mathrm{mg}$ more (15 mg) was injected. If it still did not show AV block, $3 \mathrm{mg}$ more was used and so on. Above steps were repeated for all PVs one after another. Dormant conduction was said to be present, if one or more PV potentials were seen on lasso catheter ECG. In case of residual LA to PV conduction as in Figure 5.2, additional ablation was carried out using the EAS and cryocatheter respectively according to the segment of reconduction in the circular mapping catheter. Additional ablation was performed until complete abolition of PV spikes was seen with repeat adenosine.

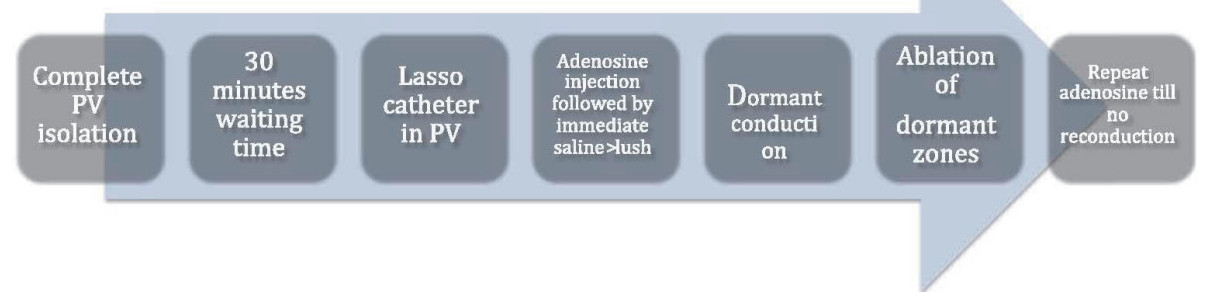

Figure 5.1 Scheme followed for revealing dormant reconduction using balloon catheters. 


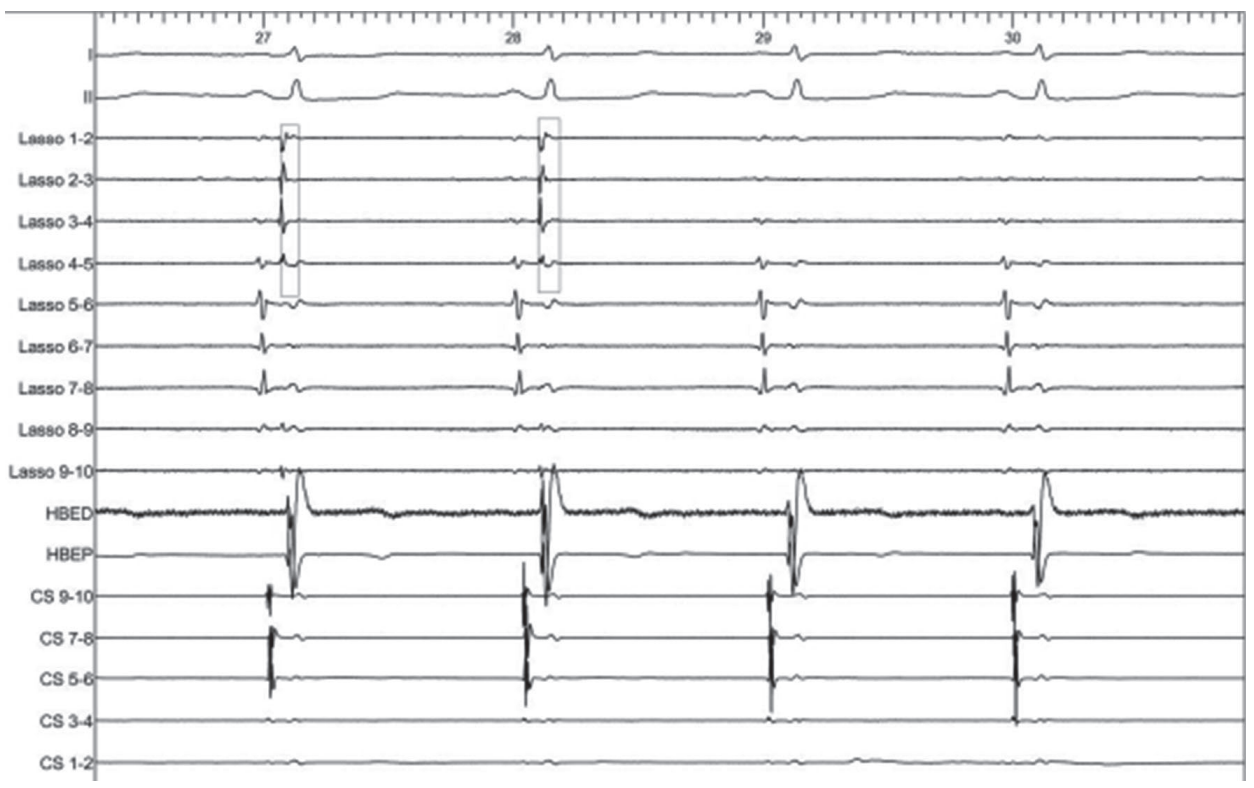

Figure 5.2 Reconnection of dormant pulmonary vein sleeves under adenosine administration after EAS (endocardial ablation system) ablation. [I, II = limb leads; lasso = decapolar catheter placed in left superior pulmonary vein; HBED/P = His bundle electrocardiogram distal $/$ proximal; $\mathrm{CS}=$ decapolar coronary sinus catheter].

\section{Statistical analysis}

Statistical analysis was performed using Statistical Package for the Social Sciences (SPSS Inc., Chicago, IL, USA). Numeric variables were expressed as mean \pm standard deviation. Categorical values are expressed as frequency or percentage and were compared using the $\chi$ 2and Fisher's exact test. The Fisher's exact test was conducted when more than $20.0 \%$ of cells have an expected frequency $<5$. A p value of $<0.05$ was considered significant.

\section{Results}

Patient characteristics are represented in Table 5.1. There were no significant differences between the two groups. 
Table $5.1 \quad$ Patient characteristics.

\begin{tabular}{|c|c|c|c|}
\hline \multirow[t]{2}{*}{ Variables } & \multicolumn{2}{|c|}{ Number of patients } & \multirow[t]{3}{*}{$p$-value } \\
\hline & EAS group & CB-2G group & \\
\hline Patients (n) & 20 & 40 & \\
\hline Pulmonary veins $(n)$ & 80 & 160 & NS \\
\hline Gender (men/women) & $15 / 5$ & $29 / 11$ & NS \\
\hline Age (years) & $58.9 \pm 8.7$ & $58 \pm 6$ & NS \\
\hline $\mathrm{BMI}\left(\mathrm{kg} / \mathrm{m}^{2}\right)$ & $29 \pm 3.5$ & $28 \pm 4$ & NS \\
\hline Additional CTI ablation (n, \%) & $2(10)$ & $4(10)$ & NS \\
\hline Average procedure time (minutes) & $180 \pm 44$ & $185 \pm 47$ & NS \\
\hline Fluoroscopy time (minutes) & $25 \pm 10$ & $36 \pm 16$ & NS \\
\hline \multicolumn{4}{|l|}{ Medical History } \\
\hline Hypertension (n, \%) & $8(40)$ & $15(38)$ & NS \\
\hline Atrial flutter (n, \%) & $2(10.0)$ & $3(7.5)$ & NS \\
\hline $\operatorname{CAD}(n, \%)$ & $4(20.0)$ & $7(17.5)$ & NS \\
\hline \multicolumn{4}{|l|}{ Medication Use } \\
\hline Amiodarone (n, \%) & $2(10.0)$ & $3(7.5)$ & NS \\
\hline Flecainide (n, \%) & $12(60.0)$ & $27(67.5)$ & NS \\
\hline Sotalol (n, \%) & $4(20.0)$ & $9(22.5)$ & NS \\
\hline \multicolumn{4}{|l|}{ Disease Characteristics } \\
\hline Paroxysmal/persistent AF (n/n, \%/\%) & $18 / 2(90 / 10)$ & $35 / 5(87.5 / 12.5)$ & NS \\
\hline $\mathrm{AF}$ duration (years, mean $\pm \mathrm{SD}$ ) & $6 \pm 4.5$ & $3.8 \pm 2$ & NS \\
\hline $\operatorname{LVEF}(\%$, mean $\pm S D)$ & $57 \pm 4$ & $58 \pm 6$ & NS \\
\hline LA volume (cc, mean \pm SD) & $60 \pm 9$ & $58 \pm 8$ & NS \\
\hline Number of prior electrical cardioversions (n, \%) & $3(15)$ & $8(20)$ & NS \\
\hline Number of prior pharmacological cardioversions ( $n, \%)$ & $3(15)$ & $5(12.5)$ & NS \\
\hline
\end{tabular}

$A F$, atrial fibrillation; $A F I$, atrial flutter; $B M I$, body mass index; $n$, numbers; $C A D$, coronary artery disease; $C B-$ $2 \mathrm{G}$, cryoballoon second generation; $\mathrm{CHF}$, congestive heart failure; CTI, Cavo-tricuspid isthumus; EAS, endoscopic ablation system; LA, left atrial; LVEF, left ventricle ejection fraction; NS, not significant; SD, standard deviation.

\section{Acute results}

All study patients underwent successful PV isolation. Median procedure time was $185 \pm 47$ and $180 \pm 44 \mathrm{~min}$, while median fluoroscopy time was $36 \pm 16$ and $25 \pm 10 \mathrm{~min}$, for CB-2G and EAS, respectively. General anesthesia was not used in any of the patients, and all patients were consciously sedated.

All the 60 patients had normal anatomy of PV, i.e., each patient having four PVs. PV isolation was achieved in all 80 PVs of 20 patients (100\%) using EAS and in 151 PVs (96.2\%) of 38 patients (95\%) using CB-2G ablation ( $p=$ not significant). Following the waiting period of $30 \mathrm{~min}$, acute reconduction was noted in none of 60 patients. The average dose of adenosine administered per vein was $12 \pm 3 \mathrm{mg}$. Seven patients (35\%) showed dormant PV potentials after adenosine administration in EAS group; in 11 PVs (13.75\%) (four LSPV, two LIPV, four RSPV, and one RIPV). In the CB-2G group, there was lower percentage of dormant reconduction in four patients $(2.5 \%)$; in four PVs (5\%) [one LSPV, one LIPV, and two RIPV]. ( $p=$ not significant). For the cryoballoon group, RIPV has been attributed to have more reconduction due to poor alignment of the 
cryoballoon resulting in poor contact of the balloon at the ostium and subsequent lack of complete ablation $^{21}$ (Figure 5.3). However, for EAS group it may be attributed to device's technical issues.

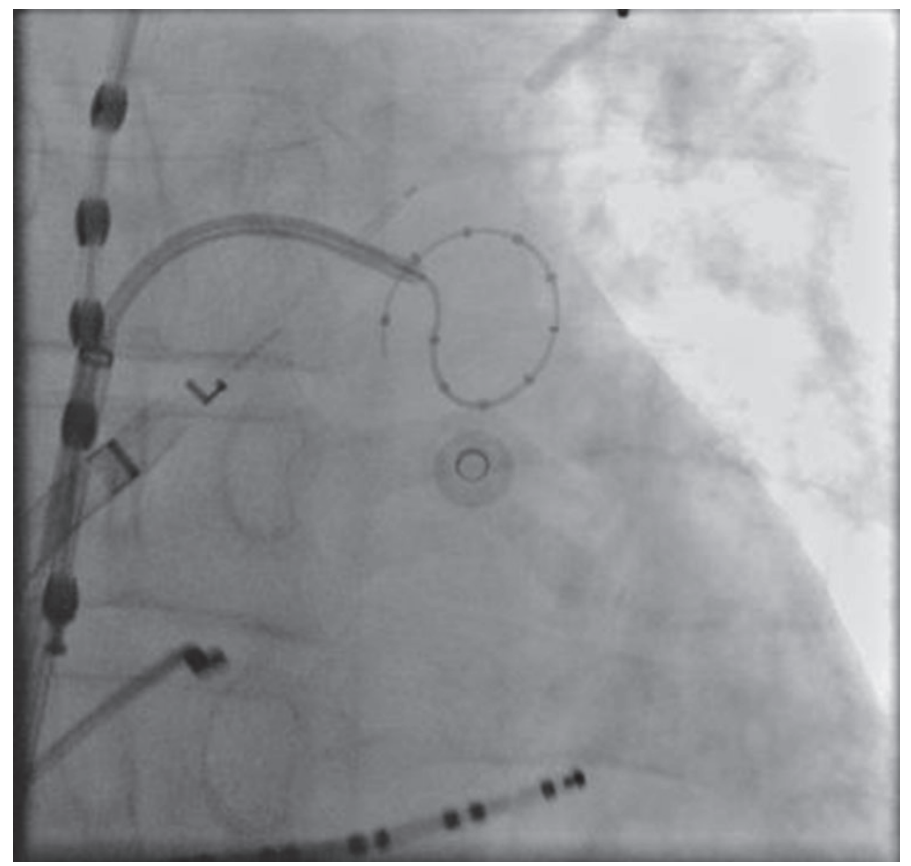

Figure 5.3 Fluoroscopic image of EAS during procedure showing different catheter positions (lasso, coronary sinus and His), esophageal temperature probe, Z marker of deflated balloon of EAS.

Finally, all veins with dormant conduction were additionally ablated as described earlier, until subsequent adenosine administration could not reveal reconduction. These findings are summarized in Figure 5.4. There were no significant differences with respect to age, gender, and type of $A F$, ejection fraction, and left atrial size between the patients with and without adenosine-induced PV reconnection.

With passage of time due to growing familiarity with device, a progressive decrease in fluoroscopy time, procedural time, number of energy applications was noted. 
A
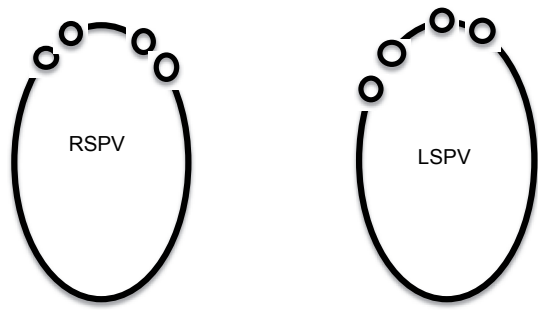

Anterior

Posterior

Anterior
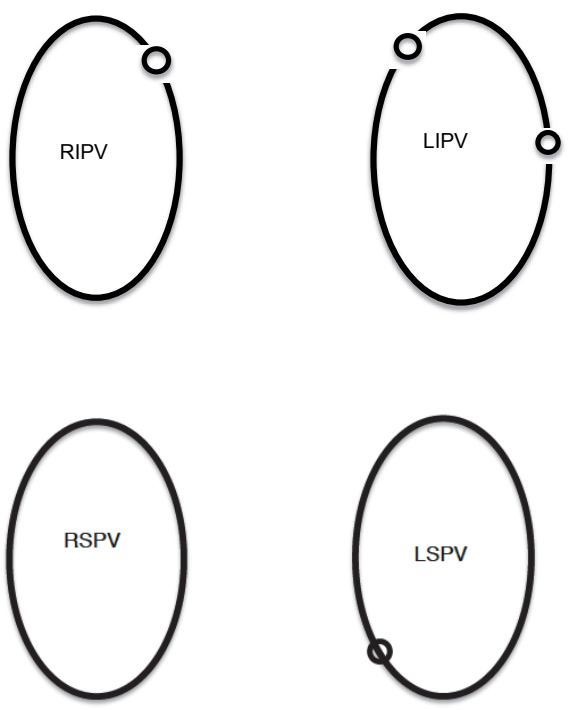

Anterior

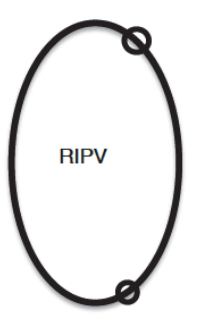

Posterior

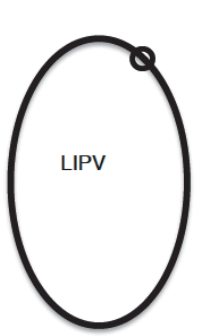

Anterior

Figure 5.4 Distribution of location of dormant conduction in A) EAS group and B) cryoballoon group. Gaps were assigned to superior, inferior, anterior, or posterior localization. PV = pulmonary vein; LIPV = left inferior PV; LSPV = left superior PV; RIPV = right inferior PV; RSPV = right superior PV. 


\section{Adverse events}

For EAS group, phrenic nerve paralysis (PNP) was observed in one patient (Table 5.2) that resolved spontaneously within 3 months. A brief gradual significant ST segment elevation was seen in a patient, which resolved with sublingual nitroglycerine. In one patient vascular access, complication (hematoma) occurred at the right groin. Headache was the symptom of another patient presenting after 3 weeks. However, extensive neurological diagnostic workup did not reveal any clear cause. Schmidt et al. observed asymptomatic cerebral lesions are independent of energy sources. ${ }^{22}$ Henceforth, it may be attributed to small number of patients in the EAS group. No other adverse events were noted in the patients. PNP was more common with CB-2G but all of them showed spontaneous recovery with first 6 months of follow-up. There was a case of gastroparesis with CB-2G, which was medically managed.

Table 5.2 Adverse events.

\begin{tabular}{lcc}
\hline Adverse events $(\mathrm{n}, \%)$ & EAS $(\mathrm{n}=20)$ & $\mathrm{CB}-2 \mathrm{G}(\mathrm{n}=40)$ \\
\hline Groin complications & 0 & $1(2.5)$ \\
Phrenic nerve palsy & & $3(7.5)$ \\
$\quad$ persisting post procedure & $1(5)$ & 0 \\
$\quad$ persisting post 1 year & 0 & 0 \\
Stroke or TIA & 0 & 0 \\
Transient myocardial Ischemia & $1(5)$ & 0 \\
LA-esophageal fistula & 0 & 0 \\
Esophageal ulceration & $1(5)$ & $1(2.5)$ \\
Gastroparesis & 0 & 0 \\
Pericardial effusion or tamponade & 0 & 0 \\
Cardiac tamponade & 0 & 0 \\
Death & 0 & \\
\hline
\end{tabular}

CB-2G, cryoballoon second generation; EAS, endoscopic ablation system, LA-left atrial; TIA, transient ischemia attack.

\section{Follow-up}

Both groups had a comparable follow-up of $337 \pm 92.4$ days for CB-2G and $267 \pm 76.9$ days for EAS group. At the end of the follow-up, the freedom of AF recurrence showed similar success rates for both groups, i.e., 85\%. Figure 5.5 shows a Kaplan-Meier graph of AF-free survival in both groups. Patients with dormant reconduction had similar AFfree follow-up as patients without reconduction. 


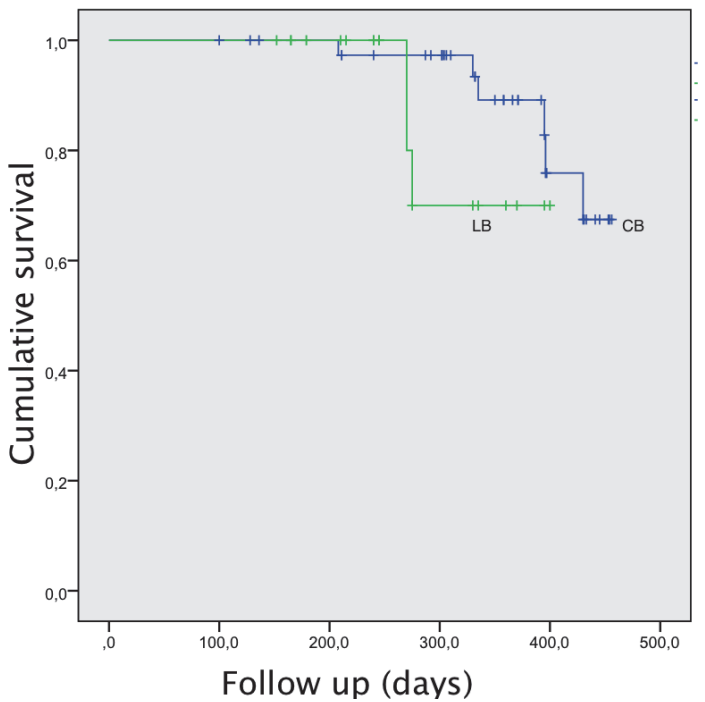

Figure 5.5 Kaplan-Meier survival curve comparison of AF free survival after a single ablation procedure off antiarrhythmic drugs, after a blanking period of 90 days for the arrhythmias. [FU follow up in days, CB cryoballoon, LB for laser balloon].

\section{Discussion}

To our knowledge, this is the first study to report adenosine testing for revealing dormant PV reconduction after using the EAS and CB-2G and mid-term follow-up. We observed a higher number of PV reconduction with the use of adenosine in EAS group. Subsequent follow-up showed a comparable high percentage of sinus rhythm, following additional ablation targeting the dormant reconduction.

\section{Adenosine testing for dormant reconduction}

PV reconduction during the index procedure has been found to be an important predictor of recurrent $\mathrm{AF}$ after $\mathrm{PV}$ isolation. ${ }^{23}$ Use of adenosine-guided ablation of dormant conduction is a useful approach to maximize the durability of PV isolation for $\mathrm{AF}$ ablation. ${ }^{24}$ It is also effective in reducing AF recurrence after ablation using energy sources as cryoballoon. ${ }^{16}$

\section{Mechanism of dormant reconduction and adenosine}

Datino et al. has shown in a canine model that PV ablation leads to depolarization of the resting membrane potential of the damaged tissue to a level that inactivates sodium channels and inhibits conduction. ${ }^{14}$ Hyperpolarization of the resting membrane 
is the main mechanism causing adenosine-induced PV dormant conduction. ${ }^{25}$ The prevalence of $A D O F$ induced $P V$ reconnection using radiofrequency catheters has been reported in several studies and was $(\sim 25 \%) .{ }^{13,26}$ Van belle et al. reported reconduction was seen in $25 \%$ of patients and $9 \%$ of veins using the first generation cryoballoon. ${ }^{16}$ In our study, the reconduction rate was lower. The newer CB-2G has double number of freezing points ( 8 instead of 4 ) together with their more distal location, leading to more uniform ablation of PVs. ${ }^{5}$ Also, the outcome was shown to be superior to the first generation balloon.

EAS has several benefits to offer in comparison with other balloon based ablation devices for PVI, e.g., the compliant balloon in EAS adjusts to the varying PV diameter and causes uniform ablation. The power to control the device single handly and also titrate the amount of energy which can be delivered are few other major advantage in the array of tools available to physician using this novel tool. Using CB-2G, on one side, the option of online recording of intracardiac electrograms using endoluminal spiral catheter (Achieve ${ }^{\mathrm{TM}}, 15$ or $20 \mathrm{~mm}$, Medtronic, Inc.) is definitely useful, but on the other side, potentially longer procedure times and higher fluoroscopic time exist compared to its alternative. In addition, improved lesion visualization may help in contiguous energy deployment. ${ }^{27}$ Figure 5.4 showing zones of reconduction further enforces about more uniform cooling with CB-2G compared with first generation balloon and subsequent findings of Van belle et al. after using adenosine.

During further scrutiny of statistical data, it became clearer that the success rates were attributed to different energy sources not just duration of follow-up, as longer duration of follow-up may individually lead to arrhythmia recurrence. Further, we observed that chances of arrhythmia recurrence tend to stabilize after approximately 1 year. The study further reveals acute success rates after adenosine use is different from other energy sources like Radiofrequency [unipolar and bipolar], older cryoballoon, epicardial bipolar radiofrequency ablation.

\section{Conclusion}

Adenosine testing after pulmonary vein isolation using second-generation balloonbased energy devices as EAS and cryoballoon reveals dormant conduction in initially isolated PVs and though ablating them yield similar annual success results. This approach needs further evaluation in a long-term prospective randomized study.

\section{Limitations}

The study population is small. However, the clinical utilities of adenosine test after second-generation balloon-based devices is indicated from these data; this study may not provide statistically significant scientific comparison necessary to favor clinical 
benefit from ablating late dormant PVs. A prospective randomized trial is necessary to firmly establish this postulate.

Further insights will be gained from soon to be published results of Adenosine following PV Isolation to Target Dormant Conduction Elimination (ADVICE) trial that randomized patients with dormant PV conduction to further adenosine-guided ablation versus no ablation. In the meantime, this study brings us one step closer toward achieving the goal of long-term maintenance of sinus rhythm with the strategy of drug provocation to target non-PV triggers and acute PV reconnections during ablation. The utility of this approach needs evaluation in long-term prospective randomized studies. 


\section{References}

1. Kirchhof P, Auricchio A, Bax J, Crijns H, Camm J, Diener HC, Goette A, Hindricks G, Hohnloser S, Kappenberger L, Kuck KH, Lip GY, Olsson B, Meinertz T, Priori S, Ravens U, Steinbeck G, Svernhage E, Tijssen J, Vincent A, Breithardt G. Outcome parameters for trials in atrial fibrillation: executive summary. Eur Heart J 2007;28:2803-2817.

2. Haïssaguerre M, Jaïs $P$, Shah DC, Takahashi A, Hocini M, Quiniou G, Garrigue S, Le Mouroux A, Le Métayer $P$, Clémenty J. Spontaneous initiation of atrial fibrillation by ectopic beats originating in the pulmonary veins. N Engl J Med 1998;339:659-666.

3. Cappato R, Negroni S, Pecora D, Bentivegna S, Lupo PP, Carolei A, Esposito C, Furlanello F, De Ambroggi L. Prospective assessment of late conduction recurrence across radiofrequency lesions producing electrical disconnection at the pulmonary vein ostium in patients with atrial fibrillation. Circulation, 2003;108:1599-1604.

4. Ouyang F, Antz M, Ernst S, Hachiya H, Mavrakis H, Deger FT, Schaumann A, Chun J, Falk P, Hennig D, Liu $X$, Bänsch D, Kuck KH. Recovered pulmonary vein conduction as a dominant factor for recurrent atrial tachyarrhythmias after complete circular isolation of the pulmonary veins: lessons from double Lasso technique. Circulation 2005;111:127-135.

5. Fürnkranz A, Bordignon S, Schmidt B, Gunawardene M, Schulte-Hahn B, Urban V, Bode F, Nowak B, Chun JK. Improved procedural efficacy of pulmonary vein isolation using the novel second-generation cryoballoon. Journal of Cardiovascular Electrophysiology 2013:24:492-497.

6. Reddy VY, Neuzil P, Themistoclakis S, Danik SB, Bonso A, Rossillo A, Raviele A, Schweikert R, Ernst S, Kuck KH, Natale A. Visually-guided balloon catheter ablation of atrial fibrillation: experimental feasibility and first-in-human multicenter clinical outcome. Circulation 2009;120:12-20.

7. Metzner A, Schmidt B, Fuernkranz A, Wissner E, Tilz RR, Chun KR, Neven K, Konstantinidou M, Rillig A, Yoshiga $\mathrm{Y}$, Mathew S, Koester I, Ouyang F, Kuck KH. One-year clinical outcome after pulmonary vein isolation using the novel endoscopic ablation system in patients with paroxysmal atrial fibrillation. Heart Rhythm 2011;8:988-993.

8. Dukkipati SR, Kuck KH, Neuzil P, Woollett I, Kautzner J, McElderry HT, Schmidt B, Gerstenfeld EP, Doshi SK, Horton R, Metzner A, d'Avila A, Ruskin JN, Natale A, Reddy VY. Pulmonary vein isolation using a visually guided laser balloon catheter: the first 200-patient multicenter clinical experience. Circ Arrhythm Electrophysiol 2013;6:467-472.

9. Dukkipati SR, Neuzil P, Kautzner J, Petru J, Wichterle D, Skoda J, Cihak R, Peichl P, Dello Russo A, Pelargonio G, Tondo C, Natale A, Reddy VY. The durability of pulmonary vein isolation using the visually guided laser balloon catheter: multicenter results of pulmonary vein remapping studies. Heart Rhythm 2012;9:919-925.

10. Metzner A, Wissner E, Schmidt B, Chun J, Hindricks G, Piorkowski C, Ouyang F, Kuck KH. Acute and longterm clinical outcome after endoscopic pulmonary vein isolation: results from the first prospective, multicenter study. J Cardiovasc Electrophysiol 2013;24(1), 7-13.

11. Arentz T, Macle L, Kalusche D, Hocini M, Jais P, Shah D, Haissaguerre M. "Dormant" pulmonary vein conduction revealed by adenosine after ostial radiofrequency catheter ablation. J Cardiovasc Electrophysiol 2004;15:1041-1047.

12. Tritto M, De Ponti R, Salerno-Uriarte JA, Spadacini G, Marazzi R, Moretti P, Lanzotti M. Adenosine restores atriovenous conduction after apparently successful ostial isolation of the pulmonary veins. Eur Heart J 2004;25:2155-2163.

13. Hachiya H, Hirao K, Takahashi A, Nagata Y, Suzuki K, Maeda S, Sasaki T, Kawabata M, Isobe M, lesaka Y. Clinical implications of reconnection between the left atrium and isolated pulmonary veins provoked by adenosine triphosphate after extensive encircling pulmonary vein isolation. J Cardiovasc Electrophysiol 2007;18:392-398.

14. Datino T, Macle L, Qi XY, Maguy A, Comtois P, Chartier D, Guerra PG, Arenal A, Fernández-Avilés F, Nattel S. Mechanisms by which adenosine restores conduction in dormant canine pulmonary veins. Circulation 2010;121:963-972.

15. Freilich A, Tepper D. Adenosine and its cardiovascular effects. Am Heart J 1992;123:1324-1328. 
16. Van Belle YL, Janse PA, de Groot NM, Anné W, Theuns DA, Jordaens L. Adenosine testing after cryoballoon pulmonary vein isolation improves long-term clinical outcome. Neth Heart J 2012; 20: 447-455.

17. Miyazaki S, Kobori A, Hocini M, Shah AJ, Komatsu $Y$, Taniguchi $H$, Kusa S, Uchiyama T, Nakamura $H$, Hachiya H, Isobe M, Hirao K, Haïssaguerre M, Takahashi A, lesaka Y. Clinical utility of adenosine-infusion test at a repeat atrial fibrillation ablation procedure. Heart Rhythm 2013;10:629-635.

18. Calkins H, Kuck KH, Cappato R, Brugada J, Camm AJ, Chen SA, Crijns HJ, Damiano RJ Jr, Davies DW, DiMarco J, Edgerton J, Ellenbogen K, Ezekowitz MD, Haines DE, Haissaguerre M, Hindricks G, lesaka $Y$, Jackman W, Jalife J, Jais P, Kalman J, Keane D, Kim YH, Kirchhof P, Klein G, Kottkamp H, Kumagai K, Lindsay BD, Mansour M, Marchlinski FE, McCarthy PM, Mont JL, Morady F, Nademanee K, Nakagawa H, Natale A, Nattel S, Packer DL, Pappone C, Prystowsky E, Raviele A, Reddy V, Ruskin JN, Shemin RJ, Tsao HM, Wilber D. 2012 HRS/EHRA/ECAS expert consensus statement on catheter and surgical ablation of atrial fibrillation: recommendations for patient selection, procedural techniques, patient management and follow-up, definitions, endpoints, and research trial design. J Interv Card Electrophysiol 2012;33:171-257.

19. Kühne M, Schaer B, Ammann P, Suter Y, Osswald S, Sticherling C. Cryoballoon ablation for pulmonary vein isolation in patients with paroxysmal atrial fibrillation. Swiss Med Wkly 2010;140:214-221.

20. Chun KR, Fürnkranz A, Metzner A, Schmidt B, Tilz R, Zerm T, Köster I, Nuyens D, Wissner E, Ouyang F, Kuck KH. Cryoballoon pulmonary vein isolation with real-time recordings from the pulmonary veins. J Cardiovasc Electrophysiol 2009;20:1203-1210.

21. Fürnkranz A, Chun KR, Nuyens D, Metzner A, Köster I, Schmidt B, Ouyang F, Kuck KH. Characterization of conduction recovery after pulmonary vein isolation using the "single big cryoballoon" technique. Heart Rhythm 2010;7:184-190.

22. Schmidt B, Gunawardene M, Krieg D, Bordignon S, Fürnkranz A, Kulikoglu M, Herrmann W, Chun KR. A prospective randomized single-center study on the risk of asymptomatic cerebral lesions comparing irrigated radiofrequency current ablation with the cryoballoon and the laser balloon. J Cardiovasc Electrophysiol 2013;24:869-874.

23. Verma A, Kilicaslan F, Pisano E, Marrouche NF, Fanelli R, Brachmann J, Geunther J, Potenza D, Martin DO, Cummings J, Burkhardt JD, Saliba W, Schweikert RA, Natale A. Response of atrial fibrillation to pulmonary vein antrum isolation is directly related to resumption and delay of pulmonary vein conduction. Circulation 2005;112:627-635.

24. Reichlin T, Michaud GF. Our approach to maximizing the durability of pulmonary vein isolation during a paroxysmal atrial fibrillation ablation procedure. J Cardiovasc Electrophysiol 2012;23:1272-1276.

25. Cheung JW, Chung JH, Ip JE, Markowitz SM, Liu CF, Thomas G, Lerman BB. Time course of adenosineinduced pulmonary vein reconnection after isolation: implications for mechanism of dormant conduction. Pacing Clin Electrophysiol 2012;35:556-563.

26. Matsuo S, Yamane T, Date T, Inada K, Kanzaki Y, Tokuda M, Shibayama K, Miyanaga S, Miyazaki H, Sugimoto K, Mochizuki S. Reduction of AF recurrence after pulmonary vein isolation by eliminating ATPinduced transient venous reconduction. J Cardiovasc Electrophysiol 2007;18:704-708.

27. Bordignon S1, Chun KR, Gunawardene M, Schulte-Hahn B, Nowak B, Fuernkranz A, Schmidt B. Endoscopic ablation systems. Expert Rev Med Devices 2013;10:177-183. 


\section{Chapter}

Impact of hybrid procedure on $\mathrm{P}$ wave duration for atrial fibrillation ablation

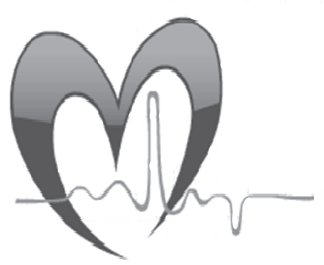

Narendra Kumar

Pietro Bonizzi

Laurent Pison

Kevin Phan

Theo Lankveld

Bart Maesen

Mark La Meir

Sandro Gelsomino

Jos Maessen

Harry Crijns

J Interv Card Electrophysiol 2015;42:91-9 


\section{Abstract}

Aim

Hybrid procedure (HP) involves epicardial isolation of pulmonary vein and posterior wall of left atrium, and endocardial checking of lesions and touchups (if needed). We aimed at observing the effect of hybrid procedure on P wave duration (PWD), calculated automatically from surface ECG leads at start and end of HP, and also for relationship to atrial fibrillation (AF) recurrence at 9 months.

\section{Methods}

Forty-one patients (32 male; mean age, 58.4 \pm 9.5 years) underwent $\mathrm{HP}$, as first ever ablation. A new automated method was used for $P$ wave segmentation and PWD estimation from recognizable $P$ waves in ECG lead I or II before and after HP, based on fitting of each $P$ wave by means of two Gaussian functions.

\section{Results}

Overall, PWD was significantly decreased after procedure $(104.4 \pm 25.1 \mathrm{~ms}$ vs. $84.7 \pm 23.8 \mathrm{~ms}$, $p=0.0151)$, especially in persistent AF patients $(122.4 \pm 32.2 \mathrm{~ms}$ vs. $85.6 \pm 24.5 \mathrm{~ms}, \mathrm{p}=0.02)$. PWD preprocedure was significantly higher in persistent than in paroxysmal patients $(122.4 \pm 32.2 \mathrm{~ms}$ vs. $92.5 \pm 17.9 \mathrm{~ms}, \mathrm{p}=0.0383$ ). PWD was significantly decreased after procedure in prior electrical cardioverted patients $(106.7 \pm 30.5 \mathrm{~ms}$ vs. $84.7 \pm 23.1 \mathrm{~ms}, \mathrm{p}=0.0353)$. After 9-month follow-up of 40 patients, HP-induced PWD decrease was significant for the 12 persistent patients without recurrence (122.4.1 $\pm 35.3 \mathrm{~ms}$ vs. $85.6 \pm 22.0 \mathrm{~ms}, \mathrm{p}=0.0210)$.

\section{Conclusion}

Preprocedure PWD was higher for persistent than paroxysmal patients. HP reduced PWD significantly. Nine month follow-up suggests that HP is successful in restoring and maintaining sinus rhythm. To individualize AF therapy, AF type-based selection of patients may be possible before procedure. Automated analysis of PWD from surface ECG is possible. 


\section{Introduction}

Atrial fibrillation (AF) is the most common cardiac arrhythmia, ${ }^{1}$ causing significant morbidity and mortality. ${ }^{2}$ Catheter ablation is a superior option to antiarrhythmic drugs (AADs) for such patients in terms of sinus rhythm (SR) maintenance and ultimately improving quality of life. ${ }^{3,4}$ The latest 2012 European Society of Cardiology guidelines state that the "weight of evidence is in favor of efficacy" of ablation for patients with symptomatic drug refractory persistent AF but that "efficacy is less well established" (class $\mathrm{Ilb}$ ) for symptomatic long-standing persistent AF refractory to AADs. Hybrid procedure is a novel approach to AF ablation involving thoracoscopic epicardial bipolar radiofrequency (RF) devices for pulmonary vein (PV) and box lesion, and endocardial electrical checking of lesions and touchups (if needed). ${ }^{5,6}$ Changes in $\mathrm{P}$ wave duration (PWD) have been described following AF ablation procedure and attempted to predict the arrhythmia recurrence. ${ }^{7-9}$ Patient history of $A F$ in terms of paroxysmal or persistent AF further affects this success rate. ${ }^{10}$

We hypothesized that hybrid procedure is effective in restoring SR in patients with different history of $A F$, by reducing PWD immediately following the procedure, and in maintaining freedom from AF over time. There is a need for methods able to predict success of treatment and freedom from AF recurrence, possibly using noninvasive recordings, as the surface ECG, in addition to echocardiographic parameters (dilated left atria), AF type (paroxysmal, persistent), and AF duration (longstanding persistent). This will help individualizing therapies and selecting the best candidates for a specific treatment. In this respect, we also investigated the possibility to predict AF recurrence using surface ECG data, and its correlation with common AF types as paroxysmal and persistent AF.

\section{Methods}

\section{Study population}

Among all patients who underwent hybrid procedure for AF $(n=124)$ at Maastricht University Medical Center from May 2008 to May 2013, retrospectively, a cohort of 41 patients (32 male; mean age, $58.4 \pm 9.5$ years) was selected with respect to the following criteria: first ever ablation procedure, recognizable $\mathrm{P}$ waves before and after the procedure (all patients converted to SR after procedure after DC cardioversion), and 1min ECG recording available. In this set, 40 patients allowed a minimum follow-up of 9 months at the point of data collection. Patients showed either paroxysmal $(n=25)$ or persistent AF $(n=16)$. Patient characteristics are described in Table 6.1. According to the recent 2012 updated ESC guidelines for AF management, ${ }^{4}$ paroxysmal AF was defined as two or more episodes of recurrent AF terminating spontaneously within 7 days; 
persistent AF was defined as AF not terminating spontaneously within 7 days or requiring electrical or chemical cardioversion. Information on 9-month AF recurrence was used as long-term postoperative indicator of freedom from AF. This 9-month period included a 3-month blanking period. AADs and anticoagulation medications were restarted as soon as possible after the procedure and terminated at 6 months.

Table 6.1 Manual (pre and post procedure) and automated (pre and post procedure) annotated P-wave durations (PWD) of patients.

\begin{tabular}{lcccc}
\hline $\begin{array}{l}\text { Patient } \\
\text { number }\end{array}$ & $\begin{array}{c}\text { Manual-pre } \\
(\mathrm{ms})\end{array}$ & $\begin{array}{c}\text { Automated-pre } \\
(\mathrm{ms})\end{array}$ & $\begin{array}{c}\text { Manual-post } \\
(\mathrm{ms})\end{array}$ & $\begin{array}{c}\text { Automated-post } \\
(\mathrm{ms})\end{array}$ \\
\hline 1 & 120 & 114 & 82 & 74 \\
2 & 114 & 111 & 76 & 166 \\
3 & 170 & 130 & 76 & 88 \\
4 & 146 & 84 & 116 & 184 \\
5 & 130 & 59 & 80 & 60 \\
6 & 132 & 101 & 114 & 109 \\
7 & 88 & 88 & 146 & 152 \\
8 & 130 & 78 & 75 \\
9 & 80 & 97 & 114 & 108 \\
10 & 72 & 114 & 74 & 70 \\
11 & 120 & 126 & 76 & 71 \\
12 & 140 & 100 & 88 & 82 \\
13 & 104 & 138 & 76 & 78 \\
14 & 150 & 159 & 108 & 100 \\
15 & 176 & 130 & 70 & 60 \\
16 & 134 & 141 & 123 & 119 \\
17 & 156 & 88 & 140 & 150 \\
18 & 89 & 93 & 125 & 86 \\
19 & 88 & 101 & & 119 \\
\hline
\end{tabular}

\section{Hybrid procedure}

All AADs, except amiodarone, were stopped 5 days before the procedure. The components of hybrid procedure were performed as reported in previous studies. ${ }^{5,11,12}$ Briefly, after placing videoports and interports in intercostal spaces, epicardial ablation of PVs was carried out using a bipolar RF clamp (Atricure, West Chester, $\mathrm{OH}, \mathrm{USA}$ ). Box lesion set comprising of roof and inferior line to isolate the posterior left atrium was also performed epicardially using bipolar RF pen or linear pen device (Coolrail, Atricure). Two additional ablation lines, one encircling the superior vena cava using the clamp, the other connecting both venae cava using the linear pen, were created for patients with dilated right atrium. Following this, a cardiac electrophysiologist checked the PVs and box lesion endocardially for electrical isolation using pacing manoeuvres and adenosine. Endocardial touchups using irrigated tip RF catheter was applied only if needed. 


\section{Follow-up management}

The patients were restarted on AADs and anticoagulation as soon as possible after procedure. After 3 months blanking period, patients were followed up at an outpatient department of the hospital at 3, 5, 6, and 9 months. Any episode lasting more than $30 \mathrm{~s}$ of AF, atrial flutter, or atrial tachycardia during ECG or 7-day, 24-48-h continuous Holter monitoring was considered failure. At 6 months, anticoagulation and AADs were discontinued following confirmation of absence of atrial arrhythmias except for patients showing recurrences during initial 6 months.

\section{P wave analysis}

The P waves from ECG lead I or II (if lead I appeared too noisy) were analyzed to identify differences in PWD pre- and postprocedure. PWD was obtained by an automated analysis of digital surface ECG recordings at $25.0 \mathrm{~mm} / \mathrm{s}$ and $10 \mathrm{~mm} / \mathrm{mV}$. Surface ECG recordings from lead I or II acquired during SR directly before the start and at the end of hybrid procedure were used. These data were used to identify acute changes in PWD resulting from the procedure. A new automated method was used for $P$ wave segmentation and PWD estimation, based on fitting of each $P$ wave by means of two Gaussian functions. P wave morphology description by means of Gaussian decomposition has been recently proposed to enhance $P$ wave patterns from the background noise. ${ }^{13,14}$ Briefly, lead I or II was preprocessed to remove baseline wander and power line interference at $50 \mathrm{~Hz}$. In order to isolate the $\mathrm{P}$ waves, $\mathrm{R}$ waves were detected using a Pan and Tompkins like algorithm. ${ }^{15} \mathrm{P}$ waves were then extracted by looking for an optimal window starting from 300 ms before the R wave. Second, linear piecewise interpolation was used to remove baseline wander on each $P$ wave.23 $P$ waves with excessive noise were excluded by means of a template matching exclusion criterion based on the cross-correlation coefficient between each $\mathrm{P}$ wave and a template $\mathrm{P}$ wave obtained by means of principal component analysis ( $\mathrm{P}$ wave excluded if cross-correlation coefficient lower than 0.5 ). Unlike previous studies, ${ }^{23}$ here, we described each $\mathrm{P}$ wave by means of two Gaussian functions, to account for left-right asymmetries in the $P$ wave morphology (Figure 6.1). Once the widths of the left (f1) and right ( $f 2$ ) Gaussian functions have been estimated (in terms of its standard deviations $\sigma 1$ and $\sigma 2$, respectively), the PWD is computed as: PWD $=3 \sigma 1+3 \sigma 2$. The factor 3 is chosen such that $50 \%$ of the area under each function is accounted for. Due to technical archive restriction in accessing the data used in this study, manual annotation of PWD was retrieved for 19 patients out of the original 41. While comparing the data, no significant difference was observed between the two analyses. It suggests that the automated measure is a good surrogate of the manual measurement of PWD (Table 6.1). 


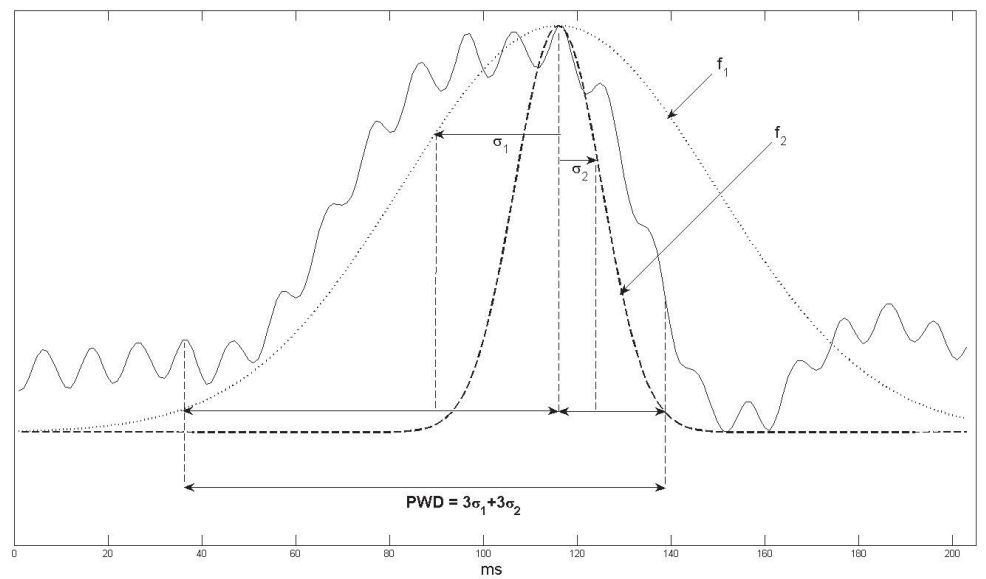

Figure 6.1 Schematic illustration of the estimation of the duration of a P-wave (PWD) by means of a left and right Gaussian functions.

\section{Statistical analysis}

Patient data were analyzed by means of MATLAB, version R2013a (MathWorks, Natick, MA, USA). All parameters are given as median \pm median absolute difference (MAD). Comparisons between different groups evaluated before or after the procedure were made using a Wilcoxon sum rank test. Pre- vs. postprocedure differences within the same group were analyzed using a Wilcoxon signed-rank test. Data were considered statistically significant at $p<0.05$.

\section{Results}

\section{Baseline measurements}

Transthoracic echocardiography was performed at baseline to obtain standard measurements. The data have been summarized in Table 6.2. There was no correlation between left atrial volume (LAV) and PWD in paroxysmal $(r=0.10 ; p=0.66)$ and persistent patients $(r=-0.46 ; p=0.10)$. No correlation was found also between right atrial volume (RAV) and PWD in paroxysmal $(r=0.01 ; p=0.95)$ and persistent patients $(r=-0.08 ; p=0.78)$. The LAV was significantly larger than the RAV in both paroxysmal $(p=0.02)$ and persistent patients $(p=0.005)$. There was no significant difference in LAV between paroxysmal and persistent patients $(p=0.88)$. Similarly, there was no difference in RAV between paroxysmal and persistent patients $(p=0.22)$. Table 6.3 displays the relations between the different conditions analyzed in this study and some 
ECG parameters (heart rate and PWD) at baseline and after procedure. To assess the effect of intrinsic heart rate on PWD, a linear regression model could not be applied, as we did not have a control group of patients who did not undergo hybrid procedure. Therefore, we assessed correlations between PWD pre and post procedure and HR. From the results shown in Table 6.4, it can be appreciated that the correlation between PWD and heart rate is very low. This finding can be comprehended by looking at the associated $p$ values. As a conclusion, it seems that PWD is unlikely intrinsically affected by heart rate.

Table 6.2 Patient characteristics.

\begin{tabular}{lc}
\hline Variables & Number \\
\hline Patients (n) & 41 \\
Gender (men/women) & $32 / 9$ \\
Age (years) & $60.1 \pm 10.1$ \\
BMI (kg/m ${ }^{2}$ ) & $27 \pm 3.8$ \\
Average procedure time (minutes) & $216 \pm 82$ \\
Medical History & \\
Hypertension (n, \%) & $19(46.3)$ \\
Diabetes (n, \%) & $2(0.05)$ \\
CAD (n, \%) & $12(29.3)$ \\
COPD (n, \%) & $1(0.02)$ \\
Disease Characteristics & \\
Paroxysmal/persistent AF (n/n, \%/\%) & $25 / 16(61 / 39)$ \\
AF duration (years, mean $\pm S D)$ & $6.3 \pm 4.3$ \\
LVEF (\%,mean $\pm S D)$ & $52 \pm 14$ \\
LA volume (cc, mean $\pm S D)$ & $93 \pm 25$ \\
Number of prior electrical/pharmacological cardioversions (n, \%) & $15 / 12(36.6 / 29.3)$ \\
Follow up at 9 months & \\
Success with AADs (number/total) (\%) & $26 / 36(72)$ \\
Success without AADs (number/total) (\%) & $4 / 36(11)$ \\
\hline
\end{tabular}

$\mathrm{AF}$ indicates atrium fibrillation; $\mathrm{BMI}=$ body mass index; $\mathrm{n}=$ numbers; $\mathrm{CTI}=$ cavo tricuspid isthmus; $C A D=$ coronary artery disease; $C H F=$ congestive heart failure; $L V E F=l e f t$ ventricle ejection fraction; $L A=l$ eft atrial; $\mathrm{SD}=$ standard deviation; $\mathrm{AFI}=$ atrial flutter.

\section{P wave changes in all patients}

PWD significantly decreased after procedure $(104.4 \pm 25.1 \mathrm{~ms}$ vs. $84.7 \pm 23.8 \mathrm{~ms}$, $\mathrm{p}=0.0151)$.

\section{AF-type-related P wave changes}

Hybrid procedure significantly decreased PWD in persistent AF patients $(122.4 \pm 32.2 \mathrm{~ms}$ vs. $85.6 \pm 24.5 \mathrm{~ms}, \mathrm{p}=0.02$ ). No significant difference was found in paroxysmal $A F$ patients $(92.5 \pm 17.9 \mathrm{~ms}$ vs. $83.3 \pm 23.4 \mathrm{~ms}, \mathrm{p}=0.2312)$. PWD preprocedure was significantly higher in persistent patients than paroxysmal patients $(122.4 \pm 32.2 \mathrm{~ms}$ vs. 92.5 $\pm 17.9 \mathrm{~ms}, \mathrm{p}=0.0383$ ). 


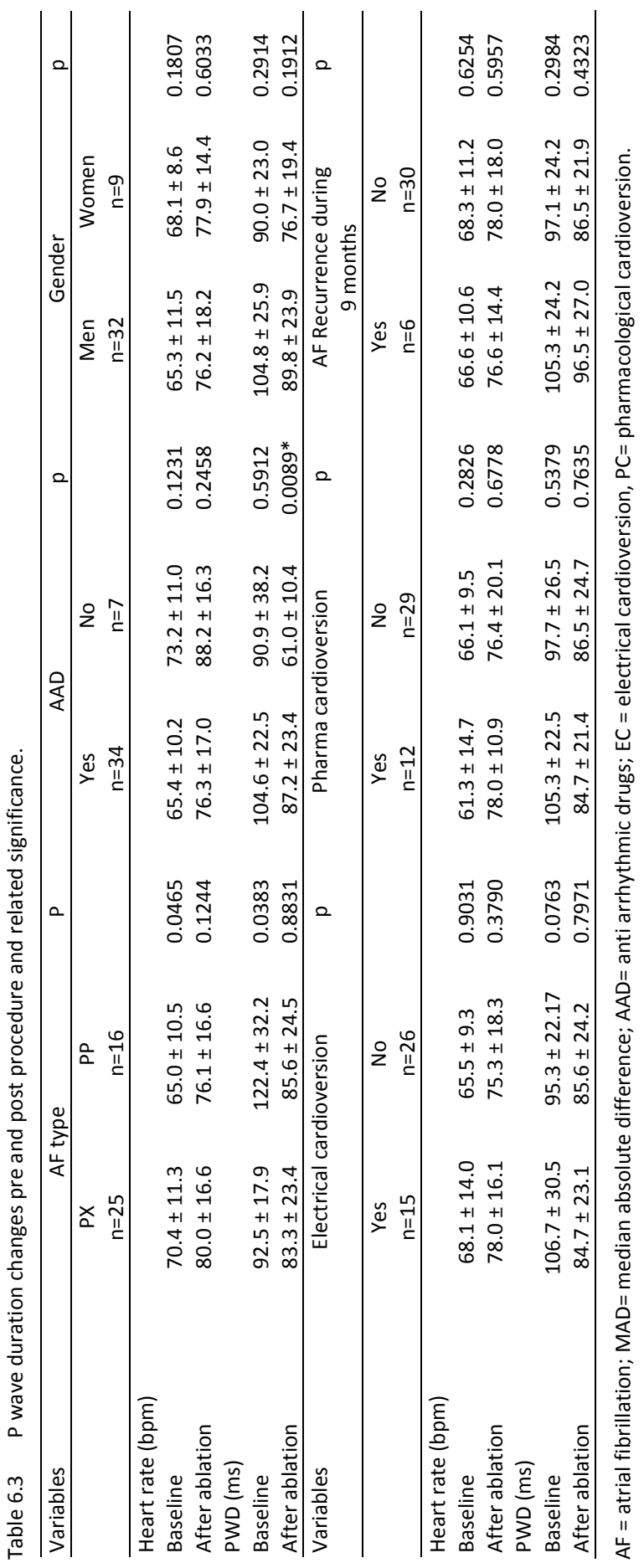


Table 6.4 The correlation between P wave duration (PWD) and heart rate (HR).

\begin{tabular}{|l|c|c|}
\hline Parameters & Correlation & p-value \\
\hline PWD pre \& HR pre & -0.32 & 0.0450 \\
\hline PWD post \& HR post & -0.37 & 0.0161 \\
\hline PWD pre-PWD post \& HR pre-HR post & -0.32 & 0.0353 \\
\hline
\end{tabular}

\section{Role of AADs, pharmacological cardioversion, and gender}

Thirty-four out of 41 patients used AADs (amiodarone, flecainide, and sotalol). PWD after procedure was significantly higher in the AADs patients than in the no-AADs ones $(87.2 \pm 23.4 \mathrm{~ms}$ vs. $61.0 \pm 10.4 \mathrm{~ms}, \mathrm{p}=0.0089)$. There was no significant difference between the two groups before hybrid procedure. Shortening of PWD in the AAD group was close to significance $(104.6 \pm 22.5 \mathrm{~ms}$ vs. $87.2 \pm 23.4 \mathrm{~ms}, \mathrm{p}=0.0503)$. Moreover, analyses on individual drugs did not show any significant difference. To observe for difference in PWD in the paroxysmal group when not on AADs, we analyzed changes in PWD pre- and postprocedure in the two subgroups of paroxysmal patients who did and did not undergo AAD therapy. Results for the persistent group are also shown for completeness in Tables 6.4. Interestingly, the paroxysmal group did not show any significant difference pre- and postprocedure regardless of with and without AAD therapy. Genderwise, PWD was significantly shortened in men $(n=34)$ by the procedure (104.8 $\pm 25.9 \mathrm{~ms}$ vs. $89.8 \pm 23.9 \mathrm{~ms}, \mathrm{p}=0.0346)$. There was no difference in PWD changes for women. Twelve out of 41 patients underwent pharmacological cardioversion before the hybrid procedure. PWD shortening in patients who did not undergo pharmacological cardioversion was close to significance $(97.7 \pm 26.5 \mathrm{~ms}$ vs. $86.5 \pm 24.7$ $\mathrm{ms}, \mathrm{p}=0.0504$ ).

\section{Role of previous electrical cardioversion}

PWD was significantly decreased after the procedure in patients who underwent electrical cardioversion prior to the procedure $(n=15 ; 106.7 \pm 30.5 \mathrm{~ms}$ vs. $84.7 \pm 23.1 \mathrm{~ms}$, $\mathrm{p}=0.0353$ ). However, there is no difference in PWD pre-ablation between those patients who received cardioversion (electrical/pharmacological) compared to those that did not $(105 \pm 29 \mathrm{~ms}$ vs. $97 \pm 23 \mathrm{~ms}, \mathrm{p}=0.2219)$ and no difference in the PWD change (PWD_pre-PWD_post) between the two groups ( $17 \pm 37 \mathrm{~ms}$ vs. $6 \pm 31 \mathrm{~ms}, \mathrm{p}=0.3118)$, suggesting that the changes seen pre- and postablation are independent of cardioversion (Table 6.5).

\section{AF recurrence at 9-month follow-up}

Associations of $\mathrm{P}$ wave changes with recurrence of $\mathrm{AF}$ at 9-month follow-up were analyzed for 40 patients (34 in SR; 6 showing AF recurrence; 9-month follow-up was missing for one patient). Pre- vs. postprocedure PWD decrease was significant for 
patients without recurrence $(98.2 \pm 26.0 \mathrm{~ms}$ vs. $85.6 \pm 21.7 \mathrm{~ms}, \mathrm{p}=0.0257)$. Relation between AF recurrence and AF type is summarized in Table 6.6. A $\chi_{2}$ test (with Yates' correction) on this contingency table did not show any significant relations between type of AF and 9-month recurrence. Figure 6.2 displays changes in PWD for both paroxysmal and persistent patients without 9-month AF recurrence. The decrease in PWD was significant in the persistent group without 9-month AF recurrence $(p=0.0210)$. No statistically significant association of changes in PWD with chance of recurrence for the whole dataset was observed. To investigate this association more in details, the dataset was divided in two groups: patients showing a significant decrease in PWD after hybrid procedure and patients who did not show a significant decrease (Table 6.7). We then analyzed possible associations with recurrence of those two groups. Interestingly, the subgroup of patients characterized by a significant decrease in PWD pre- and post ablation showed a $p$ value close to be significant $(p=0.0676)$. This seems to suggest that patients showing a significant reduction in PWD after hybrid procedure are more likely to be AF free. These results are in accordance with previous studies. ${ }^{16-18}$ PWD represents a good parameter to predict whether a patient is likely to recur after hybrid procedure for AF ablation. In this respect, a linear regression model was applied to analyze the power of PWD changes in predicting recurrence, adjusting for cardioversion and AAD. This model showed that none of the parameters are significant predictors of recurrence. This may be attributed to the small study sample.

Table 6.5 Changes in P wave duration (PWD) pre and post procedure in the two sub-groups of paroxysmal patients who did and did not undergo antiarrhythmic drugs (AADs).

\begin{tabular}{lcc}
\hline Relationship (number) & Pre vs.Post duration (ms) & p-value \\
\hline Paroxysmal \& AAD (21) & $92+/-16$ vs. $88+/-23$ & 0.5663 \\
Paroxysmal \& no AAD (4) & $100+/-28$ vs. $61+/-17$ & 0.6250 \\
Persistent \& AAD (13) & $133+/-26$ vs. $87+/-25$ & 0.0171 \\
Persistent \& no AAD (3) & $74+/-50$ vs. $61+/-1$ & 0.7500 \\
\hline
\end{tabular}

Table 6.6 Relation between AF type and AF recurrence at 9 months.

\begin{tabular}{lcc}
\hline & No AF recurrence & AF recurrence \\
\hline Paroxysmal AF & 22 & 2 \\
Persistent AF & 12 & 4 \\
\hline
\end{tabular}

Table 6.7 P wave duration changes pre and post procedure and with chances of recurrence.

\begin{tabular}{lcc}
\hline Relationship (number of patients) & Pre vs. Post (ms) & p-value \\
\hline Significant decrease \& recurrence (7) & $105+/-26$ vs. 81+/-24 & 0.6250 \\
Significant decrease \& non recurrence (27) & $106+/-30$ vs. 86+/-21 & 0.0676 \\
Non significant decrease \& recurrence (0) & - & - \\
Non significant decrease \& non recurrence (7) & $78+/-21$ vs. 66+/-17 & 0.8125 \\
\hline
\end{tabular}



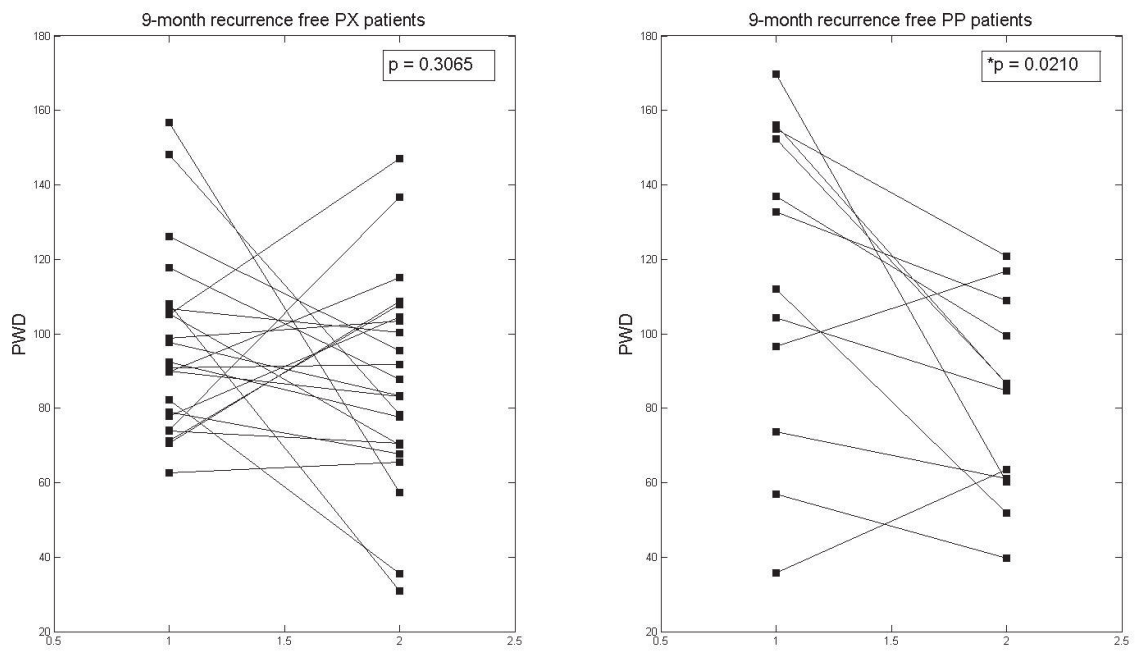

Figure 6.2 Changes in PWD following hybrid procedure for patients with paroxysmal (PX) AF (atrial fibrillation) and 9-month AF recurrence free ( $n=22$; left panel), and patients with persistent (PP) $A F$ and 9-month AF recurrence free $\left(n=12\right.$; right panel); ${ }^{*} p<0.05$.

\section{Discussion}

This study evaluated the ECG P wave duration (PWD) before and after hybrid procedure in patients with paroxysmal and persistent $A F$ and its association with other preprocedure data. Retrospectively, we further analyzed PWD with recurrence of AF at 9-month follow-up. The purpose of our study is to show that hybrid procedure significantly reduces PWD in patients affected by AF, regardless AF type. This is relevant, as PWD has been shown to be a marker of success of AF ablation procedure. ${ }^{16-18}$ Hybrid procedure combines the transvenous endocardial and the thoracoscopic epicardial ablation procedure for AF. The annual success rate defined according to the European Heart Rhythm Association, European Cardiac Arrhythmia Society consensus statement, and Heart Rhythm Society for the catheter and surgical ablation of AF was $93 \%$ for paroxysmal AF patients and $90 \%$ for persistent AF patients was reported by our group. ${ }^{5}$ The long-term follow-up of 5 years for hybrid procedure shows success rates of $80 \% .{ }^{19}$ This procedure proves its robustness even for patients of AF who have COPD, where otherwise limited ablation experience exists with nonoptimal success rate..$^{12,20,21}$ Thus, hybrid procedure efficiently prevents AF recurrence and helps to maintain sinus rhythm even in paroxysmal and persistent $A F$ patients during long term follow-up. 
There are several other noninvasive methods, which tried to predict the success or failure of $\mathrm{PV}$ ablation for $\mathrm{AF}$ including signal-averaged electrocardiogram (SAECG). ${ }^{9,16,17,22}$ Results of these studies are conflicting due to different study designs and variable definitions of recurrence. In this study, PWD shortened significantly after procedure. There are multiple mechanisms proposed to explain the PWD decrease after ablation procedure. This shortening is attributed to electrical isolation of PVs, ${ }^{9,17}$ e.g., myocardial sleeves of PVs contributing to middle portion of $\mathrm{P}$ wave ${ }^{23}$ and late activation of the left atrium-PV region representing the baseline terminal part of the $P$ wave [24]. The change of PWD after ablation needs more research. However, it hints that a prolonged PWD more likely reflects the extent of atrial injury and the predominant mechanism involved in arrhythmia recurrences rather than the effect of RF ablation alone. $^{7}$

Finally, a Gaussian function-based model was chosen as similar models of the $P$ wave have been shown to be able to extract morphological parameters useful to differentiate patients with a high risk of developing AF. ${ }^{13}$

\section{Changes in the total patient group}

PWD shortened immediately and significantly after hybrid procedure in both paroxysmal and persistent AF patients. These results are in trend with various studies correlating PWD before and after pulmonary vein isolation., ${ }^{9,16}$ Any immediate postprocedural prolongation of PWD was not observed. ${ }^{25}$ The patients who underwent hybrid procedure in our study group had shortening of PWD $19.6 \mathrm{~ms}(\mathrm{p}=0.0151)$. The immediate shortening confirms the improved effectiveness of the hybrid procedure that further translates into effective success rate. ${ }^{5}$.

The automated algorithm used in this study also provided us with $\mathrm{P}$ wave amplitude measures. Analyses of $\mathrm{P}$ wave amplitude changes did not show significant results in general.

\section{Role of AF type}

There is a global difference in PWD preprocedure between paroxysmal and persistent patients. However, there is no correlation between AF type and recurrence. This, together with the considerable overlap in the PWD between the groups in AF patients, may suggest that there is a large heterogeneity characterizing AF patients, and the frequently seen transition from paroxysmal to persistent and then towards more longstanding $A F{ }^{26}$ This is characterized by a continuous spectrum of changes of the AF substrate, which cannot be completely quantified by only focusing on the AF type. ${ }^{26}$ Persistent AF patients compared to paroxysmal counterparts are not only associated with higher morbidity rates but also the ablation success rate is relatively limited. ${ }^{27-29}$ In this respect, AF type is a useful parameter, but not enough by itself to completely determine (long term) outcome of a procedure. Other parameters, as PWD pointed out 
in this study, likely need to be taken into account to be able to properly differentiate between AF subtypes and assess procedure outcome.

Persistent AF patients had longer PWD. Thismay be due to inter- and/or intra-atrial conduction delays and could be related to the extent of atrial scarring and fibrosis. ${ }^{7}$ The presence of preprocedural significant differences and the absence of any postprocedural difference in PWD between paroxysmal and persistent patients suggest that hybrid procedure is effective in restoring a physiological substrate for cardiac conduction in patients with a diverse AF history. The relative change of the AF substrate due to the hybrid procedure is larger in persistent patients compared to those with paroxysmal AF and more reflected in corresponding changes in PWD. The paroxysmal AF patients mostly undergo PV isolation. However, a persistent AF patient during hybrid procedure routinely undergoes additional ablation other than PV isolation, e.g., box lesion, bicaval lines, and additional ablation according to standard protocol (as CTI line, mitral isthmus line). ${ }^{5}$ There was no correlation between PWD and LA volume in our study, too. ${ }^{25}$ This was attributed to the fact that $P$ wave amplitude, which determines PWD, may not always translate to actual LA intracardiac voltages. ${ }^{30,31}$

\section{Role of treatment with AADs}

AADs (flecainide and amiodarone in particular) prolong PWD. ${ }^{32,33}$ This trend was observed in this study as well, though there was no significant preprocedural difference in PWD between the AAD and the no-AAD group. Patients in the AAD group were on amiodarone or flecainide or sotalol. However, we found that postprocedural PWD was significantly longer in AAD patients. Additionally, the shortening of the PWD close to significance found in this study for the $A A D$ group further suggests that hybrid procedure is effective in restoring sinus rhythm. These results suggest that decrease in PWD following hybrid procedure is likely due to procedure-related effects rather than drug-related effects. Moreover, as AADs were not discontinued during the first 6 months of follow-up, their possible influence on AF recurrence needs further investigation. However, the fact that all AF-free patients belonging to the AAD group did not show any AF recurrence after AADs were discontinued at 6 months suggests that also procedure related changes help maintaining this AF-free state.

\section{Role of gender}

PWD has been shown to be shorter in female and healthier individuals compared with paroxysmal AF and to have good reproducibility. ${ }^{34}$ Fukunami et al. ${ }^{35}$ confirmed this finding using SAECG. The limited amount of women included in this study $(n=9)$, with respect to the total sample size, may explain the lack of reproducibility of these findings. Moreover, the significant shortening of PWD in male individuals observed in this study is likely driven by the same result observed in the total patient group. 


\section{Role of (electrical/chemical) cardioversion}

Some studies used electrical cardioversion and SAECG for prediction for AF recurrence. ${ }^{18,36,37}$ The changes in PWD in this study with respect to electrical or chemical cardioversion are in line with these studies. The baseline PWD was prolonged in cardioverted (electrical/chemical) patients. Moreover, the PWD difference postprocedure in such subgroup of patients was higher, which increases the procedure efficacy, probably by slowing the degeneration of AF into more complex forms.

\section{Role of AF recurrence at 9-month follow-up}

Our results on correlation between changes in PWD and recurrence at 9 months conform to the second hypothesis of Beeumen et al., ${ }^{16}$ stating that the "shortening of the P wave was only significant in the success group." PV arrhythmogenesis is higher in patients with broader PV-left atrial connection and so are expected to respond to PVI. ${ }^{38}$ Okumura et al. ${ }^{17}$ showed that a baseline PWD of $150 \mathrm{~ms}$ was a predictor of recurrences after PVI and patients without recurrences demonstrated a sustained significant shortening of PWD. We did not notice any significant difference in PWD before procedure between the recurrent and nonrecurrent group. Hence, we could not conclude any cut-off point of PWD for success of the procedure. This may be also due to the limited amount of recurrent patients $(n=6)$, with respect to the total 9-month follow-up patients $(n=40)$. This also suggests that care should be taken in the interpretation of these results.

However, the significant pre- vs. postprocedure PWD decrease for patients without recurrence and the absence of any significant difference in patients with recurrence seems to support that patient selection is possible before procedure to individualize $\mathrm{AF}$ therapy and suggests that this study is likely underpowered and more patients are needed to investigate the hypothesis. In particular, the results on the relation between AF type and recurrence reported in Table 6.4, even though not significant, show that AF recurrence is more frequent in persistent patients, which are in general characterized by a longer PWD. Moreover, the significant reduction of PWD in persistent patients without 9-month AF recurrence further supports the effectiveness of the hybrid procedure in treating AF. Finally, previous studies have tried to predict the success of PV ablation for AF treatment from surface ECG, including SAECG. ${ }^{9,16,17,22}$ The results that they present are conflicting due to different study designs and different definitions of recurrence. ${ }^{7}$ The Gaussian function-based model of the $P$ wave exploited in this study has the advantage of working with the original $P$ waves, with no need of further processing it. This may be a benefit when working with $\mathrm{P}$ waves characterized by a very irregular morphology as in AF patients. 


\section{Study limitations}

The cohort in this study is small. Moreover, the retrospective nature of the study did not allow for the assessment of more extensive ablation as guided by maximal PWD. Larger prospective trials may be required to substantiate the reported differences. The inclusion criteria of the study may cause selected bias in the results. Post ablation ECG recordings were not obtained after 9 months follow-up because the aim of the present study was not to study the effect of long-term follow-up on PWD. Our results are only applicable to AF patients undergoing AF ablation using the techniques described in this manuscript and may not be applicable to patients undergoing complex fractionated atrial electrogram ablation, posterior left atrial isolation or wide area circumferential ablation. Although this new method of PWD analysis has been used in setup of radiofrequency ablation for this manuscript, we further plan to test it for other energy sources as cryo, too.

\section{Conclusions}

PWD was significantly reduced by hybrid procedure. Preprocedure PWD was significantly higher in persistent than paroxysmal patients, while there was no difference after the procedure. At 9-month follow-up, 83\%of the patients were in SR. These results highlight the effectiveness of hybrid procedure in treating patients with different history of AF and suggest that AF-type-based selection of patients may be possible before procedure to individualize AF therapy. Cardioversion (electrical/ chemical) effectively favors better outcome of hybrid procedure in patients. Moreover, completely automated analysis of PWD from surface ECG is possible. 


\section{References}

1. Go AS, Hylek EM, Phillips KA, Chang Y, Henault LE, Selby JV, Singer DE. Prevalence of diagnosed atrial fibrillation in adults. JAMA2001;285:2370-2375.

2. Lin HJ, Wolf PA, Kelly-Hayes M, Beiser AS, Kase CS, Benjamin EJ, D'Agostino RB. Stroke severity in atrial fibrillation. The Framingham Study. Stroke 1996;27;1760-1764.

3. Jaïs $P$, Cauchemez $B$, Macle $L$, Daoud $E$, Khairy $P$, Subbiah $R$, Hocini $M$, Extramiana $F$, Sacher $F$, Bordachar P, Klein G, Weerasooriya R, Clémenty J, Catheter ablation versus antiarrhythmic drugs for atrial fibrillation: the A4 study. Circulation 2008;118:2498-2505.

4. Calkins H, Kuck KH, Cappato R, Brugada J, Camm AJ, Chen SA, Crijns HJ, Damiano RJ Jr, Davies DW, DiMarco J, Edgerton J, Ellenbogen K, Ezekowitz MD, Haines DE, Haissaguerre M, Hindricks G, lesaka $Y$, Jackman W, Jalife J, Jais P, Kalman J, Keane D, Kim YH, Kirchhof P, Klein G, Kottkamp H, Kumagai K, Lindsay BD, Mansour M, Marchlinski FE, McCarthy PM, Mont JL, Morady F, Nademanee K, Nakagawa H, Natale A, Nattel S, Packer DL, Pappone C, Prystowsky E, Raviele A, Reddy V, Ruskin JN, Shemin RJ, Tsao HM, Wilber D. 2012 HRS/EHRA/ECAS Expert Consensus Statement on Catheter and Surgical Ablation of Atrial Fibrillation: recommendations for patient selection, procedural techniques, patient management and follow-up, definitions, endpoints, and research trial design. Europace 2012;14:528-606.

5. Pison L, La Meir M, van Opstal J, Blaauw Y, Maessen J, Crijns HJ. Hybrid thoracoscopic surgical and transvenous catheter ablation of atrial fibrillation. J Am Coll Cardiol 2012;60:54-61.

6. La Meir M, Gelsomino S, Lucà F, Lorusso R, Gensini GF, Pison L, Wellens F, Maessen J. Minimally invasive thoracoscopic hybrid treatment of lone atrial fibrillation: early results of monopolar versus bipolar radiofrequency source. Interact Cardiovasc Thorac Surg 2012;14:445-450.

7. Blanche $\mathrm{C}$, Tran N, Rigamonti F, Burri H, Zimmermann M. Value of P-wave signal averaging to predict atrial fibrillation recurrences after pulmonary vein isolation. Europace 2013;15:198-204.

8. Caldwell J, Koppikar S, Barake W, Redfearn D, Michael K, Simpson C, Hopman W, Baranchuk A. Prolonged $\mathrm{P}$-wave duration is associated with atrial fibrillation recurrence after successful pulmonary vein isolation for paroxysmal atrial fibrillation. J Interv Card Electrophysiol 2014;39:131-8.

9. Ogawa M, Kumagai K, Vakulenko M, Yasuda T, Siegerman C, Garfinkel A, Chen PS, Saku K. Reduction of $\mathrm{P}$-wave duration and successful pulmonary vein isolation in patients with atrial fibrillation. J Cardiovasc Electrophysiol 2007;18:931-938.

10. Bunch TJ, Day JD. Achieving favorable very long-term outcomes after catheter ablation for atrial fibrillation: an exciting adventure or delusional quest? J Cardiovasc Electrophysiol 2011;22:1215-1216.

11. Kumar N, Pison L, la Meir M, Maessen J. Direct visualization of pulmonary vein stenosis after previous catheter ablation. Heart Rhythm 2014;11:1602.

12. Kumar N, Pison L, La Meir M, Maessen J, Crijns HJ. Hybrid approach to atrial fibrillation ablation using bipolar radiofrequency devices epicardially and cryoballoon endocardially. Interact Cardiovasc Thorac Surg 2014;19:590-4.

13. Censi F1, Calcagnini G, Ricci C, Ricci RP, Santini M, Grammatico A, Bartolini P. P-wave morphology assessment by a gaussian functions-based model in atrial fibrillation patients. IEEE Trans Biomed Eng 2007;54:663-672.

14. Corino VD, Chouvarda I, Maglaveras N, Mainardi LT. A beat-to-beat P wave analysis in healthy population. In Computing in Cardiology, 2010, 2010 (553-556): IEEE

15. Pan J, Tompkins W J. A real-time QRS detection algorithm. IEEE Trans Biomed Eng 1985;32:230-236.

16. Van Beeumen K, Houben R, Tavernier R, Ketels S, Duytschaever M. Changes in P-wave area and P-wave duration after circumferential pulmonary vein isolation. Europace 2010;12:798-804.

17. Okumura Y1, Watanabe I, Ohkubo K, Ashino S, Kofune M, Hashimoto K, Shindo A, Sugimura H, Nakai T, Kasamaki $Y$, Saito $S$. Prediction of the efficacy of pulmonary vein isolation for the treatment of atrial fibrillation by the signal-averaged P-wave duration. Pacing Clin Electrophysiol 2007;30:304-313.

18. Budeus $M$, Hennersdorf $M$, Perings $C$, Strauer BE. [The prediction of atrial fibrillation recurrence after electrical cardioversion with P wave signal averaged EKG]. Z Kardiol 2004;93:474-478.

19. Meir ML. Surgical options for treatment of atrial fibrillation. Ann Cardiothorac Surg 2014;3:30-37. 
20. Kumar N, Phan K, Pison L, Maessen J. (2014). Re: Clinical characteristics and prognostic significance of chronic obstructive pulmonary disease in patients with atrial fibrillation: results from a multicenter atrial fibrillation registry study. J Am Med Dir Assoc 2015;16:82-3..

21. Kumar N, Phan K, Timmermans C, Pison L, Meir ML, Maessen J, et al. Catheter ablation of atrial fibrillation: The missing links. Eur Heart J. 2014; doi:10.1093/eurheartj/ehu291

22. Redfearn DP, Skanes AC, Gula L, Griffith MJ, Marshall HJ, Stafford PJ, Krahn AD, Yee R, Klein GJ. Noninvasive assessment of atrial substrate change after wide area circumferential ablation: a comparison with segmental pulmonary vein isolation. Ann Noninvasive Electrocardiol 2007;12:329-337.

23. Lemery R, Birnie D, Tang AS, Green M, Gollob M, Hendry M, Lau E. Normal atrial activation and voltage during sinus rhythm in the human heart: an endocardial and epicardial mapping study in patients with a history of atrial fibrillation. J Cardiovasc Electrophysiol 2007;18:402-408.

24. Date T, Yamane T, Inada K, Matsuo S, Kanzaki Y, Miyanaga S, Shibayama K, Miyazaki H, Sugimoto K, Taniguchi I, Mochizuki S. The effects of pulmonary vein isolation on the morphology of $p$ waves: the contribution of pulmonary vein muscle excitation to the formation of $p$ waves. Pacing Clin Electrophysiol 2007;30:93-101.

25. Nassif M, Krul SP, Driessen AH, Deneke T, Wilde AA, de Bakker JM, de Groot JR. Electrocardiographic P wave changes after thoracoscopic pulmonary vein isolation for atrial fibrillation. J Interv Card Electrophysiol 2013;37:275-282.

26. de Vos CB, Pisters R, Nieuwlaat R, Prins MH, Tieleman RG, Coelen RJ, van den Heijkant AC, Allessie MA, Crijns HJ. Progression from paroxysmal to persistent atrial fibrillation clinical correlates and prognosis. J Am Coll Cardiol 2010;55:725-731.

27. Steinberg BA, Hellkamp AS, Lokhnygina Y, Patel MR, Breithardt G, Hankey GJ, Becker RC, Singer DE, Halperin JL, Hacke W, Nessel CC, Berkowitz SD, Mahaffey KW, Fox KA, Califf RM, Piccini JP; ROCKET-AF Steering Committee and Investigators. Higher risk of death and stroke in patients with persistent vs. paroxysmal atrial fibrillation: results from the ROCKET-AF Trial. Eur Heart 2015;36:288-96 J.

28. Cappato R, Calkins H, Chen SA, Davies W, lesaka Y, Kalman J, Kim YH, Klein G, Natale A, Packer D, Skanes A, Ambrogi F, Biganzoli E. Updated worldwide survey on the methods, efficacy, and safety of catheter ablation for human atrial fibrillation. Circ Arrhythm Electrophysiol 2010;3:32-38.

29. Tilz RR, Chun KR, Schmidt B, Fuernkranz A, Wissner E, Koester I, Baensch D, Boczor S, Koektuerk B, Metzner A, Zerm T, Ernst S, Antz M, Kuck KH, Ouyang F. Catheter ablation of long-standing persistent atrial fibrillation: a lesson from circumferential pulmonary vein isolation. J Cardiovasc Electrophysiol 2010;21:1085-1093.

30. Udyavar AR, Huang SH, Chang SL, Lin YJ, Tai CT, Lo LW, Tuan TC, Hu YF, Wongcharoen W, Tsao HM, Higa $\mathrm{S}$, Chen SA. Acute effect of circumferential pulmonary vein isolation on left atrial substrate. J Cardiovasc Electrophysiol 2009;20:715-722.

31. Gorenek B, Birdane A, Kudaiberdieva G, Goktekin O, Cavusoglu Y, Unalir A, Ata N, Timuralp B. P wave amplitude and duration may predict immediate recurrence of atrial fibrillation after internal cardioversion. Ann Noninvasive Electrocardiol 2003;8:215-218.

32. Burashnikov A, Di Diego JM, Sicouri S, Ferreiro M, Carlsson L, Antzelevitch C. Atrial-selective effects of chronic amiodarone in the management of atrial fibrillation. Heart Rhythm 2008;5:1735-1742.

33. Redfearn DP, Lane J, Ward K, Stafford PJ. High-resolution analysis of the surface P wave as a measure of atrial electrophysiological substrate. Ann Noninvasive Electrocardiol 2006;11:12-19.

34. Dhala A, Underwood D, Leman R, Madu E, Baugh D, Ozawa Y, Kasamaki Y, Xue Q, Reddy S; Multicenter $\mathrm{PHi}$-Res Study. Signal-averaged $\mathrm{P}$-wave analysis of normal controls and patients with paroxysmal atrial fibrillation: a study in gender differences, age dependence, and reproducibility. Clin Cardiol 2002;25:525-531.

35. Fukunami, M., Yamada, T., Ohmori, M., Kumagai, K., Umemoto, K., Sakai, A., et al. (1991). Detection of patients at risk for paroxysmal atrial fibrillation during sinus rhythm by $\mathrm{P}$ wave-triggered signalaveraged electrocardiogram. Circulation, 83(1), 162-169.

36. Budeus M, Wieneke H, Sack S, Erbel R, Perings C. Long-term outcome after cardioversion of atrial fibrillation: prediction of recurrence with $\mathrm{P}$ wave signal averaged ECG and chemoreflexsensitivity. Int J Cardiol 2006;112:308-315. 
37. Opolski G1, Scisło P, Stanisławska J, Górecki A, Steckiewicz R, Torbicki A. Detection of patients at risk for recurrence of atrial fibrillation after successful electrical cardioversion by signal-averaged P-wave ECG. Int J Cardiol 1997;60:181-185.

38. Nakagawa H, Aoyama H, Beckman KJ, Po SS, Wu R, Lockwood D, Spector P, Calame JD, Lustgarten DL, Herring L, Hasdemir C, Singh D, Lazzara R, Jackman WM. Relation between pulmonary vein firing and extent of left atrial-pulmonary vein connection in patients with atrial fibrillation. Circulation 2004;109:1523-1529. 


\section{Chapter}

Testing of box lesion by adenosine

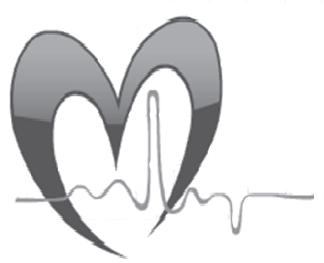

Narendra Kumar

Laurent Pison

Mark la Meir

Harry Crijns

Jos Maessen

Journal of Atrial Fibrillation 2014;6 
Chapter 7 


\section{To the editor}

With reference to Oct. 2013 special issue of "Venice arrhythmia 2013" abstract "Complete Isolation Of The Left Atrial Posterior Wall (Box Lesion) To Treat Long standing Persistent Atrial Fibrillation" by E.B. Saad, C. Slater, L.A. Inacio Jr., L.E. Camanho from Center for Atrial Fibrillation Hospital Pró-Cardíaco, Rio de Janeiro, Brazil, the writers mention, "Left atrium posterior wall isolation was proved by adenosine infusion". However, to the best of our knowledge there is no supporting literature where adenosine reveals conduction across box lesion. At Maastricht University medical center, we isolate the pulmonary veins using epicardial bipolar radiofrequency clamps. Followed by completion of box lesion epicardially using bipolar radiofrequency pen. ${ }^{1}$ After (only if needed) endocardial touch up using irrigated tip radiofrequency catheter, followed by proving bidirectional electrical block and waiting time of more than 30 minutes, $15-21 \mathrm{mg}$ (the minimal dose required to demonstrate atrioventricular block) adenosine was infused through central jugular line followed by rapid saline flush. We repeated this procedure for 8 patients (very small number though), and did not observe any dormant conduction across the box lines at all. Datino et al. ${ }^{2}$ described about significant hyperpolarization of resting membrane potential (RMP) only in pulmonary vein (PV) cells compared to left atrium (LA) attributing to due to larger $I_{\text {KAdo }}$ and smaller $I_{K 1}$. This finding has support on molecular level too. ${ }^{3}$ 


\section{References}

1. Pison L, La Meir M, van Opstal J, Blaauw Y, Maessen J, Crijns HJ. Hybrid thoracoscopic surgical and transvenous catheter ablation of atrial fibrillation. J Am Coll Cardiol 2012;60:54-61.

2. Datino T, Macle L, Qi XY, Maguy A, Comtois P, Chartier D, Guerra PG, Arenal A, Fernandez-Aviles F, Nattel $\mathrm{S}$. Mechanisms by which adenosine restores conduction in dormant canine pulmonary veins. Circulation 2010;121:963-972.

3. Ehrlich JR, Cha TJ, Zhang L, Chartier D, Villeneuve L, Hebert TE, Nattel S. Characterization of a hyperpolarization-activated time-dependent potassium current in canine cardiomyocytes from pulmonary vein myocardial sleeves and left atrium. J Physiol 2004;557:583-597. 


\section{Chapter}

The symbiosis of a contact force catheter use for hybrid ablation for atrial fibrillation

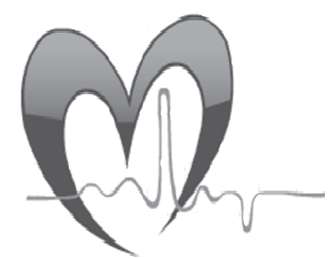

Narendra Kumar

Laurent Pison

Pieter Lozekoot

Rajin Choudhury

Mark La Meir

Sandro Gelsomino

Jos Maessen

Harry Crijns

Neth Heart J 2015 


\section{Abstract}

\section{Objective}

Reconduction across an ablation line is a common reason for arrhythmia recurrence over time. The hybrid procedure combines epicardial ablation of the pulmonary vein [PV] and creation of a box lesion with endocardial touch-ups for any electrical gaps. A high contact force (CF) between the ablation tip and cardiac tissue may increase the risk of thrombus formation, catheter tip charring, steam pop formation, and even cardiac perforation. CF monitoring is a significant new parameter for titration of the $\mathrm{CF}$ for creating an adequate lesion.

\section{Methods}

Thirty-eight consecutive patients underwent epicardial ablation using bipolar radiofrequency devices. After checking electrical bidirectional block of the ablation lines, an endocardial CF catheter was used for further ablation (if needed) to complete the isolation of PVs, box lesion, cavotricuspid isthmus (CTI), and complex fractionated atrial electrograms (CFAE).

\section{Results}

Endocardial touch-up was needed for 2 PVs (1.3\%) and 10 (26.3\%) box lesions. It was also used for the CTI line in $7(18.4 \%)$ patients, atrial tachycardia in $3(7.9 \%)$ patients, and additional CFAE ablation in 17 (44.7\%) patients. All 5 patients with arrhythmia recurrence had a mean $\mathrm{CF}<10 \mathrm{~g}$ $(p=0.03)$. Procedure duration was significantly shorter in the CF group $(223 \pm 57$ vs. $256 \pm 60$ minutes, $p=0.03$ ) compared with control group.

\section{Conclusion}

Use of CF catheters is safe, feasible, and complementary to a hybrid procedure setup for atrial fibrillation ablation. Its real-time monitoring may predict future arrhythmia recurrence, and decrease procedure time. 


\section{Introduction}

Atrial fibrillation (AF) is the most common arrhythmia globally affecting more than 20 million people and is a leading cause of stroke among people 65 years and older. ${ }^{1}$

During catheter ablation for a cardiac arrhythmia, energy is delivered to areas of interest of the heart muscle that are causing the abnormal heart rhythm. Reconduction across an ablation line is one of the most frequent reasons for arrhythmia recurrence over time, e.g. pulmonary vein (PV), and linear lesions. ${ }^{2}$ The hybrid procedure combines the epicardial ablation of PVs and creation of the box lesion by the cardiac surgeon and endocardial touch-ups (only if needed) to ensure ablation of any missed electrical gaps, by the electrophysiologists. ${ }^{3-5}$ To create a transmural lesion, contact force (CF) between the ablation tip and cardiac tissue is a major determining parameter for radiofrequency catheters, thus its monitoring assumes significance. ${ }^{6}$ Low CF may lead to an inadequate lesion. However, if it is very high, it may increase the risk of significant complications such as thrombus formation, catheter tip charring, steam pop formation and also cardiac perforation. To date CF catheters have never been used in a hybrid procedure setting for AF ablation.

To the best of our knowledge, this is the first article to study the safety and feasibility of using a CF catheter during the hybrid ablation of AF.

\section{Methods}

\section{Study population}

Thirty-eight patients with symptomatic AF underwent the hybrid procedure using epicardial bipolar RF devices and an endocardial CF catheter. The definitions of paroxysmal, persistent, long-standing persistent, and permanent AF, success and failure of ablation, and follow-up monitoring were based on the consensus statement of the Heart Rhythm Society, the European Heart Rhythm Association, and European Cardiac Arrhythmia Society.

Selection criteria of AF patients for this procedure were previously failed catheter ablation, failure of at least one antiarrhythmic drug (AAD), left atrial volume $\geq 55 \mathrm{ml}$, or patient preference for a hybrid procedure instead of a percutaneous approach. Prior catheter ablation was noted in the history for 18/38 AF patients (47.4\%) and $11 / 38$ patients $(29 \%)$ had prior catheter ablation for cavo-tricuspid isthmus (CTI) dependent atrial flutter. The preoperative work-up consisted of transthoracic echocardiography, cardiac computed tomography (for assessing PV anatomy and integration to electroanatomical mapping), and pulmonary function testing. 


\section{Control group}

A random, retrospective and randomised control group of 30 patients with similar patient characteristics (Table 8.1) was selected, to compare the endocardial ablation parameters, e.g. fluoroscopy time, procedure time and ablation time with a similar ablation setting of the radiofrequency generator. A standard non-force sensing irrigated tip catheter (ThermoCool ${ }^{\mathrm{TM}}$, Biosense Webster) was used during a hybrid procedure for the patients in the control group.

Table 8.1 Patient characteristics.

\begin{tabular}{|c|c|}
\hline Variables & Number \\
\hline Patients (n) & 38 \\
\hline Gender (men/women) & $34 / 4$ \\
\hline Age (years) & $61.8 \pm 7.2$ \\
\hline BMI $\left(\mathrm{kg} / \mathrm{m}^{2}\right)$ & $28.2 \pm 3.4$ \\
\hline Tested pulmonary veins (n, \%) & $150(100)$ \\
\hline Touch up needed in pulmonary veins $(n, \%)$ & $2(1.3)$ \\
\hline Tested box lesions ( $\mathrm{n}, \%)$ & $37(97.4)$ \\
\hline Touch up needed in box ( $n, \%)$ & $10(27 \%)$ \\
\hline Additional CTI ablation (n, \%) & $7(18.4)$ \\
\hline Additional atrial tachycardia ablation (n, \%) & $3(7.9)$ \\
\hline Additional mitral line ablation ( $\mathrm{n}, \%)$ & $0(0)$ \\
\hline Additional CFAE ablation (n, \%) & $17(44.7)$ \\
\hline Average procedure time (minutes) & $223 \pm 57$ \\
\hline \multicolumn{2}{|l|}{ Medical History } \\
\hline Hypertension (n, \%) & $16(42.1)$ \\
\hline Diabetes (n, \%) & $5(13.2)$ \\
\hline $\operatorname{CAD}(n, \%)$ & $15(39.5)$ \\
\hline COPD (n, \%) & $2(5.3)$ \\
\hline \multicolumn{2}{|l|}{ Medication use } \\
\hline Amiodarone (n, \%) & $5(13.2)$ \\
\hline Flecainide $(n, \%)$ & $19(50)$ \\
\hline Sotalol (n, \%) & $8(21.0)$ \\
\hline \multicolumn{2}{|l|}{ Disease characteristics } \\
\hline Paroxysmal/persistent/permanent AF (n/n/n, \%/\%/\%) & $14,19,4(37,50,10)$ \\
\hline AF duration (years, mean $\pm S D$ ) & $6.8 \pm 4.3$ \\
\hline $\operatorname{LVEF}(\%$, mean $\pm S D)$ & $52 \pm 14$ \\
\hline LA volume (cc, mean \pm SD) & $93 \pm 25$ \\
\hline Number of prior catheter ablations $(n, \%)$ & $18(47.4)$ \\
\hline Number of prior electrical/pharmacological cardioversions ( $n, \%)$ & $26(68.4)$ \\
\hline
\end{tabular}

$\mathrm{AF}=$ atrial fibrillation; $\mathrm{AFL}=$ atrial flutter; $\mathrm{BMI}=$ body mass index; $\mathrm{n}=$ numbers; $\mathrm{CTI}=$ cavo tricuspid isthumus; $\mathrm{CAD}=$ coronary artery disease; $\mathrm{CFAE}=$ complex fractionated atrial electrograms; $\mathrm{CHF}=$ congestive heart failure; $\mathrm{LVEF}=$ left ventricle ejection fraction; $\mathrm{LA}=$ left atrial; $\mathrm{SD}=$ standard deviation.

\section{Hybrid procedure}

The hybrid procedure was performed as described elsewhere. ${ }^{3,4,7}$ Briefly, all AADs were stopped before the procedure (considering their half-life) except amiodarone. Under general anaesthesia, after introducing two $5 \mathrm{~mm}$ working ports and a $5 \mathrm{~mm}$ video port 
in the intercostal spaces of the left and right hemithorax, patients underwent PV isolation using epicardial bipolar radiofrequency clamps (Atricure, West Chester, $\mathrm{OH}$, USA). An epicardial box lesion was made using a bipolar radiofrequency pen or a linear pen device (Coolrail, Atricure) consisting of a roof line (connecting both superior PVs) and an inferior line (connecting both inferior PVs). Using left femoral vein access, catheters were placed in the His bundle and coronary sinus. Using a single transseptal puncture a circular mapping catheter, according to the size of the PV (Lasso, Biosense Webster Inc., Diamond Bar, USA), was placed ostially to assess the PV potentials. The electrophysiologist checked for electrical isolation of ablation lines by pacing manoeuvres, electroanatomical mapping and/or adenosine bolus administration. A CARTO platform (CARTO-3; Biosense Webster, Diamond Bar, CA) was used for electroanatomical mapping. A left atrium shell was created using point-by-point acquisition with the aid of the CF catheter (SmartTouch ${ }^{\mathrm{TM}}$, Biosense Webster Inc.). Criteria for an adequate left atrial shell were: $\geq 100$ points, which were homogenously distributed to create the entire chamber.

The CF catheter was further used for endocardial ablation (if needed) to complete the $\mathrm{PV}$ isolation and box lesion, while maintaining the CF values between 10-40 $\mathrm{G}$ with the aid of a Stockert 70 radiofrequency generator (Biosense Webster) with a maximal temperature of $43^{\circ} \mathrm{C}$ and limited to $25 \mathrm{~W}$ at the posterior wall (Figure 8.1). Endocardial ablation was also used for CTI ablation in patients with a prior history of atrial flutter, any inducible atrial tachycardia, and complex fractionated atrial electrogram (CFAE) ablation is used in case of persistent AF after epicardial PV isolation and box lesion. The spatial distribution of CFAE in the left atria of AF patients was evaluated using software designed to automatically identify CFAE in the framework of the CARTO platform. In detail, the minimal amplitude threshold and maximal amplitude threshold were set to \pm 0.05 millivolt $(\mathrm{mV}$ ) and $\pm 0.15 \mathrm{mV}$, and the minimal and maximal intervals between two consecutive peaks were set to $60 \mathrm{msec}$ and $120 \mathrm{msec}^{8}$

After finishing the endocardial ablation, and retesting for arrhythmia, the induction was performed. The left atrial appendage (LAA) was removed using a stapling device in 11 patients. Finally, bilateral chest drains were inserted in the pleural cavities. Patients were extubated in the operating room before being transferred to the ICU. Within 6 hours, low-molecular-weight heparin was started and acenocoumarol was restarted after 2 days. AADs were restarted as soon as possible. After confirming absence of atrial arrhythmias after 6 months, AADs and anticoagulation were discontinued.

\section{Follow-up}

Follow-up was conducted at our hospital's outpatient clinic in the $3^{\text {rd }}, 6^{\text {th }}, 9^{\text {th }}, 12^{\text {th }}$ month after the procedure. A 7-day Holter monitoring was used for all patients; if not available patients underwent at least 48-hour Holter monitoring (3 patients). Arrhythmia recurrence was considered to be any episode of atrial fibrillation, flutter or tachycardia lasting more than 30 seconds detected after the 3-month blanking period. 
A

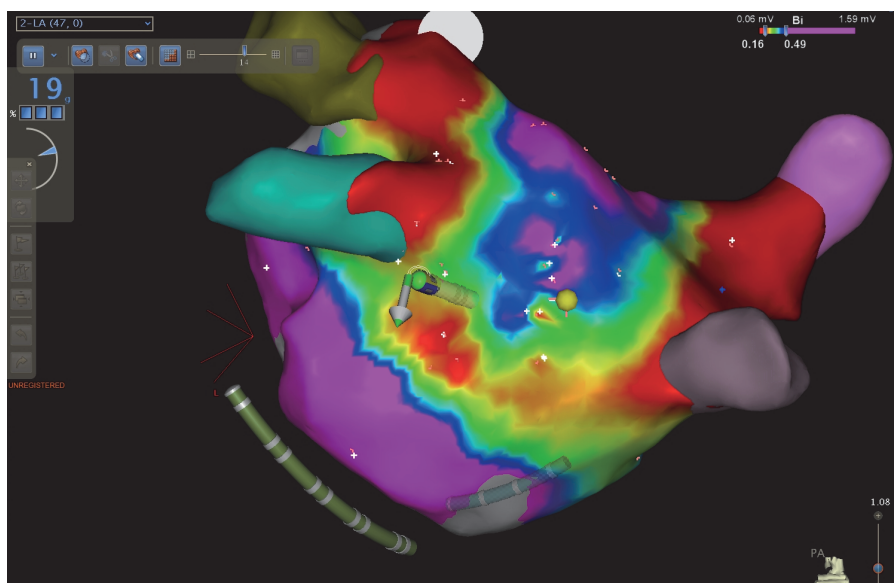

B

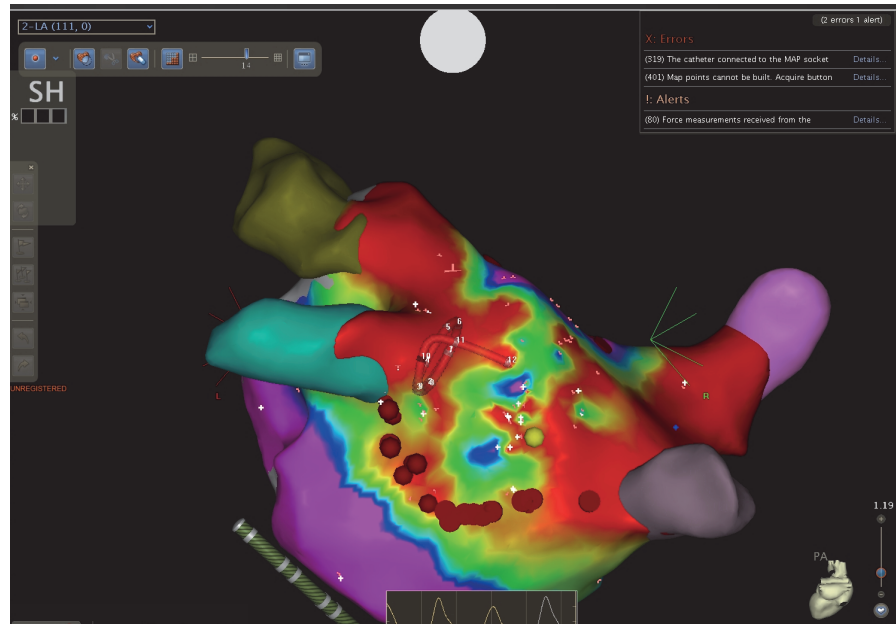

Figure 8.1 Endocardial radiofrequency ablation (red dots) using CF catheter for completion of the inferior line of box lesion. (A) At start of ablation. (B) After finishing ablation. We can further notice the visual change in the voltage map after finishing the ablation.

\section{Statistical analysis}

Continuous variables are expressed as mean \pm standard deviation. Data were retrospectively entered into a database. Statistical analysis was performed using SPSS 16.0 (SPSS Inc, Chicago, IL). Event-free survival was estimated using Kaplan-Meier and compared by the log-rank test. Possible predictors of arrhythmia recurrence were performed using the Cox proportional hazards regression models. A p value of $<0.05$ was considered significant. 


\section{Results}

The study group consisted of 38 patients (61.8 8 7.2 years; 34 male) with AF duration of $6.8 \pm 4.3$ years. A left-sided common ostium was observed in 2 patients. The body mass index was $28.2 \pm 3.4 \mathrm{~kg} / \mathrm{m}^{2}$. Eighteen patients had undergone catheter PV isolation. Electrical/pharmacological cardioversions were attempted previously for 26 patients (68.4\%). The mean procedure time (from initial skin incision to skin closure) was $223 \pm 57$ minutes. The mean left atrium size was $93 \pm 25 \mathrm{ml}$, with a mean left ventricular ejection fraction of $52 \pm 14 \%$. Epicardial bipolar radiofrequency devices were used for 150 PVs (100\%) and 37 box lesions (100\%) for 38 patients. Endocardial touch-up using a CF catheter was needed for 2 PVs (1.3\%) of different patients, i.e. left superior PV and right inferior PV, and for 10 box lesions (26.3\%). A total of 4 touch-up lesions with a mean duration of 39 seconds were applied to the PVs. It was also used for creation of a CTI line in 7 (18.4\%) patients and additional CFAE ablation in 17 (44.7\%) patients. Further, during burst pacing to test for inducible AF, 3 (7.9\%) patients developed 5 different morphologies of inducible atrial tachycardia and henceforth CF was also used for endocardial ablation for all of them. The mean grams of force per ablation lesion were $17.6 \pm 7.8 \mathrm{~g}$ for the right PVs and $15.7 \pm 7.2 \mathrm{~g}$ for the left PVs. Further details on the lesion sets and patient characteristics are shown in Table 8.1.

The control group consisted of 30 patients [paroxysmal: 11 (37\%), persistent: 16 (53\%), permanent $=3(10 \%)$ ]. The mean left atrial volume was $91 \pm 23 \mathrm{ml}$. The statistical analysis (using the Mann-Whitney test) for procedure duration was significantly shorter in the CF group ( $223 \pm 57$ vs. $256 \pm 60$ minutes, $p=0.03$ ) compared with the control group. There were no statistically significant differences observed in ablation time $(11.2 \pm 5.9$ vs $14.1 \pm 6.2$ minutes) or fluoroscopy time ( $18.5 \pm 8.6$ vs $23.4 \pm 6.4$ minutes) although all were reduced in the CF group. No difference in complications was seen between the groups. After a mean follow-up of $357 \pm 43$ days (395-334 days) for control group patients, $75 \%$ of patients were AF free without AADs.

\section{Follow-up}

During the first 3 months after the procedure, the patients were blanked for the analysis of recurrence of AF. After follow-up of $335 \pm 66.5$ days (410-320 days), $33 / 38$ patients $(86.8 \%)$ of the study population were in sinus rhythm without AADs, 2 patients needed AADs to maintain sinus rhythm. Catheter ablation was needed for 3 patients i.e. 1 typical CTI dependent atrial flutter, 1 mitral isthmus dependent flutter, and an atrial tachycardia. Non-inducible patients, who were tested immediately after ablations, had less arrhythmia during follow-up than inducible ones $(p=0.04)$. Among all patients with recurring arrhythmia, we retrospectively observed that they had received endocardial touch-up; the mean CF was $<10 \mathrm{~g}(\mathrm{p}=0.03)$, in spite of continuous attempts to improve the contact. Figure 8.2 shows a Kaplan-Meier graph of AF-free survival. 


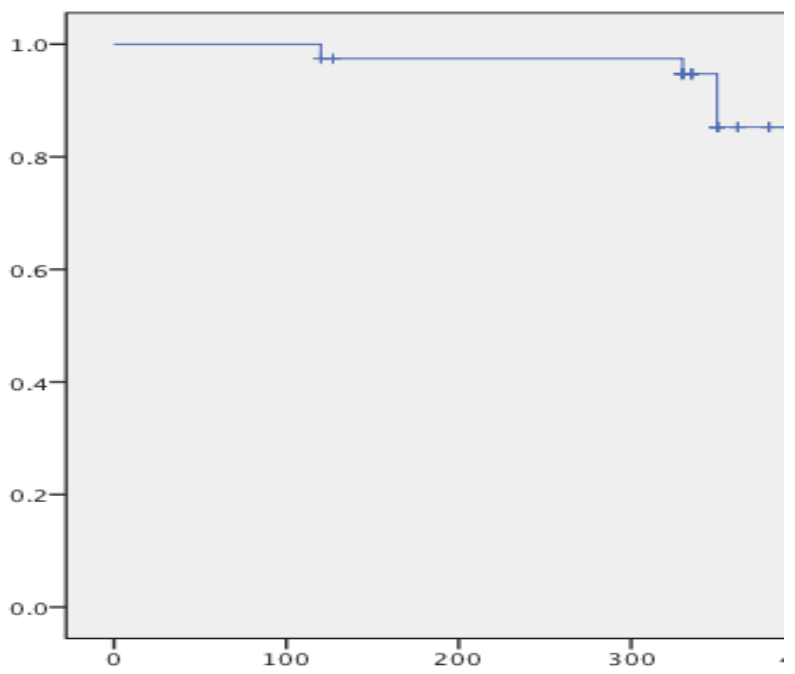

Days of survival

Figure 8.2 Kaplan-Meier survival curve of atrial arrhythmia free survival after a single hybrid procedure after a blanking period of 90 days for the arrhythmias. [DAYS = follow-up in days].

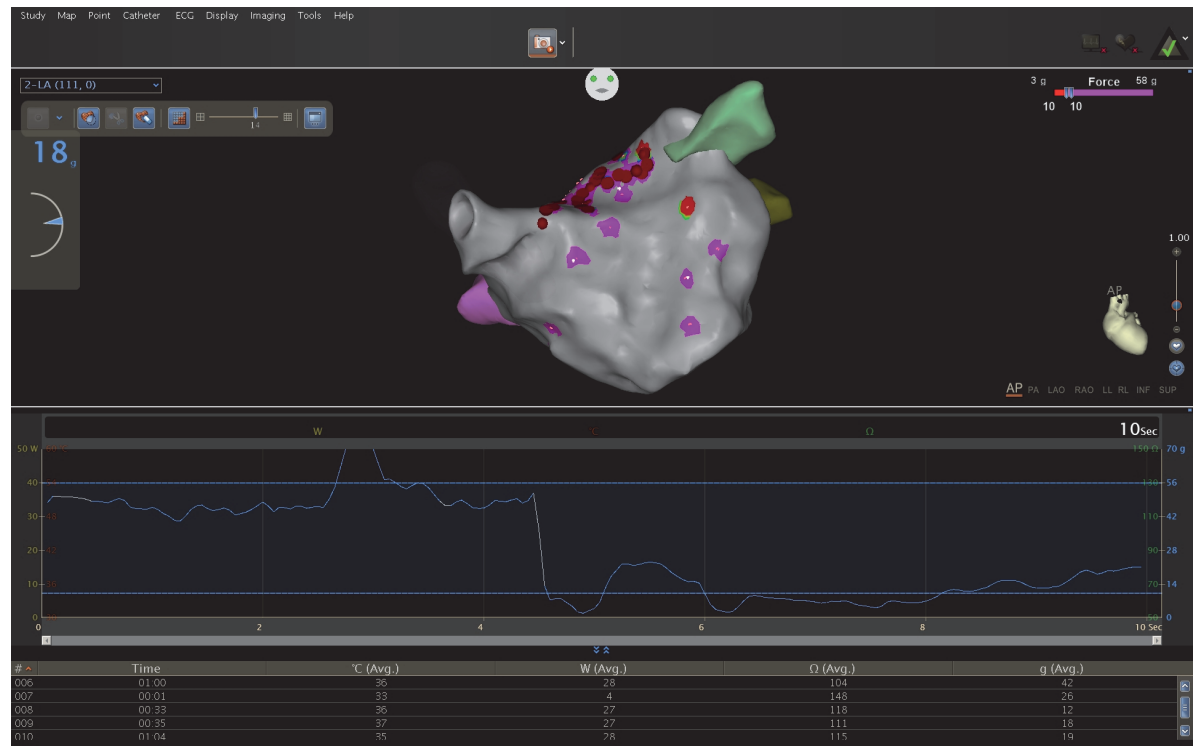

Figure 8.3 Temporal display of change of contact force (grey colored) with time during endocardial radiofrequency ablation (red dots) 


\section{Adverse events}

No thromboembolic complications or conversion to cardiopulmonary bypass were encountered. No signs of infection and phrenic nerve paralysis were seen among any of the patients. One patient had recurrent pain in the left thorax region a few weeks after the procedure. Diagnosis of atraumatic lung hernia was confirmed by high-resolution computerised tomographic $(\mathrm{HRCT})^{9,10}$. Retrospectively, the aetiology was attributed to widening of the mini invasions of $12 \mathrm{mms}$ (initially) to $3 \mathrm{~cm}$ to accommodate an epicardial left atrial appendage (LAA) clip. To the best of our knowledge, this is the only case of atraumatic lung hernia secondary to usage of an LAA clip in the literature. No other complications were associated with such clip usage. No signs of PV stenosis were seen in any patient during follow-up HRCT. ${ }^{11}$

\section{Discussion}

This manuscript describes, for the first time, combined simultaneous thoracoscopic epicardial ablation using bipolar devices and endocardial ablation using CF catheters for paroxysmal and persistent AF. Further, the use of a CF catheter results in superior transmurality of linear ablation lesions.

The pharmacological approach with AADs has not achieved optimal results in the longterm maintenance of sinus rhythm in patients with AF. ${ }^{12-14}$ Considering the limitations of medical therapy, there has been an upsurge in catheter and surgical ablation techniques for AF ablation. ${ }^{15-17}$ The recently proposed hybrid approach combines the advantages of individual approaches while simultaneously doing away with their disadvantages, complications, and ultimately ensuring the transmurality of of lesions. ${ }^{3,5,18}$ AF recurrence is often associated with PV reconnection after initial PV ablation. ${ }^{19-23}$ It is attributed to the inability of endocardial catheter based ablation techniques to guarantee long-lasting transmurality of the lesions. ${ }^{2}$

Both ablation technologies used in this setup share common principles. An epicardial bipolar radiofrequency device (Atricure Inc.) works on the principle of impedance change and endocardial ablation using a CF catheter works on CF measurement. Interestingly, several studies have correlated impedance drop with CF with due credit to the more detailed quantitative analysis and use of nonparametric statistics. ${ }^{24-26}$ Martinek et al. found that the use of CF sensing technology catheters significantly reduces ablation time, translating to an overall reduction in procedural times in PV isolation. This reasoning is well suited to the hybrid procedure as well. Avoiding radiofrequency delivery in areas with insufficient tissue electrode contact substantially reduced energy delivery. These catheters also significantly reduced ablation and procedural times in PV isolation. ${ }^{6}$ Continuous monitoring of CF values may help to provide extra helpful information to the operating physician for safer catheter manipulation. It helps to make an AF ablation procedure safer as high CF values may 
occur, not only during catheter manipulation but also during ablation (Figure 8.2 and video 1$).^{27}$

Higher incidence of cardiac tamponade is seen with endocardial left atrial linear ablations. $^{28}$ When endocardial tissue is exposed to high levels of radiofrequency energy, it may lead to cardiac tamponade with steam pop. ${ }^{29}$ Other than radiofrequency energy, CF is a significant cofactor for cardiac rupture and thrombus. Several preclinical studies have associated it with significant increases in radiofrequency lesion depth, diameter, and volume. ${ }^{30-33}$

Non-inducible patients tested immediately after ablations (using adenosine bolus, burst pacing and electrical testing) had less arrhythmias during follow-up than inducible ones. $^{34}$ This further signifies the importance of testing protocols used at the end of procedures. Lesion size is significantly affected by $\mathrm{CF}$, e.g. lower radiofrequency power (30 W) and high CF (30 to $40 \mathrm{~g}$ ) produces larger and deeper lesions while compared with the ones produced at greater power $(50 \mathrm{~W})$ but lower CF. Different anatomical sites in the left atrium can be difficult to approach with a catheter. Thus continuous measurement of catheter - tissue CF during radiofrequency ablation assumes significance to achieve good quality lesions. ${ }^{35}$

There was significantly less need for endocardial touch-ups for epicardial ablation of PVs compared with other epicardial ablations, which again reminds us of the robustness of epicardial clamps compared with the epicardial pen used for box lesions. Procedural duration and ablation efficacy are significantly determined by cathetertissue CF. Moreover, the number of lesions with low average CF or force time integral (FTI) and the time to achieve acute PV isolation are linearly related. ${ }^{36,37}$ Acute PV reconnection has been strongly associated with low values of CF and FTI. ${ }^{33}$ In our study too, reconduction zones were localised in areas with mean CF readings $<10 \mathrm{~g}$, in spite of continuous attempts to improve the contact. Low CF can predict gap formation in ablation FTI. ${ }^{35,37}$ Moreover, Kumar et al. reported that optimal CF might be easier to obtain and maintain during right as compared with left PV ablation. ${ }^{35}$ In our study too, the time with poor CF values ( $5 \mathrm{~g}$ ) was significantly shorter for right than for left PV ablation. $^{38}$

The LAA was not excluded among the remaining patients due to anatomical restrictions or surgeon preference. LAA exclusion may eliminate the extra PV triggers of AF, and might also further decrease stroke incidence in patients with a high $\mathrm{CHA}_{2} \mathrm{DS}_{2}-\mathrm{VASc}$ score ${ }^{39,40}$ but can also cause bleeding, ${ }^{41}$ which might require conversion to sternotomy. Its effect on left atrial function and remaining thromboembolic risk is incompletely understood. ${ }^{42}$ LAA removal has not always been associated with a higher success rate. ${ }^{43}$ So, in future as more patients are receiving such LAA exclusion therapies, its role to determine the success of an AF ablation will be worth looking for.

The strength of this study lies in its exclusive approach to AF ablation and good followup. Further, this procedure is less invasive with minimum complications, unlike the pure surgical approach. The wastage of unnecessary energy delivery with CF catheters was 
avoided in three way: firstly by simultaneous epicardial ablation, secondly by visualising the electrical gaps by pacing manoeuvres and electroanatomical mapping and, finally by avoiding ablations in locations with insufficient surface contact. Moreover, the success rate of this procedure is comparable with either approach individually, especially considering the dilated left atrium and long years of AF duration. Monitoring of CF values during ablation can control the success rate of the procedure.

\section{Study limitation}

The small number of patients and a control group in this single-centre retrospective study prevents definitive conclusions. However, future larger, long-term and multicentre studies may corroborate our results.

\section{Conclusion}

Use of CF catheters is safe, feasible, and complementary to a hybrid procedure setup for $\mathrm{AF}$ ablation. The monitoring of real-time $\mathrm{CF}$ values predicts future arrhythmia recurrence and decreases procedure time. 


\section{References}

1. Kannel WB, Abbott RD, Savage DD, McNamara PM. Epidemiologic features of chronic atrial fibrillation: the Framingham study. N Engl J Med 1982;306:1018-1022.

2. Medi C, Sparks PB, Morton JB, Kistler PM, Halloran K, Rosso R, Vohra JK, Kumar S, Kalman JM. Pulmonary vein antral isolation for paroxysmal atrial fibrillation: results from long-term follow-up. J Cardiovasc Electrophysiol 2011;22:137-141.

3. La Meir M, Gelsomino S, Lucà F, Lorusso R, Gensini GF, Pison L, Wellens F, Maessen J. Minimally invasive thoracoscopic hybrid treatment of lone atrial fibrillation: early results of monopolar versus bipolar radiofrequency source. Interact Cardiovasc Thorac Surg. 2012;14:445-450.

4. Kumar N, Pison L, La Meir M, Maessen J, Crijns HJ. Hybrid approach to atrial fibrillation ablation using bipolar radiofrequency devices epicardially and cryoballoon endocardially. Interact Cardiovasc Thorac Surg. 2014;19:590-594.

5. Kumar N, Bonizzi P, Pison L, Phan K, Lankveld T, Maessen B, La Meir M, Gelsomino S, Maessen J, Crijns $\mathrm{H}$. Impact of hybrid procedure on $\mathrm{P}$ wave duration for atrial fibrillation ablation. J Interv Card Electrophysiol 2015;42:91-99.

6. Martinek M, Lemes $C$, Sigmund E, Derndorfer M, Aichinger J, Winter S, Nesser HJ, Pürerfellner $H$. Clinical impact of an open-irrigated radiofrequency catheter with direct force measurement on atrial fibrillation ablation. Pacing Clin Electrophysiol 2012;35:1312-1318.

7. Kumar N, Pison L, la Meir M, Maessen J. Direct visualization of pulmonary vein stenosis after previous catheter ablation. Heart Rhythm. Heart Rhythm. 2014;11:1602.

8. Wu J, Estner H, Luik A, Ucer E, Reents T, Pflaumer A, Zrenner B, Hessling G, Deisenhofer I. Automatic 3D mapping of complex fractionated atrial electrograms (CFAE) in patients with paroxysmal and persistent atrial fibrillation. J Cardiovasc Electrophysiol 2008;19: 897-903.

9. Kumar N, Pison L, La Meir M, Maessen J. Atraumatic Lung Hernia: A Rare Complication Of Minimally Invasive Surgical Atrial Fibrillation Ablation. J Atrial Fib. 2013;6:3.

10. Kumar N, Timmermans C, Das M, Pison L, Maessen J, Crijns H. Re: CT imaging of complications of catheter ablation for atrial fibrillation. Clin Radiol 2014;69:e367-368.

11. Kumar N, Phan K, Aksoy I, et al. Management of pulmonary vein stenosis following catheter ablation of atrial fibrillation. J Atrial Fib. 2014;7(1):7.

12. Chimienti M, Cullen MT, Jr., Casadei G. Safety of long-term flecainide and propafenone in the management of patients with symptomatic paroxysmal atrial fibrillation: report from the Flecainide and Propafenone Italian Study Investigators. Am J Cardiol 1996;77:60A-75A.

13. Wyse DG, Waldo AL, DiMarco JP, Domanski MJ, Rosenberg Y, Schron EB, Kellen JC, Greene HL, Mickel MC, Dalquist JE, Corley SD; Atrial Fibrillation Follow-up Investigation of Rhythm Management (AFFIRM) Investigators. A comparison of rate control and rhythm control in patients with atrial fibrillation. N Engl J Med 2002;347:1825-1833.

14. Jost N, Kohajda Z, Kristóf A, Kovács PP, Husti Z, Juhász V, Kiss L, Varró A, Virág L, Baczkó I. Atrial remodeling and novel pharmacological strategies for antiarrhythmic therapy in atrial fibrillation. Curr Med Chem 2011;18:3675-3694.

15. Haïssaguerre M1, Gencel L, Fischer B, Le Métayer P, Poquet F, Marcus FI, Clémenty J. Successful catheter ablation of atrial fibrillation. J Cardiovasc Electrophysiol 1994;5:1045-1052.

16. Cox JL. The first Maze procedure. J Thorac Cardiovasc Surg 2011;141:1093-1097.

17. de Vries L, Akca F, Khan M, Dabiri-Abkenari L, Janse P, Theuns DA, Peters E, de Ruiter G, Szili-Torok T. Clinical outcome of ablation for long-standing persistent atrial fibrillation with or without defragmentation. Neth Heart J 2014;22:30-36.

18. Kumar N, Pison L, Blaauw $\mathrm{Y}$ et al. Pulmonary vein stenosis after laser balloon ablation for atrial fibrillation. JACC: Clinical Electrophysiology 2015.; doi 10.1016/j.jacep.2015.04.001

19. Ouyang F, Bänsch D, Ernst S, Schaumann A, Hachiya H, Chen M, Chun J, Falk P, Khanedani A, Antz M, Kuck $\mathrm{KH}$. Complete isolation of left atrium surrounding the pulmonary veins: new insights from the double-Lasso technique in paroxysmal atrial fibrillation. Circulation 2004;110:2090-2096. 
20. Verma A1, Kilicaslan F, Pisano E, Marrouche NF, Fanelli R, Brachmann J, Geunther J, Potenza D, Martin DO, Cummings J, Burkhardt JD, Saliba W, Schweikert RA, Natale A. Response of atrial fibrillation to pulmonary vein antrum isolation is directly related to resumption and delay of pulmonary vein conduction. Circulation 2005;112:627-635.

21. Kumar N, Bonizzi P, Lankveld T, Rad MM. Left atrial dyssynchrony time measured by tissue Doppler imaging to predict atrial fibrillation recurrences after pulmonary vein isolation: Is this a mirage or the panacea? Anatol J Cardiol. 2015;15:123-134.

22. Yaksh A, Kik C, Knops P, Roos-Hesselink JW, Bogers AJ, Zijlstra F, Allessie M, de Groot NM. Atrial fibrillation: to map or not to map? Neth Heart J 2014;22:259-266.

23. Kumar N, Dinh T, Magdi Abbas M, Phan K, Manusama R, Philippens S, Maessen J, Timmermans C. Failure to Reach the Optimal Temperature During Cryoablation Due to Refrigerant Cylinder Problem. Res Cardiovasc Med 2015;4:e25592.

24. Ullah W, Hunter RJ, Baker V, Dhinoja MB, Sporton S, Earley MJ, Schilling RJ. Target indices for clinical ablation in atrial fibrillation: insights from contact force, electrogram, and biophysical parameter analysis. Circ Arrhythm Electrophysiol 2014;7:63-68.

25. Nakagawa H, Kautzner J, Natale A, Peichl P, Cihak R, Wichterle D, Ikeda A, Santangeli P, Di Biase L, Jackman WM. Locations of high contact force during left atrial mapping in atrial fibrillation patients: electrogram amplitude and impedance are poor predictors of electrode-tissue contact force for ablation of atrial fibrillation. Circ Arrhythm Electrophysiol 2013;6:746-753.

26. Kumar S, Haqqani HM, Chan M, Lee J, Yudi M, Wong MC, Morton JB, Ling LH, Robinson T, Heck PM, Kelland NF, Halloran K, Spence SJ, Kistler PM, Kalman JM. Predictive value of impedance changes for real-time contact force measurements during catheter ablation of atrial arrhythmias in humans. Heart Rhythm 2013;10:962-969.

27. Kuck KH, Reddy VY, Schmidt B, Natale A, Neuzil P, Saoudi N, Kautzner J, Herrera C, Hindricks G, Jaïs P, Nakagawa $H$, Lambert $H$, Shah DC. A novel radiofrequency ablation catheter using contact force sensing: Toccata study. Heart Rhythm 2012;9:18-23.

28. Jaïs $P$, Shah DC, Haïssaguerre M, Takahashi A, Lavergne T, Hocini M, Garrigue S, Barold SS, Le Métayer $P$, Clémenty J. Efficacy and safety of septal and left-atrial linear ablation for atrial fibrillation. Am J Cardiol 1999;84:139R-146R.

29. Hsu LF, Jaïs P, Hocini M, Sanders P, Scavée C, Sacher F, Takahashi Y, Rotter M, Pasquie JL, Clémenty J, Haïssaguerre $M$. Incidence and prevention of cardiac tamponade complicating ablation for atrial fibrillation. Pacing Clin Electrophysiol 2005;28 Suppl 1:S106-109.

30. Wittkampf FH, Nakagawa H. RF catheter ablation: Lessons on lesions. Pacing Clin Electrophysiol 2006;29:1285-1297.

31. Yokoyama K, Nakagawa H, Wittkampf FH, Pitha JV, Lazzara R, Jackman WM. Comparison of electrode cooling between internal and open irrigation in radiofrequency ablation lesion depth and incidence of thrombus and steam pop. Circulation 2006;113:11-19.

32. Nakagawa H, Yamanashi WS, Pitha JV, Arruda M, Wang X, Ohtomo K, Beckman KJ, McClelland JH, Lazzara R, Jackman WM. Comparison of in vivo tissue temperature profile and lesion geometry for radiofrequency ablation with a saline-irrigated electrode versus temperature control in a canine thigh muscle preparation. Circulation 1995;91:2264-2273.

33. Eick OJ, Bierbaum D. Tissue temperature-controlled radiofrequency ablation. Pacing Clin Electrophysiol 2003;26:725-730.

34. Kumar N, Pison L, La Meir M, Maessen J, Crijns HJ. Testing of box lesion by adenosine. Journal of Atrial Fibrillation 2013-2014;6(4).

35. Kumar S, Morton JB, Lee J, Halloran K, Spence SJ, Gorelik A, Hepworth G, Kistler PM, Kalman JM. Prospective characterization of catheter-tissue contact force at different anatomic sites during antral pulmonary vein isolation. Circ Arrhythm Electrophysiol 2012;5:1124-1129.

36. Thiagalingam A, D'Avila A, Foley L, Guerrero JL, Lambert H, Leo G, Ruskin JN, Reddy VY. Importance of catheter contact force during irrigated radiofrequency ablation: evaluation in a porcine ex vivo model using a force-sensing catheter. J Cardiovasc Electrophysiol 2010;21:806-811.

37. Neuzil P, Reddy VY, Kautzner J, Petru J, Wichterle D, Shah D, Lambert H, Yulzari A, Wissner E, Kuck KH. Electrical reconnection after pulmonary vein isolation is contingent on contact force during initial treatment: results from the EFFICAS I study. Circ Arrhythm Electrophysiol 2013;6:327-333. 
38. Stabile G, Solimene F, Calò L, Anselmino M, Castro A, Pratola C, Golia P, Bottoni N, Grandinetti G, De Simone A, De Ponti R, Dottori S, Bertaglia E. Catheter-tissue contact force for pulmonary veins isolation: a pilot multicentre study on effect on procedure and fluoroscopy time. Europace 2014;16:335-340.

39. Lip GY, Nieuwlaat R, Pisters R, Lane DA, Crijns HJ. Refining clinical risk stratification for predicting stroke and thromboembolism in atrial fibrillation using a novel risk factor-based approach: the euro heart survey on atrial fibrillation. Chest 2010;137:263-272.

40. Ohtsuka T, Ninomiya M, Nonaka T, Hisagi M, Ota T, Mizutani T. Thoracoscopic stand-alone left atrial appendectomy for thromboembolism prevention in nonvalvular atrial fibrillation. J Am Coll Cardiol 2013;62:103-107.

41. Driessen AH, Krul SP, de Mol BA, de Groot JR. Second chance for a totally thoracoscopic video-assisted pulmonary vein isolation for atrial fibrillation. Ann Thorac Surg 2012;93:2051-2053.

42. Dawson AG, Asopa S, Dunning J. Should patients undergoing cardiac surgery with atrial fibrillation have left atrial appendage exclusion? Interact Cardiovasc Thorac Surg 2010;10:306-311.

43. Krul SP, Pison L, La Meir M, Driessen AH, Wilde AA, Maessen JG, De Mol BA, Crijns HJ, de Groot JR. Epicardial and endocardial electrophysiological guided thoracoscopic surgery for atrial fibrillation: a multidisciplinary approach of atrial fibrillation ablation in challenging patients. Int J Cardiol 2014;173:229-235. 


\section{Chapter}

Atraumatic lung hernia: $A$ rare complication of minimally invasive surgical atrial fibrillation ablation

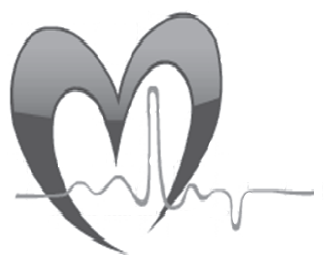

Narendra Kumar

Laurent Pison

Mark La Meir

Jos Maessen

Harry Crijns

Journal of Atrial Fibrillation,2013; 6:39 


\section{Abstract}

Lung herniation after minimally invasive thoracoscopic pulmonary vein ablation has never been described before so far. We report for the first time, of its incidence in a 62-year-old patient, 6 weeks after a minimally invasive cardiac surgery (MICS) for atrial fibrillation ablation. We suggest that even after MICS, a high resolution computerized tomography scan should be performed in patients presenting with breathing difficulty and chest pain to rule out this condition too, other than pulmonary vein stenosis. 


\section{Introduction}

Pulmonary vein (PV) isolation is considered key to atrial fibrillation (AF) ablation. ${ }^{1}$ Due to limitations of medical therapy in achieving sinus rhythm, there has been recent upsurge in surgical and catheter-based technologies to achieve this goal. ${ }^{2-4}$ Recently, a new concept of bringing the advantages together of a cardiac surgeon and an electrophysiologist in order to overcome the drawbacks and suboptimal results of both catheter ablation and surgical AF treatment is successful with promising results. Atraumatic lung hernia is a rare entity secondary to minimally invasive cardiac surgery (MICS). To the best of our knowledge, it has never been described secondary to any lateral approach thoracoscopic MICS. With increasing number of surgical arrhythmia procedures in future, cardiac surgeons and physicians must keep a watchful eye for such complication.

We report herein a case of lung herniation after MICS for AF ablation.

\section{Case report}

A 62-year-old woman with a 3-year history of symptomatic paroxysmal AF was refractory to anti arrhythmic drugs including amiodarone, Inspite of undergoing endocardial PV isolation by radiofrequency (RF) catheter a year ago. Echocardiography showed a structurally and functionally normal heart with mildly dilated left atrium.

\section{Hybrid procedure}

The details of the procedure have been described elsewhere. ${ }^{9}$ To summarize, after inducing general anaesthesia, a $12 \mathrm{~mm}$ videoport in $5^{\text {th }}$ intercostal space and 2 working ports of $5 \mathrm{~mm}$ and $12 \mathrm{~mm}$ were inserted along anterior axillary line in $3^{\text {rd }}$ and $6^{\text {th }}$ or $7^{\text {th }}$ intercostal spaces respectively. The pericardium was opened posterior to phrenic nerve and it was extended upto the diaphragm and superior vena cava on opposite sides. A bipolar RF clamp (Atricure, West Chester, OH, USA) was placed at the antrum of the PVs. Four to 6 applications of about 15 seconds with a median output of 10 to 15 Watt were performed. Both roofline and an inferior line were made epicardially using a bipolar RF pen device (Coolrail, Atricure). At the end of procedure, incision for a left working port (12 mm) was extended to $3 \mathrm{cms}$ to facilitate positioning the epicardial left atrial appendage (LAA) clip (AtriClip, Atricure Inc.). Using the Gillinov-Cosgrove ${ }^{\mathrm{TM}}$ Selection Guide (Atricure Inc.) a $35 \mathrm{~mm}$ LAA clip was selected. Avoiding the pulmonary and circumflex arteries, the clip was placed at the base of the appendage. The clip can be repositioned before deployment, if the clip's position is not satisfactory. After the 
clip was in optimal location, it was closed and released from the deployment tool manually. The Clip did not migrate intra-operatively.

After endocardial placement of $\mathrm{His}$ and coronary sinus catheters, a transseptal puncture was done using long 8-F sheath (SLO, St. Jude Medical) into the left atrium guided by fluoroscopy and trans-esophageal echocardiography. PVs and linear lesions were checked for electrical isolation. AF inducibility was attempted using endocardial burst pacing and adenosine administration. No endocardial touchup was needed due to intact surgical ablation lines and no evidence of dormant PV reconduction. The pericardium was approximated with a stitch, and a chest tube was placed in both pleural cavities. There was no drain left in the pericardial space. The insertion sites for working ports were closed using surgical skin staplers. The exclusion of appendage was successful as assessed by postoperative trans-esophageal echocardiography.

\section{Post procedure events}

Post- procedure recovery was uneventful. Six weeks later, she presented at our hospital's clinic with complaints of pain in left thorax region associated with dyspnea (NYHA class 2). Pain used to increase on inspiration, was dull aching and non-radiating type. General physical examination was otherwise normal. Transthoracic echocardiography showed no pericardial effusion, no valvular (aortic or mitral) dysfunction and normal left ventricular function.

Her chest radiograph was within normal limits and subsequently advised medical management with painkillers. After 3 days, she returned with similar complaints. Due to history of MICS and strong clinical suspicion to rule out any complication, high resolution computerized tomographic (HRCT) scan was ordered. The scan showed (Figure 9.1 and 9.2) a lung herniation in left chest wall through two intercostal levels that was caused by ports placement (and extra widening) in the chest wall. Finally, she underwent surgical release of the entrapped lung tissue through hernial sac, freed from adhesions, and reduced back into the thoracic cavity. Now after 12 weeks follow up, she is asymptomatic. 


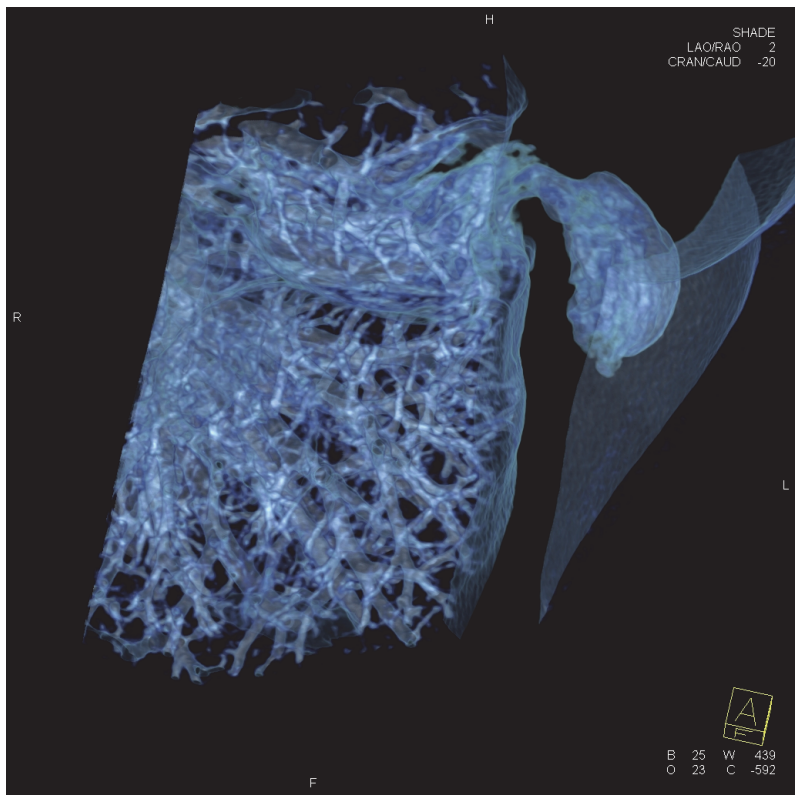

Figure 9.1 Three-dimensional reconstruction of high-resolution computerized tomography scans of the lung hernia.

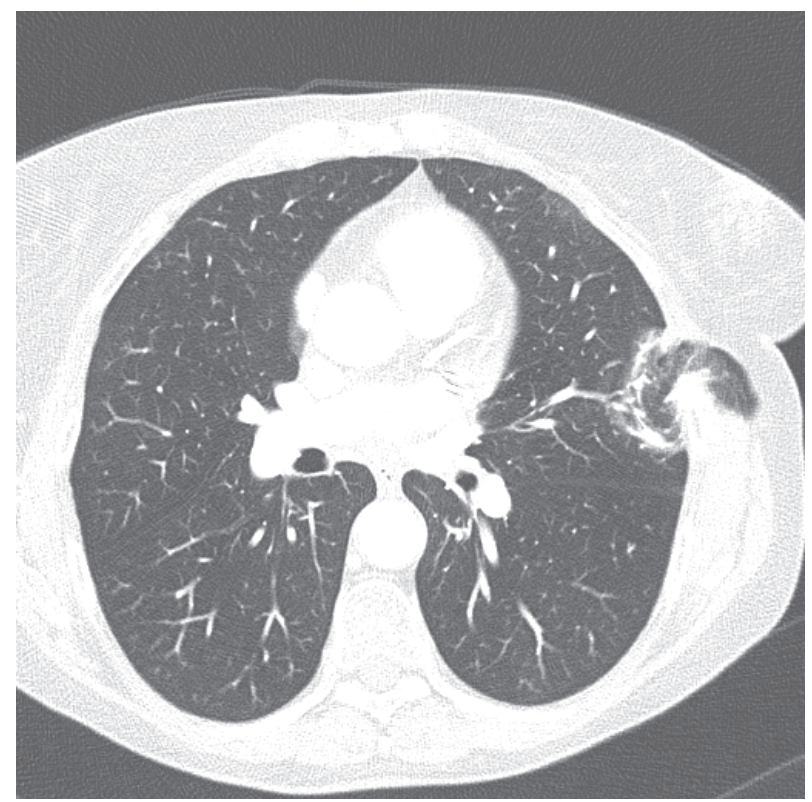

Figure 9.2 High-resolution computerized tomography scans (axial view) of lung hernia. 


\section{Discussion}

MICS for AF ablation is a novel tool. It has evolved over time, to reduce the complications and cosmetic disadvantages of conventional cardiac surgery incision leading to a shorter hospital stay. ${ }^{10}$ Herniation of pulmonary tissue was described earliest in 1499 by Roland. ${ }^{11,12}$ Later in 1946, Maurer and Blades established the definition of lung herniation as "a protrusion of the pleural-covered lung beyond its normal boundaries through an abnormal opening in the thoracic enclosure." ${ }^{13}$ They are also classified according to their etiology as spontaneous, traumatic or postthoracotomy and according to their location as cervical, thoracic, abdominal, or thoraco-abdominal. ${ }^{14}$

To decrease the future risk of thromboembolism, a LAA exclusion or excision surgery is recommended in patients undergoing surgical treatment for AF or mitral valve. ${ }^{15}$ LAA clip occlusion epicardially may not only provide stroke prevention but also reduce the recurrence of AF by causing acute electrical isolation of the LAA. ${ }^{16}$ The Clip used in this procedure is pre-loaded on a disposable Clip applier and used for open occlusion of the heart's LAA. No device-related perioperative complication has been observed and follow up with CT imaging has shown stable clip placement.

Most of the previous cases of lung hernia happened with minimal-access thoracotomy in anterior wall of thorax, however particular for our patient has been their lateral and posterior location. We concluded main culprit being the extra operative trauma due to widening of the mini invasions of $12 \mathrm{mms}$ (initially) to $3 \mathrm{cms}$ to accommodate an epicardial LAA clip. If epicardial Clip was not indicated for a patient, the size of working port lesion would not been widened. The other possible reasons are inadequate closure of lesions (for insertion of videoports and interports), inherent weakness of intercostal muscles and intensive cauterization of the intercostal muscles. However, we did not observe any unexpected bleeding from sites of working ports insertion during the procedure. The patient's activity during the period of chest-wall healing should be limited regardless of the size of the skin incision. ${ }^{12}$

\section{Important findings}

The classical triad of patient's history and the clinical symptoms and physical examination brings the physician closer to the diagnosis. However, it may sometimes not bring close enough as in this case. CT scan helped to fill the necessary void by delineating the size and location of the defect and dimensions of the hernia and leading to correct diagnosis. ${ }^{19}$ The patient may present with a well-demarcated bulge increasing in size by expiration and vice-versa and more evident during coughing or Valsalva manoeuvre. Hernia may not pose a serious threat unless associated with incarceration and strangulation of the pulmonary tissue. The diagnosis of lung hernia 
should be confirmed after ruling out bronchopleural fistula, subcutaneous emphysema, lipoma and a gas-forming infection which require different treatment strategy. ${ }^{10}$

\section{Conclusion}

Lung hernia may occur after MICS for AF ablation, as a rare complication. Thus, it seems important to recommend CT scan in similarly symptomatic patients during their routine follow up. 


\section{References}

1. Haïssaguerre $M$, Jaïs $P$, Shah DC, Takahashi A, Hocini M, Quiniou G, Garrigue S, Le Mouroux A, Le Métayer $P$, Clémenty J. Spontaneous initiation of atrial fibrillation by ectopic beats originating in the pulmonary veins. N Engl J Med 1998;339:659-66.

2. Galperín J, Elizari MV, Chiale PA, Molina RT, Ledesma R, Scapín AO, Vázquez Blanco M; GEFCA Investigators-GEMA Group, Buenos Aires, Argentina. Efficacy of amiodarone for the termination of chronic atrial fibrillation and maintenance of normal sinus rhythm: a prospective, multicenter, randomized, controlled, double blind trial. J Cardiovasc Pharmacol Ther 2001;6:341-50.

3. Wyse DG, Waldo AL, DiMarco JP, Domanski MJ, Rosenberg Y, Schron EB, Kellen JC, Greene HL, Mickel MC, Dalquist JE, Corley SD; Atrial Fibrillation Follow-up Investigation of Rhythm Management (AFFIRM) Investigators. A comparison of rate control and rhythm control in patients with atrial fibrillation. N Engl J Med 2002;347:1825-33.

4. Cox JL, Schuessler RB, Cain ME, Corr PB, Stone CM, D'Agostino HJ Jr, Harada A, Chang BC, Smith PK, Boineau JP. Surgery for atrial fibrillation. Semin Thorac Cardiovasc Surg 1989;1:67-73.

5. Stamou SC, Khabbaz KR, Mahmood F, Zimetbaum P, Hagberg RC. A multidisciplinary approach to the minimally invasive pulmonary vein isolation for treatment of atrial fibrillation. Ann Thorac Surg 2010; 89:648-50.

6. Pison L, La Meir M, van Opstal J, Blaauw Y, Maessen J, Crijns HJ. Hybrid thoracoscopic surgical and transvenous catheter ablation of atrial fibrillation. J Am Coll Cardiol 2012;60:54-61.

7. Ross RT, Burnett CM. Atraumatic lung hernia. The Annals of thoracic surgery 1999;67:1496-7.

8. Athanassiadi K, Bagaev E, Simon A, Haverich A. Lung herniation: a rare complication in minimally invasive cardiothoracic surgery. Eur J Cardiothorac Surg 2008;33:774-6.

9. La Meir M, Gelsomino S, Lucà F, Lorusso R, Gensini GF, Pison L, Wellens F, Maessen J. Minimally invasive thoracoscopic hybrid treatment of lone atrial fibrillation: early results of monopolar versus bipolar radiofrequency source. Interact Cardiovasc Thorac Surg 2012;14:445-50.

10. Ng PC, Chua AN, Swanson MS, Koutlas TC, Chitwood WR, Jr., Elbeery JR. Anterior thoracotomy wound complications in minimally invasive direct coronary artery bypass. Ann Thorac Surg 2000;69:1338-40.

11. Roland. De pulmonibus sanaripot. In: Chavliac G, editor. Cyrurgia. Liber III (cap); $p 144$.

12. Gouda H, Multz AS, Khan A, Rossoff $L$, Green LM, Graver D. Lung hernia as a sequela to limited-access mitral valve surgery. Texas Heart Institute journal / from the Texas Heart Institute of St Luke's Episcopal Hospital, Texas Children's Hospital 2002;29:203-5.

13. Maurer E, Blades B. Hernia of the lung. J Thorac Surg 1946;15:77-98.

14. Sulaiman A, Cottin V, De Souza Neto EP, Orsini A, Cordier JF, Gamondes JP, Tronc F. Cough-induced intercostal lung herniation requiring surgery: Report of a case. Surg Today 2006;36:978-80.

15. Calkins H, Kuck KH, Cappato R, Brugada J, Camm AJ, Chen SA, Crijns HJ, Damiano RJ Jr, Davies DW, DiMarco J, Edgerton J, Ellenbogen K, Ezekowitz MD, Haines DE, Haissaguerre M, Hindricks G, lesaka $Y$, Jackman W, Jalife J, Jais P, Kalman J, Keane D, Kim YH, Kirchhof P, Klein G, Kottkamp H, Kumagai K, Lindsay BD, Mansour M, Marchlinski FE, McCarthy PM, Mont JL, Morady F, Nademanee K, Nakagawa H, Natale A, Nattel S, Packer DL, Pappone C, Prystowsky E, Raviele A, Reddy V, Ruskin JN, Shemin RJ, Tsao HM, Wilber D. HRS/EHRA/ECAS Expert Consensus Statement on Catheter and Surgical Ablation of Atrial Fibrillation: recommendations for patient selection, procedural techniques, patient management and follow-up, definitions, endpoints, and research trial design. Europace 2012;14:528-606.

16. Starck CT, Steffel J, Emmert MY, Plass A, Mahapatra S, Falk V, Salzberg SP. Epicardial left atrial appendage clip occlusion also provides the electrical isolation of the left atrial appendage. Interact Cardiovasc Thorac Surg 2012;15:416-8.

17. Salzberg SP, Gillinov AM, Anyanwu A, Castillo J, Filsoufi F, Adams DH. Surgical left atrial appendage occlusion: evaluation of a novel device with magnetic resonance imaging. Eur J Cardiothorac Surg 2008; 34:766-70.

18. Salzberg SP, Plass A, Emmert MY, Desbiolles L, Alkadhi H, Grünenfelder J, Genoni M. Left atrial appendage clip occlusion: early clinical results. J Thorac Cardiovasc Surg 2010;139:1269-74. 
19. Bhalla M, Leitman BS, Forcade C, Stern E, Naidich DP, McCauley DI. Lung hernia: radiographic features. AJR Am J Roentgenol 1990;154:51-3.

20. Eisa N, Alraiyes AH, Shaheen K, Alraies MC: Lung hernia. BMJ Case Rep 2013;2013. 


\section{Chapter 10}

Adenosine Testing after Second generation Cryoballoon Ablation (ATSCA) study improves clinical success rate for atrial fibrillation

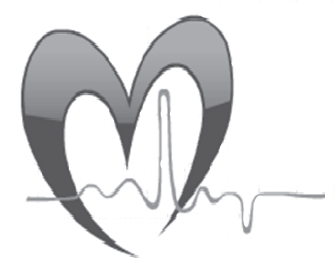

Narendra Kumar

Trang Dinh

Kevin Phan

Carl Timmermans

Willem Dassen

Suzanne Philippens

Nousjka Vranken

Laurent Pison

Jos Maessen

Harry J Crijns

Europace 2015;17:871-6 


\section{Abstract}

Aim

Adenosine administration after pulmonary vein (PV) isolation using radiofrequency, laser, and cryoablation can cause acute recovery of conduction to the PVs and predict atrial fibrillation (AF) recurrence. This study evaluates whether ablation of dormant potentials post adenosine administration following second-generation cryoballoon (CB-2G) ablation may improve the success rate for AF.

\section{Methods}

In 45/90 patients after waiting period of 30 minutes, a bolus $15-21 \mathrm{mg}$ of adenosine was administered followed by rapid saline flush. The response was assessed for each PV using a circular octapolar catheter. If needed, further ablation using a cryoballoon and/or cryocatheter was performed until no reconduction was observed after repeat adenosine administration. The remaining 45 patients did not receive adenosine after the procedure.

\section{Results}

Acute PV isolation was achieved in 352/358 PVs (98.3\%) of 86/90 patients (95.6\%) using CB-2G. The adenosine group showed dormant reconduction in 5/45 patients (11\%), 8/179 PVs (4.5\%) including 1 LSPV, 3 LIPV, 1 RSPV, and 3 RIPV. The success rate for adenosine and without adenosine group was $84 \%$ and $79 \%$ after a mean follow up of $397 \pm 47$ and $349 \pm 66$ days; without any AF recurrence in patients in whom adenosine induced dormant conduction was ablated.

\section{Conclusion}

Adenosine Testing after Second generation Cryoballoon Ablation (ATSCA) study showed that reablation of initially isolated $\mathrm{PV}$ s increases the clinical success rate for AF. 


\section{Introduction}

Atrial fibrillation (AF) is the most common arrhythmia in the clinical setting, with significant morbidity and mortality. ${ }^{1}$ Pulmonary vein (PV) isolation is considered the cornerstone for ablative treatment of $A F ;^{1}$ however, its long-term efficacy is curtailed by reconduction of ablation lines between $\mathrm{PVs}$ and the atrium, leading to $\mathrm{AF}$ reconduction. ${ }^{2}$ Cryoballoon ablation is an effective therapy for AF ablation. ${ }^{3}$ Recently, the second-generation cryoballoon (CB-2G) has been introduced having a larger and more homogeneous freezing zone leading to lower ablation temperature for procedures and improved success rates. ${ }^{4,5}$

Adenosine administration after PV isolation can unmask dormant PV conduction that may predict AF recurrence. ${ }^{6}$ The administration of adenosine activates sensitive potassium channels, causing 'depolarization of resting membrane potential beyond the critical threshold value'. ${ }^{7}$ Adenosine testing has been used for cryoballoon (first and second generation), laser balloon, and radiofrequency ablation, ${ }^{8}$ and targeting dormant PV conduction may increase procedure success rate. Ciconte et al. ${ }^{9}$ observed that adenosine-induced dormant conduction occurred in 4\% patients after CB-2G ablation, and after ablation $86 \%$ patients were free from $\mathrm{AF}$ after a short follow-up of 7 months only. However, our group had observed in another study that success rate for secondgeneration balloon devices tends to stabilize only after 1 -year follow-up. ${ }^{10}$

This study aimed to evaluate the acute reconduction post adenosine administration after CB-2G ablation and whether ablating dormant conduction affects the annual success rate.

\section{Methods}

\section{Study population}

Between December 2012 and June 2013, PV isolation was performed in 90 symptomatic paroxysmal $(n=79)$ and persistent $(n=11)$ AF using a CB-2G (Arctic Front ${ }^{\mathrm{TM}}$, Medtronic). They were divided between two groups. The first group called 'adenosine group' consisted of 45 patients receiving adenosine and other group 'non-adenosine group' was not subjected to any pharmacological testing. Atrial fibrillation was documented on Holter monitors or 12 lead electrocardiograms (ECGs). Patients were considered for ablation only if they are clinically symptomatic, and AF was refractory to at least one antiarrhythmic drug (AAD). Exclusion criteria in this study were: patients with a dilated left atrial (LA) diameter $>50 \mathrm{~mm}$, previous LA procedures, obstructive pulmonary disease, left ventricular ejection fraction, $<30 \%$, presence of an intracardiac thrombus, moderate or severe valvular heart disease, history of myocardial infarction or any cardiac surgery within the prior 3 months, and stroke or a transient ischaemic 
attack in the last 6 months. After a detailed discussion on potential risks and benefits of the procedure, informed written consent was obtained from all patients. Before PV isolation, a transoesophageal echocardiography, and/or a cardiac CT scan was performed in all patients to rule out the presence of intracardiac thrombi, and to assess LA geometry, and the PV morphology.

Paroxysmal and persistent AF was defined according to Heart Rhythm Society/European Heart Rhythm Association/European Cardiac Electrophysiology Society (HRS/EHRA/ECAS) consensus statement updated in $2012 .{ }^{11}$ Procedural success is defined as freedom from any atrial arrhythmia lasting $>30 \mathrm{~s}$ after the procedure and without the use of AADs. The first 3 months after ablation were considered as blanking period and the follow-up of the patients was done using 7-day Holter monitoring at 3 months. Anti-coagulation and AADs were stopped 3 months after the procedure, depending on the $\mathrm{CHA}_{2} \mathrm{DS}_{2}$-VASc score. Patients without AF recurrence but continuing AADs were classified as failures. Procedural endpoints were PV isolation demonstrated by entry Block and/or exit block.

\section{Electrophysiological procedure}

All procedures were performed under local anesthesia, and if needed, under conscious sedation using titrating boluses of midazolam, and/or morphine. Blood pressure and oxygen saturation were continuously monitored. A coronary sinus catheter (Medtronic) and a His catheter (St Jude Medical) were placed via the femoral route and under fluoroscopic guidance. After a single transseptal puncture using an $8 \mathrm{~F}$ sheath (SLO, St Jude Medical), a guidewire was advanced into a PV and, thereafter the sheath was exchanged for a 12 F Flexcath Sheath (Medtronic). Following a transseptal puncture, patients were heparinized (a bolus injection of $1000 \mathrm{U}$ heparin per $10 \mathrm{~kg}$ body weight and thereafter a heparin infusion) to maintain the activated clotting time $>300 \mathrm{~s}$ and $<400 \mathrm{~s}$ throughout the procedure. During rapid ventricular pacing, contrast was injected through the long sheath to visualize LA and PV anatomy. The CB-2G balloon was advanced to the ostium of PV using an inner lumen endoluminal spiral catheter (Achieve $^{\mathrm{TM}}, 15$ or $20 \mathrm{~mm}$, Medtronic, Inc.). After twice $4 \mathrm{~min}$ applications of each PV and in case of electrical isolation, we proceeded with adenosine testing. His catheter was also used for stimulating the phrenic nerve during right superior PV (RSPV) ablation.

\section{Adenosine testing}

After cryoablation, the Achieve ${ }^{\mathrm{TM}}$ catheter was placed at PV ostium to evaluate entrance and exit block. After a waiting time of 30 min after the last cryoapplication, 12 mg adenosine was administered, followed by a rapid saline flush. If atrioventricular block was not observed, the bolus was increased by $3 \mathrm{mg}(15 \mathrm{mg})$. However, if this also did not result in an atrioventricular block, additional $3 \mathrm{mg}$ more was used and henceforth. The above procedure was repeated for all PVs individually. Dormant 
conduction is defined as one or more PV potentials recorded with the Achieve $^{\mathrm{TM}}$ catheter ECG. For PVs with dormant LA to PV conduction, additional ablation was carried out using the cryoballoon and/or a cryocatheter targeting the reconduction segment as recorded with the circular mapping catheter. Ablation was continued until no more PV potentials were present after repeat adenosine administration.

\section{Statistical analysis}

Statistical analysis was performed using Statistical Package for the Social Sciences (SPSS Inc.). Numeric variables were expressed as mean \pm standard deviation. A p-value of $<0.05$ was considered significant. Categorical values are expressed as frequency or percentage, and groups were compared using the $\chi^{2}$ test. The Fisher's exact test was conducted when $>20 \%$ of cells have an expected frequency $<5$. Analysis of AF-free survival was performed using the Kaplan-Meier method (Figure 10.1). The Log-rank test was used to test whether the adenosine and no adenosine groups differ in AF-free survival.

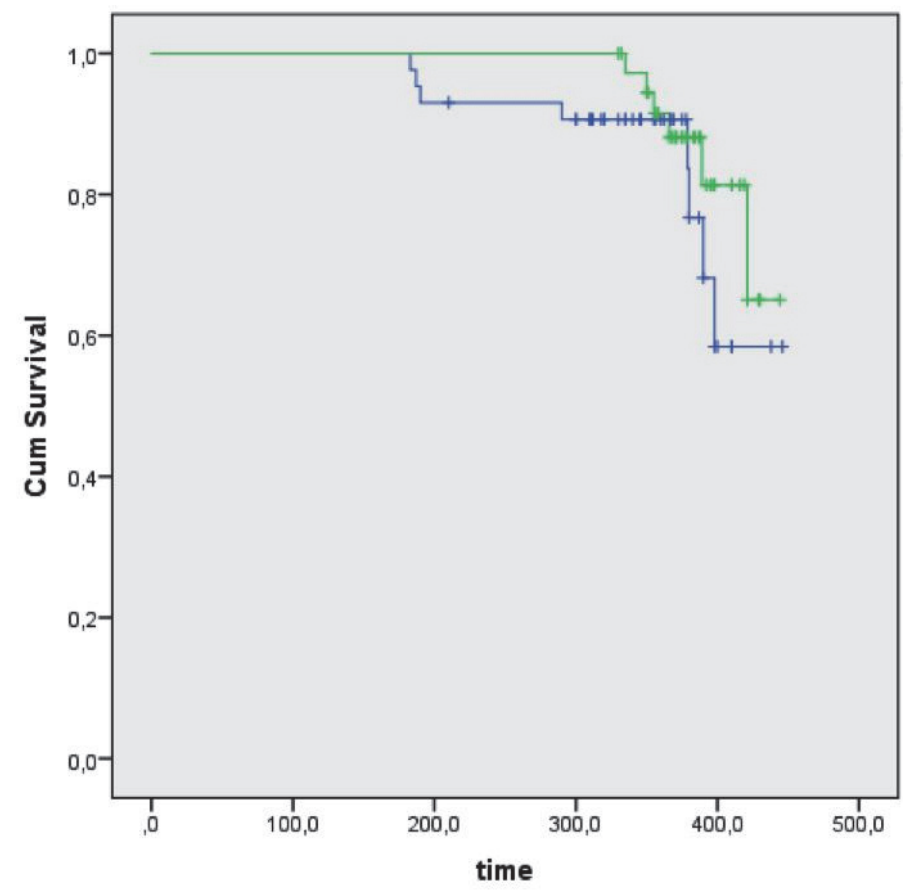

Figure 10.1 Kaplan-Meir curve analysis of atrial fibrillation ablation using CB-2G with ablation of dormant conduction after adenosine administration (green line) and without adenosine testing (blue line) procedure. 


\section{Results}

Among 90 patients, one patient each in adenosine and no adenosine group had a common left ostium. Acute PV isolation was achieved in 352 of 358 PVs (98.3\%) of 86 patients (95.6\%) using CB-2G ablation. Among four patients, in whom acute PV isolation was not achieved, two had paroxysmal and remaining had persistent AF. After a waiting period of $30 \mathrm{~min}$ followed by adenosine administration of $15 \pm 3 \mathrm{mg}$, acute reconduction was observed in 8 of 179 PVs (4.5\%), i.e. 1 left superior PV, 3 left inferior PV (LIPV), 1 RSPV, and 3 right inferior PV (RIPV) among 5 of 45 patients (11\%). The same cryoballoon that was used earlier for cryoablation was used again for up to two additional freezing cycles to close the dormant conduction gaps. If still unsuccessful, a $4 \mathrm{~mm}$ cryocatheter was used for ablating the dormant conduction in PV $(n=2)$. The anatomical location was antero-superior segment of LIPV and postero-inferior segment of RIPV.

For adenosine and non-adenosine cohorts, the median procedure time was $174 \pm 44$ and $212 \pm 47 \mathrm{~min}$, and the median fluoroscopy time was $34 \pm 13$ and $40 \pm 18 \mathrm{~min}$, respectively. The mean minimal temperature $\left(8^{\circ} \mathrm{C}\right)$ in patients with dormant reconduction was $42.6 \pm 12.3$, and $36.8 \pm 11.4$ for group without dormant reconduction $(p=0.47)$.

In non-adenosine group, $23 \mathrm{~mm}$ cryoballoon was used in 9 of 45 patients (with 36 PVs) and none of them had any recurrence during the 1-year follow-up. Among these patients, initially $28 \mathrm{~mm}$ cryoballoon was used (for four PVs) considering better safety profile for two of nine patients. However, later due to smaller size of PVs and subsequently to further improve the grade of occlusion, bigger balloon was replaced by $23 \mathrm{~mm}$ cryoballoon (for four PVs). In adenosine group, $23 \mathrm{~mm}$ cryoballoon was used for 7 of 45 patients (28 PVs) and one of them had arrhythmia recurrence during the followup. As previously mentioned for non-adenosine group, among adenosine group patients too, $28 \mathrm{~mm}$ cryoballoon was used for two PVs in one of seven patients. To improve the occlusion grade after observing smaller PV size, bigger balloon was replaced by $23 \mathrm{~mm}$ cryoballoon for two PVs.

Table 10.1 illustrates the patient characteristics of the adenosine and the nonadenosine groups. The Log-rank (Mantel-Cox) test of equality of AF-free survival among the adenosine and non-adenosine groups showed no statistically significant difference; i.e. $p=0.06$ during the comparison of the AF-free survival among adenosine and nonadenosine groups. 
Table 10.1 Patient and procedure characteristics.

\begin{tabular}{|c|c|c|c|}
\hline \multirow[t]{2}{*}{ Variables } & \multicolumn{2}{|c|}{ Number of patients } & \multirow[t]{2}{*}{$p$-value } \\
\hline & Adenosine group & $\begin{array}{l}\text { No-adenosine } \\
\text { group }\end{array}$ & \\
\hline Patients (n) & 45 & 45 & \\
\hline Pulmonary veins (n) & 179 & 179 & NS \\
\hline Gender (men/women) & $27 / 18$ & $34 / 11$ & NS \\
\hline Age (years) & $57.4 \pm 9.5$ & $56.6 \pm 11.2$ & NS \\
\hline BMI $\left(\mathrm{kg} / \mathrm{m}^{2}\right)$ & $26 \pm 2.9$ & $27 \pm 3.8$ & NS \\
\hline Follow up (days) & $397 \pm 47$ & $349 \pm 66$ & NS \\
\hline Median procedure time (minutes) & $212 \pm 47$ & $174 \pm 44$ & NS \\
\hline Fluoroscopy time (minutes) & $40 \pm 18$ & $34 \pm 13$ & NS \\
\hline \multicolumn{4}{|l|}{ Medical History } \\
\hline Hypertension (n, \%) & $14(31)$ & $18(40)$ & NS \\
\hline Atrial flutter (n, \%) & $5(11)$ & $4(9)$ & NS \\
\hline CAD (n, \%) & $9(20)$ & $8(18)$ & NS \\
\hline \multicolumn{4}{|l|}{ Medication history } \\
\hline Flecainide (n, \%) & $22(60.0)$ & $25(67.5)$ & NS \\
\hline Sotalol (n, \%) & $16(20.0)$ & $14(22.5)$ & NS \\
\hline Amiodarone (n, \%) & $4(10.0)$ & $5(7.5)$ & NS \\
\hline \multicolumn{4}{|l|}{ AF characteristics } \\
\hline Paroxysmal/persistent AF (n/n, \%/\%) & $40 / 5(89 / 11)$ & $39 / 6(87 / 13)$ & NS \\
\hline $\mathrm{AF}$ duration (years, mean $\pm \mathrm{SD}$ ) & $8 \pm 7.1$ & $7 \pm 3.8$ & NS \\
\hline $\operatorname{LVEF}(\%$, mean $\pm S D)$ & $56 \pm 6$ & $57 \pm 8$ & NS \\
\hline LA volume (cc, mean $\pm S D)$ & $72 \pm 14$ & $77 \pm 18$ & NS \\
\hline Number of prior electrical cardioversions ( $n, \%)$ & $9(20)$ & $10(22)$ & NS \\
\hline Number of prior pharmacological cardioversions ( $n, \%)$ & $10(22)$ & $7(16)$ & NS \\
\hline
\end{tabular}

$A F$, atrial fibrillation; $A F I$, atrial flutter; $B M I$, body mass index; $n$, numbers; $C A D$, coronary artery disease; $L A$, left atrial; LVEF, left ventricle ejection fraction; NS, not significant; SD, standard deviation.

\section{Adverse events}

Adenosine administration was associated with transient hypotension directly proportional to its dose. Facial flushing was present in six patients (13\%). Spontaneous recovery of phrenic nerve paralysis $(n=2)$ was observed within first 6 months of followup (Table 10.2). Two days after the procedure, one patient of the non-adenosine group was admitted because of haemoptysis, which was medically managed. ${ }^{12}$ This clinical symptom was attributed to $23 \mathrm{~mm}$ cryoballoon's deeper placement in a PV. ${ }^{12,13}$

\section{Follow-up}

Among all the 90 patients in the study, none of them was on AAD after a 3-month blanking period of ablation. After a mean follow-up of $397 \pm 47$ days for the adenosine group and $349 \pm 66$ days for no-adenosine group revealed a success rate of 84 and $79 \%$ of the patients were free from AF (Figure 10.2). No AF recurrence was observed during follow-up in patients in whom dormant reconduction was ablated irrespective of $\mathrm{AF}$ 
type (paroxysmal or persistent). Statistical analysis to rule out procedure failure due to longer follow-up of the adenosine group was insignificant.

Table 10.2 Adverse events.

\begin{tabular}{lcc}
\hline Adverse events $(\mathrm{n}, \%)$ & Adenosine $(\mathrm{n}=45)$ & No Adenosine $(\mathrm{n}=45)$ \\
\hline Groin complications & $1(2)$ & $1(2)$ \\
Phrenic nerve palsy & & $1(2)$ \\
$\quad$ After procedure & $1(2)$ & 0 \\
After 1 year & 0 & 0 \\
Facial flushing & $6(13 \%)$ & 0 \\
Transient hypotension & $6(13 \%)$ & 0 \\
Pericardial effusion/tamponade & 0 & $1(2)$ \\
Hemoptysis & 0 &
\end{tabular}

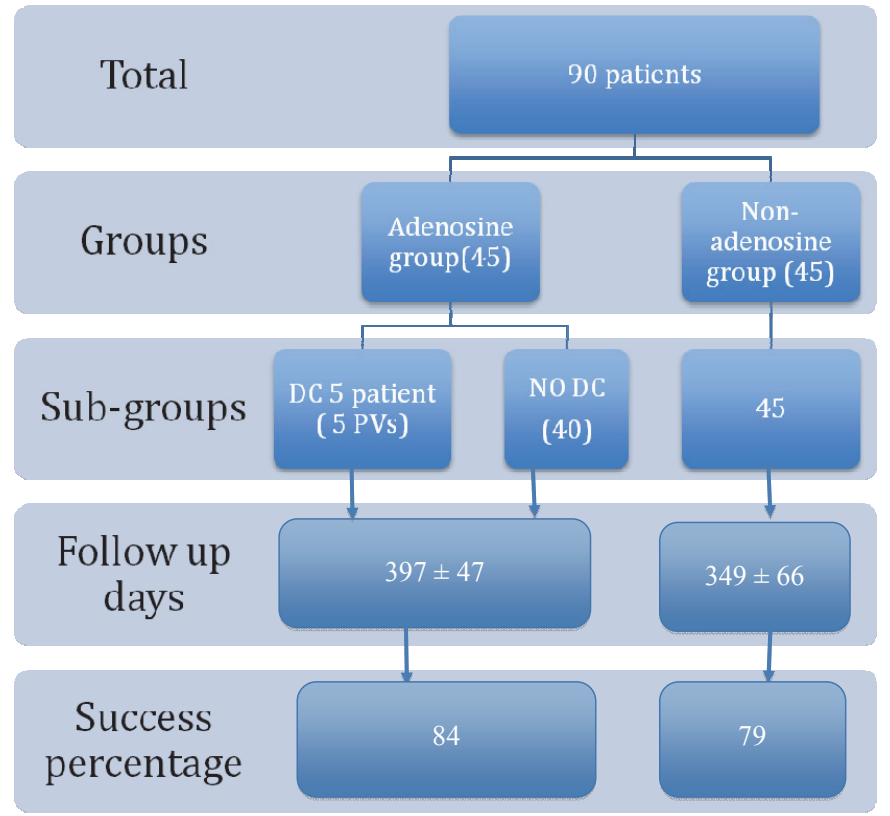

Figure 10.2 Scheme of patient's set-up during the ATSCA (Adenosine Testing after Second generation Cryoballoon Ablation) study.

\section{Discussion}

To the best of our knowledge, this is the first study reporting on the mid-term follow-up of adenosine administration after ablation using the CB-2G. Compared with the patients without adenosine administration after $\mathrm{CB}-2 \mathrm{G}$ ablation, the success rate was 
significantly higher in patients in whom dormant PV conduction was unmasked by adenosine and reablated (84 vs. $79 \%$ ). Moreover, none of the AF recurrence occurred in patients where reablation targeted the dormant reconduction.

Adenosine in cardiology has been used previously for conversion to sinus rhythm of paroxysmal supraventricular tachycardia, including that associated with accessory bypass tracts (Wolff-Parkinson-White syndrome). It also acts as an adjunct to thallium201 myocardial perfusion scintigraphy in patients finding difficult to exercise. An important predictor of recurrent $\mathrm{AF}$ after $\mathrm{PV}$ isolation is $\mathrm{PV}$ reconduction after the index procedure. ${ }^{14}$ The use of adenosine-guided ablation of dormant conduction is a useful approach to maximize the durability of PV isolation for AF ablation using radiofrequency; ${ }^{15,16}$ also after cryoablation. ${ }^{8}$

The CB-2G has been recently introduced with double freezing points than in first generation. The annual success rates for this procedure are better with lesser procedure time compared with first generation. The CB-2G provides the option of online recording of intracardiac electrograms of a PV using Achieve ${ }^{\mathrm{TM}}$. However, the procedure time and fluoroscopic time with CB-2G are longer compared with other balloon devices, such as laser balloon. ${ }^{10}$

Hyperpolarization of the resting membrane is the main mechanism leading to adenosine-induced PV dormant conduction. The prevalence of adenosine-induced PV reconnection using radiofrequency ablation is up to $25 \%$ patients. ${ }^{17}$ Van belle et al. ${ }^{8}$ observed reconduction in $25 \%$ of patients and $9 \%$ of veins using the first-generation cryoballoon after administration of adenosine. The lower reduction rate observed in our study is attributable to better ablation of a PV, secondary to double number of freezing points ( 8 instead of 4 ) together with their more distal location. ${ }^{18}$

During our previous study, we observed, 'Chances of arrhythmia recurrence after adenosine use tend to stabilize after approximately 1 year'. ${ }^{10}$ The acute success rate after adenosine use is different from other energy sources, e.g. radiofrequency, older cryoballoon, laser balloon, and epicardial bipolar radiofrequency ablation. Inferior PVs had more reconduction due to improper alignment of the cryoballoon leading to its less optimal contact at the ostium and subsequent incomplete ablation. ${ }^{19}$ We also did not observe any AF recurrence during the limited follow-up of patients in whom adenosineinduced dormant reconduction was targeted. ${ }^{9}$ For the cryoballoon ablation, RIPV has been attributed to have more reconduction due to poor alignment of the cryoballoon, resulting in poor contact of the balloon at the ostium and subsequent lack of complete ablation. ${ }^{19}$ Though, we did not notice zonal preference among the PVs of patients of with and without dormant LA-PV conduction.

Good occlusion is an important parameter for successful PV isolation. Experimental studies by Andrade et al. ${ }^{20}$ support big CB-2G compared with smaller one. However, considering practical smaller size of PVs in several patients, it may be necessary to use smaller size cryoballoon. ${ }^{21,22}$ Although $23 \mathrm{~mm} \mathrm{CB}-2 \mathrm{G}$ is associated with lower temperature, during the study we did not appreciate any significant association of PNPS 
with smaller size CB-2G.We actively monitored for PNPs, by placing palm of a physician/nurse/assistant over the patient's diaphragm region. Direct visualization of diaphragmatic contraction or hiccoughs, and occasional flash of fluoroscopy in case of any doubt were also used. In case of any missing diaphragmatic contraction (even if in case of occasional loss of phrenic nerve capture due to misalignment of pacing catheter), cryoablation was immediately aborted.

One patient among the non-adenosine group developed haemoptysis on next day after PV ablation and was symptomatic throughout day. Acenocoumarol was immediately interrupted and replaced by low molecular weight heparin immediately on presentation to the hospital on day 3 after procedure. Haemoptysis episodes were of mild type, i.e. the expectoration volume was $50 \mathrm{~mL}(25-40 \mathrm{~mL})$ of blood in $24 \mathrm{~h}$. Chest radiogram and international normalized ratio were within normal limits. As soon as the haemoptysis had been stopped, an immediate bronchoscopy showed hyperaemic mucosa and erosion. High-resolution CT was performed for the patient on the same day of presentation with haemoptysis. Computed tomography scans revealed ground glass opacification in the RIPV but did not show any PV stenosis later during follow-up. ${ }^{23,24}$ Retrospectively, the statistical analysis further pointed to lower temperature of the RIPV $\left(65 \pm 7^{\circ} \mathrm{C}\right)$ compared with that of the control group $\left(57.5 \pm 21.08{ }^{\circ} \mathrm{C} ; \mathrm{p}=0.025\right)$, and also deeper positioning of a $23 \mathrm{~mm}$ cryoballoon. ${ }^{25}$

Adenosine following PV isolation to target dormant conduction elimination (ADVICE) trial, which randomized patients with dormant PV conduction to further adenosineguided ablation vs. no ablation, proved that it is worthwhile to ablate dormant reconduction. ${ }^{26}$ This study strengthens the concept of adenosine provocation to target acute PV reconnections during cryoablation and to achieve the goal of longer maintenance of sinus rhythm. To the best of our knowledge, this is the first study to prove the benefit of ablating adenosine-induced dormant conduction after CB-2G ablation.

\section{Limitations}

The study population is constrained by its small sample size. There is evidence to indicate the clinical utilities of adenosine test after second-generation balloon-based devices; however, this study may not provide statistically significant scientific comparison necessary to favour clinical benefit from ablating late dormant PVs. A prospective randomized trial is necessary to firmly establish this postulate. The utility of this approach needs evaluation in long-term prospective randomized studies. 


\section{Conclusions}

Adenosine testing after PV isolation using a CB-2G reveals dormant conduction in initially isolated PVs and ablating them improves annual success results. This approach needs further evaluation in a long-term prospective randomized study. 


\section{References}

1. Haissaguerre M, Jais P, Shah DC, Takahashi A, Hocini M, Quiniou G et al. Spontaneous initiation of atrial fibrillation by ectopic beats originating in the pulmonary veins. N Engl J Med 1998;339:659-666.

2. Ouyang F, Antz M, Ernst S, Hachiya $H$, Mavrakis $H$, Deger FT et al. Recovered pulmonary vein conduction as a dominant factor for recurrent atrial tachyarrhythmias after complete circular isolation of the pulmonary veins: lessons from double Lasso technique. Circulation 2005;111:127-135.

3. Klein G, Oswald H, Gardiwal A, Lusebrink U, LisselC, YuHet al. Efficacy of pulmonary vein isolation by cryoballoon ablation in patients with paroxysmal atrial fibrillation. Heart Rhythm 2008;5:802-806.

4. Coulombe N, Paulin J, SuW. Improved in vivo performance of second-generation cryoballoon for pulmonary vein isolation. J Cardiovasc Electrophysiol 2013;24:919-925.

5. Giovanni GD, Wauters K, Chierchia GB, Sieira J, Levinstein M, Conte G et al. One-year follow-up after single procedure cryoballoon ablation: a comparison between the first and second generation balloon. J Cardiovasc Electrophysiol 2014;25:834-839.

6. Hachiya H, Hirao K, Takahashi A, Nagata Y, Suzuki K, Maeda S et al. Clinical implications of reconnection between the left atrium and isolated pulmonary veins provoked by adenosine triphosphate after extensive encircling pulmonary vein isolation. J Cardiovasc Electrophysiol 2007;18:392-398.

7. Datino T, Macle L, Qi XY, Maguy A, Comtois P, Chartier D et al. Mechanisms by which adenosine restores conduction in dormant canine pulmonary veins. Circulation 2010;121:963-972.

8. Van Belle YL, Janse PA, de Groot NM, AnneW, Theuns DA, Jordaens L. Adenosine testing after cryoballoon pulmonary vein isolation improves long-term clinical outcome. Netherlands Heart J 2012;20:447-455.

9. Ciconte G, Chierchia GB, DE Asmundis C, Sieira J, Conte G, Julia J et al. Spontaneous and adenosineinduced pulmonary vein reconnection after cryoballoon ablation with the second-generation device. J Cardiovasc Electrophysiol 2014.

10. Kumar N, Blaauw Y, Timmermans C, Pison L, Vernooy K, Crijns H. Adenosine testing after secondgeneration balloon devices (cryothermal and laser) mediated pulmonary vein ablation for atrial fibrillation. J Intervent Cardiac Electrophysiol 2014.

11. Calkins H, Kuck KH, Cappato R, Brugada J, Camm AJ, Chen SA et al. 2012 HRS/EHRA/ECAS expert consensus statement on catheter and surgical ablation of atrial fibrillation: recommendations for patient selection, procedural techniques, patient management and follow-up, definitions, endpoints, and research trial design. J Intervent Cardiac Electrophysiol 2012;33:171-257.

12. KumarN, Timmermans C, Pison L, Crijns H. Hemoptysis: deja vu for cryoballoon use for pulmonary vein isolation for atrial fibrillation ablation. Chest 2014;145:1435.

13. Kumar N, Timmermans C, Das M, Pison L, Maessen J, Crijns H. Re: CT imaging of complications of catheter ablation for atrial fibrillation. Clin Radiol 2014;69:e367-368.

14. Verma A, Kilicaslan F, Pisano E, Marrouche NF, Fanelli R, Brachmann J et al. Response of atrial fibrillation to pulmonary vein antrum isolation is directly related to resumption and delay of pulmonary vein conduction. Circulation 2005;112:627-635.

15. Reichlin T, Michaud GF. Our approach to maximizing the durability of pulmonary vein isolation during a paroxysmal atrial fibrillation ablation procedure. J Cardiovasc Electrophysiol 2012;23:1272-1276.

16. KumarN, Pison L, La Meir M, Maessen J, Crijns HJ.Testing of box lesion by adenosine. J Atrial Fibrillation 2013-2014; 6.

17. Matsuo S, Yamane $T$, Date $T$, Inada K, Kanzaki Y, Tokuda M et al. Reduction of AF recurrence after pulmonary vein isolation by eliminating ATP-induced transient venous re-conduction. J Cardiovasc Electrophysiol 2007;18:704-708.

18. Furnkranz A, Bordignon S, Schmidt B, Gunawardene M, Schulte-Hahn B, Urban V et al. Improved procedural efficacy of pulmonary vein isolation using the novel second-generation cryoballoon. J Cardiovasc Electrophysiol 2013;24:492-497.

19. Furnkranz A, Chun KR, Nuyens D, Metzner A, Koster I, Schmidt B et al. Characterization of conduction recovery after pulmonary vein isolation using the "single big cryoballoon" technique. Heart Rhythm 2010;7:184-190. 
20. Andrade JG, Dubuc M, Guerra PG, Landry E, Coulombe N, LeducHet al. Pulmonary vein isolation using a second-generation cryoballoon catheter: a randomized comparison of ablation duration and method of deflation. J Cardiovasc Electrophysiol 2013;24:692-698.

21. Malmborg H, Lonnerholm S, Blomstrom-Lundqvist C. Acute and clinical effects of cryoballoon pulmonary vein isolation in patients with symptomatic paroxysmal and persistent atrial fibrillation. Europace 2008;10:1277-1280.

22. Defaye P, Kane A, Chaib A, Jacon P. Efficacy and safety of pulmonary veins isolation by cryoablation for the treatment of paroxysmal and persistent atrial fibrillation. Europace 2011;13:789-795.

23. Kumar N, Phan K, Pison L, Maessen J. Re: Clinical characteristics and prognostic significance of chronic obstructive pulmonary disease in patients with atrial fibrillation: results from a multicenter atrial fibrillation registry study. J Am Med Dir Assoc 2014.

24. Kumar N, Phan K, Timmermans C, Pison L, Meir ML, Maessen J et al. Catheter ablation of atrial fibrillation: the missing links. Eur Heart J 2014.

25. Kumar N, Timmermans C, Das M, DassenW, Phillippens S, Maessen J et al. Hemoptysis after cryoablation for atrial fibrillation: truth or just a myth? Chest 2014.

26. Macle L, Khairy P, Verma A,Weerasooriya R, Willems S, Arentz T et al. Adenosine following pulmonary vein isolation to target dormant conduction elimination (ADVICE): methods and rationale. Can J Cardiol 2012;28:184-190. 


\section{Chapter 11}

General discussion

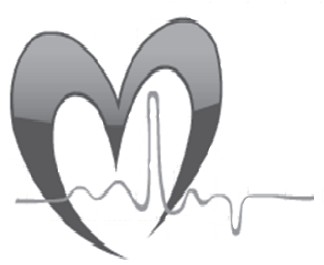


Chapter 11 


\section{General discussion}

Atrial fibrillation (AF) is the most common arrhythmia having significant morbidity and mortality; pulmonary vein (PV) isolation is considered to be the key for its treatment. With the passage of time the ablation lines between the PVs and the atrium resume conduction that may lead to AF recurrence. The technologies used currently and the ones that could be used in future for the treatment of AF are immense and represent just some of the most exciting opportunities to improve the quality of cardiac care. However, they may also be associated with substantial costs to the healthcare providers. It is therefore imperative that their effectiveness is understood to support their appropriate introduction to clinical practice.

This thesis aims to describe key emerging AF ablation techniques, their applications, several complications that are associated with their use, and possible solutions. It details the most promising emerging arrhythmia technologies and their potential to influence the patient care by arrhythmologists including a cardiac surgeon or, and an electrophysiologist. Just as every coin has two sides, so too do these ablation technologies. They are used with good intention to treat the arrhythmias and prevent their recurrences, however, inadvertent side effects also occur. The potential of a technology to improve quality of care, including its effectiveness and efficiency, remains the main goal. This thesis also highlights some complications reported with these technologies that an arrhythmologists and health care providers should keep in mind, when systematically introducing such techniques to a large pool of patients. This thesis does not intend to make any specific recommendations on which techniques policymakers should rely.

The basic concept for the AF cardiac surgeon was to compartmentalize the atrial chambers into areas small enough to prevent the occurrence of re-entry circuits. By putting this idea into practice with the Maze procedure, the cutting lines stop the propagation of the activation and make it impossible for the substrate to fibrillate. Developed in 1987, and after several modifications, this procedure remains the gold standard of the cardiac surgeon's approach to AF. With a success rate exceeding $90 \%$ in many centers, this procedure is applied whenever a patient with AF presents with an indication for open-heart surgery.

Haissaguerre et al. observed ectopic electric activity, which initiate episodes of paroxysmal AF originate from the PVs. Ongoing progress regarding online anatomic imaging, atrial electrical activity mapping, and applied 'coagulation' area visualization make it reasonable to conceive that, in the not so distant future, computer-based programs, integrating anatomical and electrocardiographic information, will allow for the design of individualized ideal ablation patterns prior to the intervention.

Pitfalls for an AF ablation procedure include complications such as hemoptysis, lung hernia and PV stenosis. Potential solutions include the use of new devices such as a contact force catheter, a combination of epicardial radiofrequency and endocardial 
cryoballoon ablation, drug administration (adenosine) etc. There are several ways to treat AF using ablation techniques.

\section{Endocardial AF ablation}

Catheter ablation lesions mimic the Maze procedure avoiding the invasiveness of openheart surgery. The search for continuous refinement of this approach is reflected in the discussions concerning the appropriate mapping techniques as well as the choice of ablation devices that are in use or under development, ranging from heating to freezing. All of them share a common endpoint of generating not only continuous but also transmural lines blocking electrical conduction. Large surveys have been conducted that included patients with all types of AF but only minimal information is available regarding ablation targets. Controlled clinical studies have shown favorable outcomes, but the most sensitive drawback of catheter ablation is the frequent need for reinvention. The high recurrence rate (including a high rate of silently recurring AF), the lack of documentation of long-term hemodynamic benefits, and the small number of available cost - benefit data remain of concern. Even in the absence of a unanimously accepted definition of recurrence, the ablation of CFAEs (Complex Fractionated Atrial Electrograms) alone (i.e. without PV isolation) showed an $80 \%$ recurrence rate of $A F$ in the Substrate and Trigger Ablation for Reduction of Atrial Fibrillation (STAR AF) trial.

There is limited literature available regarding PV stenosis management. Starting from its incidence to the follow-up using imaging technologies to monitor the success and the way of management, different groups have varied opinions. PV stenosis remains a potential complication of catheter ablation for $\mathrm{AF}$, with a reported incidence varying from $1 \%$ to $21 \%$. With growing awareness of such a complication and the improved management, PV stenosis continues to decrease which is in the best interests of not only the patients and but physicians too.

Cryoballoon ablation is an effective therapy to treat AF. Recently, the secondgeneration cryoballoon has been introduced. This catheter has a larger and more homogeneous freezing zone that leads to lower temperatures, faster procedures and an improved success rate. Complications of cryoenergy ablation may be due to damage of structures close to the application site resulting in phrenic nerve paralysis, gastroparesis, atrio-esophageal fistula or oesophageal lesions. Only a few reports have described lung injury after cryo ablation, in about $35 \%$ of the animals. Previously, we summarized the relationship between cryoablation and hemoptysis with evidence ranging from several animal studies and to case reports. Between 2010 and 2013, we retrospectively analyzed patients with hemoptysis after cryoablation at Maastricht. We concluded that hemoptysis is an uncommon side effect associated with cryoballoon ablation for AF attributable to a deep position of the cryoballoon in a PV and low temperature during cryoablation. 
Adenosine testing has been used for cryoballoon (first and second generation), laser balloon, and radiofrequency ablation, and targeting dormant PV conduction may increase procedure success rate. Ciconte et al. observed adenosine induced conduction occurred in $4 \%$ of the patients after second generation cryoballoon and reported that $86 \%$ of the patients were free from AF after a follow-up of 7 months only. However, our group observed that the success rate for second generation balloon devices tends to stabilize only after a follow-up a year.. If needed, further ablation using a cryoballoon and/or cryocatheter was performed until no reconduction was observed after repeat adenosine administration. The success rate for adenosine group was higher than in without adenosine group. The Adenosine Testing after Second generation Cryoballoon Ablation (ATSCA) study showed that re-ablation of initially isolated PVs increases the clinical success rate for AF.

The endoscopic ablation system (EAS) is a recently introduced endocardial catheter ablation device and using a laser energy source for ablation. Adenosine testing after PV isolation using second-generation balloon based energy devices such as EAS and cryoballoon revealed dormant conduction in initially isolated PVs and ablating yields similar annual success results for both systems.

\section{Hybrid ablation}

Neither the endocardial approach nor the surgical ablation procedure alone may define the specific properties of the underlying atrial electrical substrate or warrant the isolation of PVs permanently. However, both techniques seem to be complementary as when performed in combination. The epicardial application of bipolar RF clamps to the PVs result in more persistent antral lesions. During an epicardial application, direct anatomical visualization and stable catheter tip-tissue contact are obtained. Moreover, the effect of the circulating blood on the delivery of power is excluded due to clamping of the tissue between two jaws. However, difficult anatomy and epicardial fat may obscure transmurality. The epicardial approach also partially eliminates the ganglionated plexi and allows a safer exclusion of the left atrial appendage. The endocardial approach may confirm the quality of the lesion set, and allows to make a left and right isthmus line and to eliminate CFAEs. Both approaches when done together, have the potential to reduce complications related to the individual procedures. The combined approach avoids the necessity for a more invasive surgical procedure on the epicardial side and the very limited endpoints of acute exit and entry block can be improved by a more complete endocardial mapping. On the endocardial side, the hybrid approach avoids complications such as tamponade, phrenic nerve injury, oesophageal fistula, and prolonged fluoroscopy. The risk of thrombo-embolic events with the epicardial technique is almost non-existing.

It is well known that COPD (chronic obstructive pulmonary disease) is an independent risk factor for cardiovascular mortality; and that, "AF and COPD usually aggravate each other, making the treatment complicated." B. Huang et al. reported on the clinical 
characteristics and prognostic significance of these 2 common morbidities, AF and COPD. The long-term ( 3 years) follow-up of after ablation of patients suffering from AF and COPD-Global Initiative for Chronic Obstructive Lung Disease (GOLD) class 4 patients. is encouraging when using a unique approach of endocardial cryoballoon and epicardial bipolar radiofrequency devices at Maastricht. The most common side effect when using a cryoballoon for the right superior PV is phrenic nerve paralysis (even though transient), is that it may deteriorate the lung vitals of a patient. Most of COPD patients tend to have obesity; which is an independent risk factor and increasing the propensity up to 2.4 times to develop AF.

We reported the effect of a hybrid procedure on the $P$ wave duration (PWD), calculated automatically from the surface ECG leads at the start and end of the intervention. We also studied the relationship between PWD and AF recurrence during follow-up. A hybrid procedure reduced PWD significantly more in persistent patients than paroxysmal ones. Based on this information, AF therapy may be individualized in the future.

To the best of our knowledge there is no supporting literature where adenosine reveals conduction across box lesion and we shared our experience in a small set of patients. Datino et al. described about significant hyperpolarization of resting membrane potential (RMP) only in pulmonary vein (PV) cells compared to left atrium (LA) attributing to due to larger IKAdo and smaller IK1. This finding has support on molecular level too.

Reconduction across an ablation line is the most common reason for an arrhythmia recurrence over time e.g. PVs and linear lesions. To create a transmural lesion, contact force (CF) between the ablation tip and cardiac tissue is a major determinant parameter for radiofrequency catheters and its monitoring is a significant new parameter. Use of CF catheters is safe, feasible, and complementary to hybrid procedure setup for AF ablation. It's real time monitoring may predict future arrhythmia recurrence, and decrease procedure time.

With an increasing number of arrhythmia treatment procedures in the future, cardiac surgeons, and physicians must be watchful for complications. An atraumatic lung hernia is a rare entity secondary to minimally invasive cardiac surgery. It has never been described secondary to a lateral approach. We concluded the main culprit to be the extra operative trauma due to the widening of the mini invasions to accommodate an epicardial left atrial appendage clip and the patient needs to limit his/her activity during the period of chest-wall healing. 


\section{References}

1. Kirchhof P, Auricchio A, Bax J, Crijns H, Camm J, Diener HC, et al. Outcome parameters for trials in atrial fibrillation: executive summary. Eur Heart J, 2007;28:2803-17.

2. Haissaguerre M, Jais P, Shah DC, Takahashi A, Hocini M, Quiniou G, et al. (1998). Spontaneous initiation of atrial fibrillation by ectopic beats originating in the pulmonary veins. N Engl J Med 1998;339:659-66.

3. Cappato, R., Negroni, S., Pecora, D., Bentivegna, S., Lupo, P. P., Carolei, A., et al. (2003). Prospective assessment of late conduction recurrence across radiofrequency lesions producing electrical disconnection at the pulmonary vein ostium in patients with atrial fibrillation. Circulation, 2003;108:1599-604.

4. Ouyang F, Antz M, Ernst S, Hachiya H, Mavrakis H, Deger FT, et al. Recovered pulmonary vein conduction as a dominant factor for recurrent atrial tachyarrhythmias after complete circular isolation of the pulmonary veins: lessons from double Lasso technique. Circulation 2005;111:127-35.

5. Cox JL, Schuessler RB, D'Agostino HJ Jr, Stone CM, Chang BC, Cain ME, et al. The surgical treatment of atrial fibrillation. III. Development of a definitive surgical procedure. J Thorac Cardiovasc Surg 1991; 101:569-83.

6. Damiano RJ Jr, Schwartz FH, Bailey MS, Maniar HS, Munfakh NA, Moon MR, et al. The Cox maze IV procedure: predictors of late recurrence. J Thorac Cardiovasc Surg 2011;141:113-21.

7. Kumar N, Pison L, La Meir M, Maessen J, Crijns HJ. Hybrid approach to atrial fibrillation ablation using bipolar radiofrequency devices epicardially and cryoballoon endocardially. Interact Cardiovasc Thorac Surg 2014;19:590-4.

8. Kumar N, Blaauw Y, Timmermans C, Pison L, Vernooy K, Crijns H. Adenosine testing after secondgeneration balloon devices (cryo and laser) pulmonary vein ablation for atrial fibrillation. J Interv Card Electrophysiol 2014;41:91-7.

9. Kumar N, Pison L, La Meir M, Maessen J, Crijns HJ. Safety and feasibility of use of contact force catheter during hybrid procedure for atrial fibrillation ablation. Innovations:Technology and Techniques in Cardiothoracic and Vascular Surgery 2014;9:190-227 110.1097/

10. Kappenberge L. A new look at atrial fibrillation: lessons learned from drugs, pacing, and ablation therarpies. Eur Heart J 2013;34:2739-45a.

11. Cappato R, Calkins H, Chen SA, Davies W, lesaka Y, Kalman J, et al. Updated worldwide survey on the methods, efficacy, and safety of catheter ablation for human atrial fibrillation. Circ Arrhythm Electrophysiol 2010;3:32-8.

12. Calkins H, Kuck KH, Cappato R, Brugada J, Camm AJ, Chen SA, et al. 2012 HRS/EHRA/ECAS Expert Consensus Statement on Catheter and Surgical Ablation of Atrial Fibrillation: recommendations for patient selection, procedural techniques, patient management and follow-up, definitions, endpoints, and research trial design. Europace 2012;14:528-606.

13. Dang L, Virag N, Ihara Z, Jacquemet V, Vesin JM, Schlaepfer J, et al. Evaluation of ablation patterns using a biophysical model of atrial fibrillation. Ann Biomed Eng 2005;33:465-74.

14. Nademanee K, McKenzie J, Kosar E, Schwab M, Sunsaneewitayakul B, Vasavakul T, et al. A new approach for catheter ablation of atrial fibrillation: mapping of the electrophysiologic substrate. J Am Coll Cardiol 2004;43:2044-53.

15. Verma A, Mantovan R, Macle L, De Martino G, Chen J, Morillo CA, et al. Substrate and Trigger Ablation for Reduction of Atrial Fibrillation (STAR AF): a randomized, multicentre, international trial. Eur Heart J 2010;31:1344-56.

16. Neumann T, Vogt J, Schumacher B, Dorszewski A, Kuniss M, Neuser H, et al. Circumferential pulmonary vein isolation with the cryoballoon technique results from a prospective 3-center study. J Am Coll Cardiol 2008;52:273-8.

17. Klein G, Oswald H, Gardiwal A, Lusebrink U, Lissel C, Yu H, et al. Efficacy of pulmonary vein isolation by cryoballoon ablation in patients with paroxysmal atrial fibrillation. Heart Rhythm 2008;5:802-6.

18. Furnkranz A, Bordignon S, Schmidt B, Gunawardene M, Schulte-Hahn B, Urban V, et al. Improved procedural efficacy of pulmonary vein isolation using the novel second-generation cryoballoon. J Cardiovasc Electrophysiol 2013;24:492-7. 
19. Andrade JG, Dubuc M, Guerra PG, Landry E, Coulombe N, Leduc H, et al. Pulmonary vein isolation using a second-generation cryoballoon catheter: a randomized comparison of ablation duration and method of deflation. J Cardiovasc Electrophysiol 2013;24:692-8.

20. Coulombe N, Paulin J, Su W. Improved in vivo performance of second-generation cryoballoon for pulmonary vein isolation. J Cardiovasc Electrophysiol 2013;24:919-25.

21. Saad EB, Rossillo A, Saad CP, Martin DO, Bhargava M, Erciyes D, et al. Pulmonary vein stenosis after radiofrequency ablation of atrial fibrillation: functional characterization, evolution, and influence of the ablation strategy. Circulation 2003;108:3102-7.

22. Di Biase L, Fahmy TS, Wazni OM, Bai R, Patel D, Lakkireddy D, et al. Pulmonary vein total occlusion following catheter ablation for atrial fibrillation: clinical implications after long-term follow-up. J Am Coll Cardiol 2006;48:2493-9.

23. Dong J, Vasamreddy CR, Jayam V, Dalal D, Dickfeld T, Eldadah Z, et al. Incidence and predictors of pulmonary vein stenosis following catheter ablation of atrial fibrillation using the anatomic pulmonary vein ablation approach: results from paired magnetic resonance imaging. J Cardiovasc Electrophysiol 2005;16:845-52.

24. Holmes DR Jr, Monahan KH, Packer D. Pulmonary vein stenosis complicating ablation for atrial fibrillation: clinical spectrum and interventional considerations. JACC Cardiovasc Interv 2009;2:267-76.

25. Saad EB, Marrouche NF, Saad CP, Ha E, Bash D, White RD, et al. Pulmonary vein stenosis after catheter ablation of atrial fibrillation: emergence of a new clinical syndrome. Ann Intern Med 2003;138:634-8.

26. Arentz T, Jander N, von Rosenthal J, Blum T, Furmaier R, Gornandt L, et al. Incidence of pulmonary vein stenosis 2 years after radiofrequency catheter ablation of refractory atrial fibrillation. Eur Heart J 2003;24:963-9.

27. Kumar N, Phan K, Aksoy I, Pison L, Timmermans C, Maessen J, et al. Management of pulmonary vein stenosis following catheter ablation of atrial fibrillation. JAFIB: Journal of Atrial Fibrillation 2014;7(1).

28. Huang B, Yang Y, Zhu J, Liang $Y$, Zhang H, Tian L, et al. Clinical characteristics and prognostic significance of chronic obstructive pulmonary disease in patients with atrial fibrillation: results from a multicenter atrial fibrillation registry study. J Am Med Dir Assoc 2014;15:576-81.

29. Kumar N, Phan K, Pison L, Maessen J. Re: Clinical characteristics and prognostic significance of chronic obstructive pulmonary disease in patients with atrial fibrillation: results from a multicenter atrial fibrillation registry study. J Am Med Dir Assoc 2015;16:82-3.

30. Abe K, Oka J, Takahashi H, Funatsu T, Fukuda H, Miyamoto Y. Effect of high-frequency jet ventilation on oxygenation during one-lung ventilation in patients undergoing thoracic aneurysm surgery. J Anesth 2006;20:1-5.

31. Vestbo J, Hurd SS, Agusti AG, Jones PW, Vogelmeier C, Anzueto A, et al. Global strategy for the diagnosis, management, and prevention of chronic obstructive pulmonary disease: GOLD executive summary. Am J Respir Crit Care Med 2013;187:347-65.

32. Kuhne, M., Knecht, S., Altmann, D., Kawel, N., Ammann, P., Schaer, B., et al. Phrenic nerve palsy during ablation of atrial fibrillation using a 28- $\mathrm{mm}$ cryoballoon catheter: predictors and prevention. J Interv Card Electrophysiol 2013;36:47-54.

33. Magnani, J. W., Hylek, E. M., \& Apovian, C. M. Obesity begets atrial fibrillation: a contemporary summary. Circulation, 2013;128:401-5.

34. Kuck, K. H., \& Furnkranz, A. Cryoballoon ablation of atrial fibrillation. J Cardiovasc Electrophysiol 2010;21:1427-31.

35. Guiot A, Savoure A, Godin B, Anselme F. Collateral nervous damages after cryoballoon pulmonary vein isolation. J Cardiovasc Electrophysiol 2012;23:346-51.

36. Stockigt F, Schrickel JW, Andrie R, Lickfett L. Atrioesophageal fistula after cryoballoon pulmonary vein isolation. J Cardiovasc Electrophysiol 2012;23:1254-7.

37. Furnkranz A, Bordignon S, Schmidt B, Bohmig M, Bohmer MC, Bode F, et al. Luminal esophageal temperature predicts esophageal lesions after second-generation cryoballoon pulmonary vein isolation. Heart Rhythm 2013;10:789-93.

38. Bhagwandien R, Van Belle Y, De Groot N, Jordaens L. (2011). Hemoptysis after pulmonary vein isolation with a cryoballoon: an analysis of the potential etiology. J Cardiovasc Electrophysiol 2011;22:1067-9. 
39. Vogt J, Heintze J, Muntean B, Scholz U, Luong LT, Horstkotte D. Long-term success and side effects of antral isolation of pulmonary veins with cryoballoon technique in a large patient cohort with atrial fibrillation. In Journal of the American College of Cardiology, 2009 (Vol. 53, pp. A116-A116, Vol. 10): ELSEVIER SCIENCE INC 360 PARK AVE SOUTH, NEW YORK, NY 10010-1710 USA

40. Weig H, Weretka S, Parade U, Rueb N, Laszlo R, Gawaz M, et al. Cryo-specific complications using the single big cryoballoon technique for pulmonary vein isolation in patients with paroxysmal atrial fibrillation. In Eur Heart J 2010;31:556-556: OXFORD UNIV PRESS GREAT CLARENDON ST, OXFORD OX2 6DP, ENGLAND

41. Defaye $P$, Kane A, Chaib A, Jacon P. Efficacy and safety of pulmonary veins isolation by cryoablation for the treatment of paroxysmal and persistent atrial fibrillation. Europace 2011;13:789-95.

42. Rabb JM, Renaud ML, Brandt PA, Witt CW. Effect of freezing and thawing on the microcirculation and capillary endothelium of the hamster cheek pouch. Cryobiology 1974;11:508-18.

43. Hoffmann NE, Bischof JC. The cryobiology of cryosurgical injury. Urology 2002;60:40-9.

44. Chapman WC, Debelak JP, Blackwell TS, Gainer KA, Christman JW, Pinson CW, et al. Hepatic cryoablation-induced acute lung injury: pulmonary hemodynamic and permeability effects in a sheep model. Archives of Surgery 2000;135:667.

45. Sadikot R, Wudel LJ Jr, Jansen D, Debelak J, Yull F, Christman J, et al. Hepatic cryoablation-induced multisystem injury: Bioluminescent detection of NF-KB activation in a transgenic mouse model. Journal of Gastrointestinal Surgery 2002;6:264-70.

46. Washington K, Debelak JP, Gobbell C, Sztipanovits DR, Shyr Y, Olson S, et al. Hepatic cryoablationinduced acute lung injury: histopathologic findings. J Surg Res 2001;95;1-7.

47. Blackwell TS, Debelak JP, Venkatakrishnan A, Schot DJ, Harley DH, Pinson CW, et al. Acute lung injury after hepatic cryoablation: correlation with NF-kappa B activation and cytokine production. Surgery 1999;126:518-26.

48. Kumar N, Timmermans C, Pison L, Crijns HJ. Hemoptysis: déjà vu for cryoballoon use for pulmonary vein isolation for atrial fibrillation ablation.. Chest. 2014;145:1435..

49. Neel HB 3rd, Farrell KH, Payne WS, DeSanto LW. Cryosurgery of respiratory structures. II. Cryonecrosis of the lung. Laryngoscope 1974;84:417-26.

50. Avitall B, Lafontaine D, Rozmus G, Adoni N, Le KM, Dehnee A, et al. The safety and efficacy of multiple consecutive cryo lesions in canine pulmonary veins-left atrial junction. Heart Rhythm 2004;1:203-9.

51. Avitall B, Urboniene D, Rozmus G, Lafontaine D, Helms R, Urbonas A. New cryotechnology for electrical isolation of the pulmonary veins. J Cardiovasc Electrophysiol 2003;14:281-6.

52. Tuesday, 1 September 2009. Eur Heart J 2009;30(suppl 1):587-843.

53. Monday, 30 August 2010. Eur Heart J 2010;31(suppl 1):297-587.

54. Conte G, Chierchia GB, Casado-Arroyo R, Ilsen B, Brugada P. Pulmonary vein intramural hematoma as a complication of cryoballoon ablation of paroxysmal atrial fibrillation. J Cardiovasc Electrophysiol 2013;24:830-1.

55. Ferrero-de Loma-Osorio A, Izquierdo-de Francisco M, Martinez-Brotons A, Sanchez-Gomez JM, Mascarell-Gregori B, Ruiz-Ros V, et al. Medium-term results of cryoballoon ablation of the pulmonary veins in patients with paroxysmal and persistent atrial fibrillation. First experience of a Spanish center. J Interv Card Electrophysiol 2013;37:189-96.

56. Kumar N, Timmermans C, Das M, Pison L, Maessen J, Crijns H. Re: CT imaging of complications of catheter ablation for atrial fibrillation. Clin Radiol 2014;69:e367-8..

57. Kumar N, Phan K, Timmermans C, Pison L, Meir ML, Maessen J, et al. (2014). Catheter ablation of atrial fibrillation: The missing links. Eur Heart J. doi:10.1093/eurheartj/ehu291

58. Kumar N, Timmermans C, Das M, Dassen W, Philippens S, Maessen J, et al. Hemoptysis after cryoablation for atrial fibrillation: Truth or just a myth? Chest 2014;5:e173-e175.

59. Reddy VY, Neuzil P, Themistoclakis S, Danik SB, Bonso A, Rossillo A, et al. Visually-guided balloon catheter ablation of atrial fibrillation: experimental feasibility and first-in-human multicenter clinical outcome. Circulation 2009;120:12-20.

60. Metzner A, Schmidt B, Fuernkranz A, Wissner E, Tilz RR, Chun KR, et al. One-year clinical outcome after pulmonary vein isolation using the novel endoscopic ablation system in patients with paroxysmal atrial fibrillation. Heart Rhythm 2011;8:988-93. 
61. Dukkipati SR, Kuck KH, Neuzil P, Woollett I, Kautzner J, McElderry HT, et al. Pulmonary vein isolation using a visually guided laser balloon catheter: the first 200-patient multicenter clinical experience. Circ Arrhythm Electrophysiol 2013;6:467-72.

62. Dukkipati SR, Neuzil P, Kautzner J, Petru J, Wichterle D, Skoda J, et al. The durability of pulmonary vein isolation using the visually guided laser balloon catheter: multicenter results of pulmonary vein remapping studies. Heart Rhythm 2012;9:919-25.

63. Metzner A, Wissner E, Schmidt B, Chun J, Hindricks G, Piorkowski C, et al. Acute and long-term clinical outcome after endoscopic pulmonary vein isolation: results from the first prospective, multicenter study. J Cardiovasc Electrophysiol 2013;24:7-13.

64. Arentz T, Macle L, Kalusche D, Hocini M, Jais $P$, Shah D, et al. "Dormant" pulmonary vein conduction revealed by adenosine after ostial radiofrequency catheter ablation. J Cardiovasc Electrophysiol 2004;15:1041-7.

65. Tritto M, De Ponti R, Salerno-Uriarte JA, Spadacini G, Marazzi R, Moretti P, et al. Adenosine restores atrio-venous conduction after apparently successful ostial isolation of the pulmonary veins. Eur Heart J 2004;25:2155-63.

66. Hachiya H, Hirao K, Takahashi A, Nagata Y, Suzuki K, Maeda S, et al. Clinical implications of reconnection between the left atrium and isolated pulmonary veins provoked by adenosine triphosphate after extensive encircling pulmonary vein isolation. J Cardiovasc Electrophysiol 2007;18:392-8.

67. Datino T, Macle L, Qi XY, Maguy A, Comtois P, Chartier D, et al. Mechanisms by which adenosine restores conduction in dormant canine pulmonary veins. Circulation 2010;121:963-72.

68. Freilich A, Tepper D. Adenosine and its cardiovascular effects. Am Heart J 1992;123:1324-8.

69. Van Belle YL, Janse PA, de Groot NM, Anne W, Theuns DA, Jordaens LJ. Adenosine testing after cryoballoon pulmonary vein isolation improves long-term clinical outcome. Neth Heart J 2012;20: 447-55.

70. Miyazaki S, Kobori A, Hocini M, Shah AJ, Komatsu Y, Taniguchi $H$, et al. Clinical utility of adenosineinfusion test at a repeat atrial fibrillation ablation procedure. Heart Rhythm 2013;10:629-35.

71. Verma A, Kilicaslan F, Pisano E, Marrouche NF, Fanelli R, Brachmann J, et al. Response of atrial fibrillation to pulmonary vein antrum isolation is directly related to resumption and delay of pulmonary vein conduction. Circulation 2005;112:627-35.

72. Reichlin T, Michaud GF. Our approach to maximizing the durability of pulmonary vein isolation during a paroxysmal atrial fibrillation ablation procedure. J Cardiovasc Electrophysiol 2012;23:1272-6.

73. Kumar N, Dinh T, Phan K, Timmermans C, Dassen W, Phillippens S, et al. Adenosine Testing after Second generation Cryoballoon Ablation (ATSCA) study improves clinical success rate for atrial fibrillation. [Clinical research]. Europace 2015;17:871-6.

74. Kumar N, Blaauw Y, Timmermans C, Pison L, Vernooy K, Crijns H. Adenosine testing after secondgeneration balloon devices (cryothermal and laser) mediated pulmonary vein ablation for atrial fibrillation. J Interv Card Electrophysiol 2014;41:91-7.

75. Kumar N, Blaauw Y, Timmermans C, Pison L, Vernooy K, Crijns H. Adenosine testing after secondgeneration balloon devices (cryothermal and laser) mediated pulmonary vein ablation for atrial fibrillation. J Interv Card Electrophysiol 2014;41:91-7.

76. Pison L, La Meir M, van Opstal J, Blaauw Y, Maessen J, Crijns HJ. Hybrid thoracoscopic surgical and transvenous catheter ablation of atrial fibrillation. J Am Coll Cardiol 2012;60:54-61.

77. Ehrlich JR, Cha TJ, Zhang L, Chartier D, Villeneuve L, Hebert TE, et al. Characterization of a hyperpolarization-activated time-dependent potassium current in canine cardiomyocytes from pulmonary vein myocardial sleeves and left atrium. J Physiol 2004;557:583-97.

78. Kumar N, Pison L, La Meir M, Maessen J, Crijns HJ. Testing Of Box Lesion By Adenosine. Journal of Atrial Fibrillation 2013-2014:6(4).

79. Medi C, Sparks PB, Morton JB, Kistler PM, Halloran K, Rosso R, et al. Pulmonary vein antral isolation for paroxysmal atrial fibrillation: results from long-term follow-up. J Cardiovasc Electrophysiol 2011;22:137-41.

80. Kumar N, Pison L, la Meir M, Maessen J. Direct visualization of pulmonary vein stenosis after previous catheter ablation. Heart Rhythm 2014;11:1602. 
81. Martinek M, Lemes C, Sigmund E, Derndorfer M, Aichinger J, Winter S, et al. Clinical impact of an openirrigated radiofrequency catheter with direct force measurement on atrial fibrillation ablation. Pacing Clin Electrophysiol 2012;35:1312-8.

82. Ross RT, Burnett CM. Atraumatic lung hernia. Ann Thorac Surg 1999;67:1496-7.

83. Athanassiadi K, Bagaev E, Simon A, Haverich A. Lung herniation: a rare complication in minimally invasive cardiothoracic surgery. Eur J Cardiothorac Surg 2008;33:774-6.

84. Kumar N, Pison L, La Meir M, Maessen J. Atraumatic lung hernia: a rare complication of minimally invasive surgical atrial fibrillation ablation. [case report]. Journal of Atrial Fibrillation 2012;6:3.

85. Kumar N, Pison L, La Meir M, Maessen J. Atraumatic lung hernia: a rare complication of minimally invasive surgical atrial fibrillation ablation. JAFIB: Journal of Atrial Fibrillation 2012;6(4).

86. Gouda H, Multz AS, Khan A, Rossoff $\amalg$, Green LM, Graver D. Lung hernia as a sequela to limited-access mitral valve surgery. Tex Heart Inst J 2002;29:203-5.

87. Ciconte G(1), Chierchia GB, DE Asmundis C, Sieira J, Conte G, Juliá J, DI Giovanni G, Wauters K, Baltogiannis G, Saitoh Y, Mugnai G, Catanzariti D, Tondo C, Brugada P. (2014). Spontaneous and adenosine-induced pulmonary vein reconnection after cryoballoon ablation with the secondgeneration device. J Cardiovasc Electrophysiol 2014;25:845-51. 
Summary

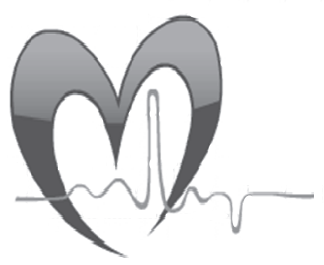




\section{Summary}

The cornerstone of atrial fibrillation (AF) is electrical isolation of the pulmonary veins (PVs). In patients with non-paroxysmal AF, PV isolation alone is insufficient and the atrial arrhythmogenic substrate needs to be modified. Endocardial ablation mostly using catheters is commonly used though with limited success rate. This technique enables one to characterize the underlying substrate in order to tailor the ablation procedure, but these ablation lesions may not always be transmural. Newer technologies as contact force catheters and second-generation balloon devices (cryothermal and laser) are helping to increase the success rates for AF ablation, especially the paroxysmal type. Hybrid ablation combining endocardial and thoracoscopic epicardial ablation is emerging as a suitable option for persistent and long- standing persistent AF. The more often a technology is used the more often the side effects are encountered, e.g., hemoptysis, PV stenosis and lung hernia. Thoracoscopic surgical AF ablation techniques create more reliable linear lesions but the lesion set is based on empirical assumptions rather than specific patient characteristics. Performed in combination (epicardial and endocardial), both approaches are complementary as they overcome their mutual shortcomings. Newer testing techniques as ablation of adenosine- induced dormant conduction seem to be really promising to further increase the success rates of the individual ablation techniques. In this thesis, we revealed that the success rates of AF ablation approaches might be increased by newer techniques as adenosine testing and also combining the different energy sources. Annual and long-term results are promising for the individual approaches. 
Samenvatting

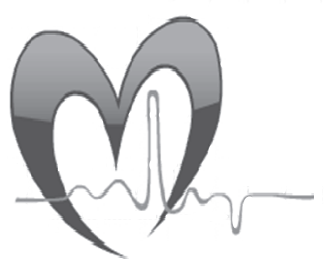




\section{Samenvatting}

In de behandeling van atriumfibrilleren staat electrische isolatie van de pulmonaalvenen centraal. Desondanks biedt ènkel deze behandeling bij patiënten met nietparoxysmaal atriumfibrilleren onvoldoende verbetering en dient bij deze patiënten ook het atriale aritmogene substraat veranderd te worden. Derhalve is endocardiale catheter ablatie een gebruikelijke techniek, maar is het succespercentage gelimiteerd. Endocardiale catheter ablatie stelt de elektrofysioloog in staat om het substraat in kaart te brengen, en een patiënt-specifieke ablatieprocedure uit te voeren. Desalniettemin zijn de laesies vaak niet transmuraal. Technische innovaties, zoals een 'contact force catheter' en een tweede generatie (cryothermie en laser) ballon, hebben het succespercentage aanzienlijk vooral bij patiënten met paroxysmaal atriumfibrilleren. Een hybride behandeling, waarin een endocardiale ablatie gecombineerd wordt met een thoracoscopische epicardiale ablatie, wordt in toenemende mate toegepast om persistent en langdurig persistent atriumfibrilleren te behandelen. Naarmate een nieuwe techniek vaker wordt toegepast, worden de complicaties van deze behandeling zichbaarder zoals hemoptoe, pulmonaalvene stenose en long herniatie. Thoracoscopische chirurgische ablatietechnieken creëeren betrouwbaardere lineaire lesies, waarbij opgemerkt dient te worden dat de gecreëerd lesie-set enkel gebaseerd is op empirische aannames en dus niet patiëntspecifiek is. Wanneer de endocardiale en (thoracoscopische) epicardiale behandeling gecombineerd worden, vullen zij elkaar goed aan, aangezien beide behandelingen elkaars tekortkomingen teniet doen. In dit proefschrift beschrijven wij dat het succespercentage van ablaties bij patiënten met atrium fibrilleren verder verbeterd wordt door de toediening van adenosine en ablatie van 'dormant conduction' en door het combineren van verschillende energiebronnen. Voor de verschillende behandelingen zijn zowel de resultaten na een jaar en lange termijn resultaten veel veelbelovend. 
सारांश

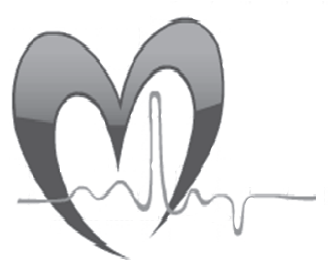




\section{साराश}

एट्रियल फिल्ब्रेलेशन (एएफ) के असली आधार पल्मॅनरी वेन्स (पीवी) के इलेक्ट्रिकल आइसोलेशन हअ। नॉन-पैरोक्सिज्मल एएफ वाला मरीजन में, पीवी आइसोलेशन पर्याप्त मात्रा में ना होला आउर एट्रियल एर्हिथ्मोजेनिक सब्सट्रेट में परिवर्तन जरूरी होला। इंडोकार्डियल एब्लेशन में सबसे जादा कैथेटर्स के इस्तेमाल कईल जाला आ सामान्य रूप से एकर इस्तेमाल होला, हालांकि एकर सफलता दर सीमित बा। एह तकनीक के सहारे एकरा में समाईल गुण-दोष के बारे में बतावल जा सकेला, जवना से अपक्षरण (एब्लेशन) प्रक्रिया के अनुकूल बनावल जा सके, लेकिन एह अपक्षरण (एब्लेशन) घाव के हमेशा ट्रांसम्यूरल होखल ज़रूरी नईखे। कॉन्टैक्ट फोर्स कैथेटर्स आउर सेकंड-जेनरेशन बैलून उपकरण (क्राइयोथर्मल आउर लेजर) लेखा नया तकनीक से एएफ एब्लेशन के सफलता दर के बढ़ावे में मदद मिल रहल बा, खासकर पैरोक्सिज्मल टाईप के एब्लेशन में। इंडोकार्डियल आउर थोरैकोस्कोपिक एपिकार्डियल एब्लेशन के मिश्रण वाला हाइत्रिड एब्लेशन दीर्घस्थायी एएफ के उपयुक्त विकल्प के रूप में उभर रहल बा। कवनो भी तकनीक के जतना अधिक उपयोग कईल जाला, ओकर दुष्परिणाम भी ओतना अधिक ही सामने आवेला, जइसे- हेमोप्टाइसिस, पीवी स्टेनोसिस और लंग हर्निया। थोरैकोस्कोपिक सर्जिकल एएफ एब्लेशन तकनीक के जरिए जादा भरोसेमंद रैखिक घाव कईल जाला, लेकिन ई लिशन सेट कवनो खास मरीज के गुण-दोष के बजाय प्रायोगिक अवधारणा पर आधारित होला। मिला-जुला के (एपिकार्डियल आउर इंडोकार्डियल) कईल जाए वाला, दूनों ही एप्रोच पूरक बा, काहें कि एह से 
एक-दूसरा के दोष के दूर करे में मदद मिल पावेला। एडेनोसाइन-इंड्युस्ड डोर्मेंट कंडक्शन के एब्लेशन जईसन नया-नया टेस्टिंग तकनीक से सही मायने में ढेर उम्मीद बंधअता, जवना से व्यक्तिगत एब्लेशन तकनीक के सफलता दर के आउर अधिक बढ़ावे में मदद मिली। एह थेसिस में, हमनी के एह बात के खुलासा कईनीं जा कि एडेनोसाइन टेस्टिंग लेखा नया तकनीक के जरिए आउर अलग-अलग ऊर्जा स्रोत के मिला के, एएफ एब्लेशन एप्रोच के सफलता दर बढ़ावल जा सकेला। व्यक्तिगत एप्रोच के हिसाब से सालाना आउर दीर्घकालिक परिणाम आशाजनक बा। 
Valorisation

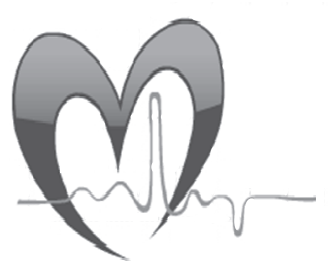




\section{Valorisation}

\section{Summary}

This thesis may help to reduce the complications of current treatment modalities for the most common heart arrhythmia, i.e., atrial fibrillation (AF) during a hybrid procedure and a cryoablation, increase the success rate and standardize the procedure for a possible general adoption in the future.

New parameters for ablation: Recurrence of arrhythmias is due to incomplete, nonuniform and non-transmural lesions causing the conduction of unwanted electrical impulses. Addition of a new parameter like "temperature time integral" (TTI) to existing cryoablation, can help to further describe its efficacy in a better way. Even for epicardial lesions using radiofrequency, addition of contact force parameters may help in achieving uniform lesions.

Automation: To standardize a procedure and make it free of operator-dependent errors, and their respective learning curve, "Automation" must be introduced in the hybrid procedure setting to make it more efficient. Further, new combinations of energy sources can be tested to make a better ablation line and increase its success rate.

Least invasive lesions: To make minimally invasive cardiac surgery (MICS) less invasive by possibly using holes (making this a single-sided approach) to access the heart to put ablative lesions and if possible limit them to one side only.

Contiguous and transmural lesions: Cox Maze IV has the highest success rate among all procedures. The single important limitation to replicate this procedure is the nonuniform and/or non-transmural lesion (either endocardial alone or in a minimally invasive setting).

\section{Relevance}

The most common arrhythmia worldwide is AF with an incidence of 6 million patients in the United States. AF is a major cause of stroke and an independent risk factor for mortality. Despite advances in medical therapy, it has only been effective in restoring sinus rhythm (SR) in half of all the patients with AF. This disease entity also independently predicts the risk of death, hospitalization, stroke, and all-cause mortality. The global prevalence and costs of AF are expected to surge owing to factors such as economic growth, an ageing population, and increased prevalence of risk factors for AF in both Western countries and rapidly developing countries such as Brazil, China, India, and Indonesia. 
Epidemiological and clinical studies have also proven that AF is a strong independent risk factor for stroke, exposing patients to a 3- to 5-fold increased risk. Uncontrolled AF may contribute to the development of chronic heart failure. Due to the increasing age of the general population, the AF burden will grow further. By the year 2050, there will be a 2.5-fold increase in the number of affected US adults, resulting in almost 6 million patients and half of them will be 80 years or older.

\section{Target groups}

My work can be of special interest to the arrhythmologists and health care providers who use these techniques for treating patients with AF. It may give them insight into how to achieve better success rates, and avoid the complications.

Inherently to my theme of research, this work might also interest the patient who undergoes such procedures, their well wishers including family members, and relatives too. Opting for ablation therapy not only affects the procedural outcomes, e.g., complications and success rates, but also can help to restore faith in the medical community due to the AF burden.

These research results should interest medical companies because of the favourable outcomes this novel device may bring about. It could help them technically modify and improve their product that we have discussed in various chapters of the thesis.

\section{Activities/Products}

With the findings regarding complications, a cryoballoon (Medtronic, Inc) can be made safer for clinical use. Furthermore, a new parameter, i.e., temperature-time curve can be used during cryoablation. The new parameter may give a more realistic approach for an effective cryotherapy.

Moreover, one of the chapters describes the unique combination of epicardial and endocardial ablation; the real contrasts of radiofrequency and freezing in the same patient for the first time. This opens a whole new window of opportunities for device makers to explore this domain and to attempt different energy combinations.

The possibility of using hot water/steam in a balloon based catheter as an ablative medium rather than using nitrous oxide or laser can be attempted.

One of the suggestive combinations is a cryoballoon with thin electromagnetic wafers which will be placed inside PVs and epicardially another energy source, e.g., a cryo probe or radiofrequency probe would be attached and then ablation will be done. By 
using this hybrid approach and acting on both sides of the heart, transmurality of the ablation lesion created might ultimately become better, thus transforming to better success rates. Simultaneous use of an epicardial and an endocardial energy source may be better employed to complement each other for different purposes, e.g., not only for pacing but also signal detection. "Automation of an electrophysiological procedure" is the key to increasing the efficiency of the staff members and an institution. I really believe in the concept of a fusion device that combines a pacemaker (as it can detect signals as PV potential) after pacing from an endocardial coronary sinus (CS) catheter, and an epicardial ablation system placed around the target PV (with inner surface divided into 5-6 segments). A small current will be sent from the CS catheter and the sensors in the epicardial device would detect the PV potential using the same algorithm of the pacemaker. And whichever segment of the device detects them, it would start to automatically and selectively ablate in only that segment.

\section{Innovation}

TTI is a new parameter that has never been used for cryoablation.

To standardize a procedure and make it free of operator-dependent errors and their respective learning curve, "automation" must be tried in a hybrid procedure setting to make it more efficient. This can be achieved easily based on existing technologies which are used in a modern pacemaker- everything that is needed is to modify them suitably and test them further. For physicians, both electrophysiologists and surgeons, the procedures will become less complex. More importantly, the possibilities to get information on the mechanisms of $\mathrm{AF}$ from a completely new perspective may potentially bring about a patient-tailored ablation approach, making it more affordable.

\section{Schedule \& Implementation}

Development of the new parameter of TTI may take up to 16-18 months including 5-6 months for development of a new program and later finally testing it to see its effect and annual success rate.

However for the rest it may take 2-3 years minimum with the aims of developing and evaluating this platform of new instruments. To obtain the functionality needed, existing technologies can be used and combined. Previously developed animal models in our institution will facilitate this tract. In addition, the presence of a hybrid intervention room offers the right conditions to evaluate results in humans. In parallel to the tool development part of the program, patient-related mechanisms of AF would be studied from a new perspective as mapping studies could be performed simultaneously from the inside and outside of the atrial wall. This approach is necessary 
to enhance our knowledge of $\mathrm{AF}$ as the mechanism of $\mathrm{AF}$ is considered three dimensional in nature.

\section{Patents}

There is neither a European nor US patent existing on these concepts. 
Acknowledgements

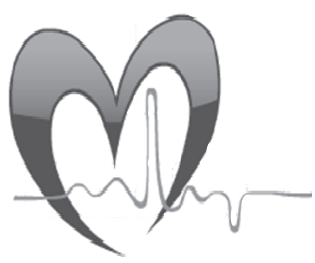




\section{Acknowledgements}

I am thankful to Prof. Jos Maessen for accepting to be my promoter and guide. He has always been kind, understanding, and giving freedom to work with immense faith. He is a man who leads by example of innovative thinking, open nature, and futuristic mindset. I am honored to have worked under his guidance.

Prof. Harry J. Crijns thank you for allowing me to work in the Cardiology department and for the occasional fruitful academic discussions and personal feedback you had for me.

Dr. Carl Timmermans thank you from the bottom of my heart for everything. You literally held my hand and showed me how to proceed to the next step while performing different invasive EP procedures. You were patient (mostly) enough to explain the fundamental concepts with insightful discussions to a naive young guy. Thank you for introducing me to the world of cardiac electrophysiology and academic writing.

It has been kind of Prof. Dr. Sandro Gelsomino for helping me during in-vivo hybrid ablation experiments. With time to come and able co-operation with $\mathrm{Dr}$ Pieter Lozekoot, I am sure this ambitious project is in safe hands to blossom and prosper in future.

Liegeois Lysette has been quite kind to help and guide me with the various managerial issues and official paperwork at innumerable stages. I can still never forget your help offered even before my Maastricht arrival.

Dr. Mark La Meir is always so energetic, enthusiastic, and helpful to offer his help especially in relation to hybrid procedures.

Suzanne Philippines is always so cheerful in helping with most of the data accumulation, and doing follow-up of patients during innumerable studies.

Antoine P. Simons - my dear friend always has a possible solution and helping hand whenever I used to feel stuck or confused anywhere regarding the professional topics. Thank you my friend for being there and for the wonderful discussions in our office space.

Dr. Laurent Pison has been nice to help me with manuscript revisions, intellectual input for academic work, and trusting me for hybrid procedure projects. 
Dr. Mohamed Magdi Abbas (Sharjah, UAE) for your frequent guidance and continuous support not just for me, but also for the global EP community.

Dr Muralidhar Kanchi has always been so supportive and encouraged us to dream big and aim higher. Being the dean of Narayana Hrudayalaya and chief of dept. of anaesthesiology and critical care, you still managed to squeeze time to give tips to the needy students. Dr. Devi Shetty for having the faith in this young guy for entrusting me with a completely new department and encourage him to follow his dreams. Dr Ravi Kishore thank you for your words of advice and finding time for me in spite of your busy schedule, whenever I felt lost in the professional world.

Thank you Kevin Phan- brother from another mother. It has been such a fruitful cooperation for different projects.

Dr Andreaz Metzner, Prof. Karl Heinz Kuc, Prof. Gerhard Hindricks and Dr Andrea Natale - Your words of wisdom that you shared, will always be there with me as part of my life. It was nothing sort of blissful enchants.

I am really thankful to Willy Rompelberg, Solange Haegmans, Patrick Zweiphennig, Bert Hounjet, Niki Claessens, Mary Stevelmans, Luc Debbie, Mariska Merken, Elly Pattiwael, Ruud Duysings, Leon Lamerichs, Rachel Hehalatu, Alexa holthuijsen, Karen Zomers, Michel Janssen, Jacque Duits, Rolanda, Erik Brands(Cath. Lab); Paul kwant and IDEE colleagues; Nousjka Vranken(Dept. of CTC); Erik (Dept. of ICT), and many more unnamed colleagues for being so kind and always helpful. I am thankful to from the bottom of my heart to Martine Berghof, Marjo Zwaneberg, Inge de Roo, Miriam Habex Froidmont who helped my stint at Maastricht into a much smoother journey.

I am really thankful to Prof. Frits Van Merode, Dr Ismail Aksoy, Dr Randolph Manusama, Dr Robert Bolderman, Dr. Yuri Blaauw, Dr Mustafa Ilhan, Dr Kevin Vernooy, Dr Rachel ter Bekke, Dr Willem Daessen, Dr Trang Dinh, Dr Justin Luermans, Dr. Theo Lankveld, Dr Bart Maesen, Dr Masih Mafi Rad, Dr Paul Volders, Dr Nathalie van Brugel for the academic help provided during my stint at Maastricht University Medical Center.

I am falling short of words to thank my dear friends Peter van Roosmalen, Dr George Koshy (Jupiter Hospital, Dubai), Dr Venkatesh Murthy (University of Michigan, USA), Dr Yasuaki Sagara (Harvard Medical School, Boston), Dr Sameer Ahmed, Dr Jewel Ahmed, Dr Amiay Kumar, Dr Sunil Kumar, Dr Abhinav Malhotra, Eliene Albers, Mimi Hanneman, Dr Ajay Sharma, Dr Madhav Tamhankar, Naveen Kashyap, the Hollnacks and many more for being there as my buddies. 
I am always grateful for the unconditional love under parental umbrella bestowed by my father Prof. Sheo Jag Singh and mother Kaushalya Devi who taught me "It is good to be a better professional, but best to be a human being." They always showered me abundant affection, care, faith in my decisions and supported me. My brother Er. Om Prakash Singh, sister Anisha Singh, uncle honorable retd. Justice Bishwanath Singh who all always extended me their help through thick and thin times. My dear Kiran Kumari you are always there fresh in our memories forever.

I cannot forget the words of encouragement and love from Mausaji (uncle) Er. Vishwanath singh and Mausiji (aunt) Mrs Malti Devi since childhood days. Er. Roshan Kumar, Mrs Shikha Choudhary, and family- how can I forget you my lovely brother, you have been the best buddy and brother I can have. Thank you all for making me feel nothing less than blessed.

Last but not the least, everyone who became part of my life- named and unnamed and helped me achieve and being the man who I am today. Heartfelt thank you to everyone. 
Curriculum Vitae

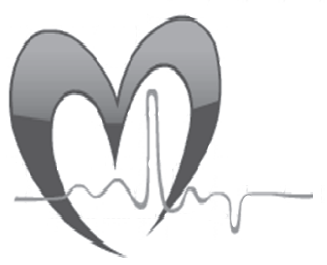


CV 


\section{Curriculum Vitae}

Narendra Kumar was born on $8^{\text {th }}$ October 1982 at Bikramganj, India. After finishing his elementary schooling at Bhagalpur, and secondary school at Patna, he moved to Bangalore to study medicine at $\operatorname{Dr}$ B R Ambedkar Medical College (Rajiv Gandhi University of Health Sciences). He graduated as medical doctor (2000-05). After finishing clinical internship (2005-06) at K.C. General Hospital, Bangalore, he obtained Post Graduate Diploma in Clinical Cardiology with distinction in 2009 from Narayana Hrudayala Institute of Cardiac Sciences, Bangalore. He continued to work there at the Department of Cardiology till mid-September 2010 before joining Maastricht University Medical Center. By September 2012 he was allowed to work as a clinical fellow and obtain training in the cardiac electrophysiology department under the supervision of Dr. Carl Timmermans. Since mid 2013, he worked as a consultant for DISCOVERY, PAINFREE-SST and Improve SCA clinical trials. He was invited to join the young cardiac electrophysiologist of the "European Society of Cardiology" 2014. Later, in June 2014 he pursued advanced medical teaching techniques from Harvard Medical School. He passed the 2015 EHRA invasive cardiac electrophysiology board examination with distinction. He is involved with several journals as a reviewer including "The Lancet", "Surgery", "Heart Rhythm Journal" etc. He has been invited by Journals including "Nature Review", and "E-Journal of Cardiology Practice" published by European Society of Cardiology to contribute on various topics. He received Erasmus training scholarship 2015 to visit St. Georg Hospital under mentorship of Prof. Karl-Heinz Kuck. 
List of publication

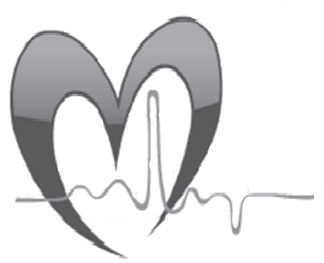




\section{Abstracts/presentations}

- Oral abstract presentation N. Kumar, L. Pison, M. La Meir, J. Maessen, H.J. Crijns "Hybrid approach to atrial fibrillation ablation using cryoballoon endocardially and bipolar RF clamp epicardially" at 63rd annual conference of cardiological society of India at Mumbai-December 2011.

- Safety and feasibiity of adenosine administartion during hybrid atrial fibrillation ablation to test dormant pulmonary vein conduction. L. Pison, N. Kumar, Y. Blaauw, K. Vernooy, J. Maessen, H.J. Crijns, M. La Meir. Maastricht University Medical Centre, Maastricht, Netherlands at $18^{\text {th }}$ world congress in Canada, july 2013.

- Adenosine testing after endoscopic ablation system (EAS) pulmonary vein ablation for atrial fibrillation N. Kumar,Y. Blaauw, C. Timmermans, L. Pison, R.T. Bekke, K. Vernooy, J. Maessen, H.J. Crijns. Venice arrythmias October 2013

- Safety and Feasibility of Use of Contact Force Catheter during Hybrid Procedure for Atrial Fibrillation Ablation. N. Kumar, L. Pison, M. La Meir, J. Maessen, H.J. Crijns. At ISMICS, Boston May 2014.

- Chaired a session during TM's 4th World Cardiovascular Online Conference during session 9 on "Epidemiology of Cardiovascular Diseases" and presented "Impact of hybrid procedure for atrial fibrillation ablation on P-wave duration and its association with other pre-operative data." N. Kumar, L. Pison, M. La Meir, J. Maessen, H.J. Crijns. 


\section{List of publications}

- Kumar N, Pison L, la Meir M, Maessen J. Direct visualization of pulmonary vein stenosis after previous catheter ablation. Heart Rhythm, DOI:10.1016/j.hrthm.2013.10.052.

- Kumar N, Pison L, La Meir M, Maessen J. Atraumatic lung hernia: A rare complication of minimally invasive surgical atrial fibrillation ablation. Journal of Atrial Fibrillation. 2013;6:3

- Kumar N, Pison L, La Meir M, Maessen J, Crijns HJ. Testing of box lesion by adenosine. Journal of Atrial Fibrillation. 12/2013; 6(4).

- Kumar N, Timmermans C, Pison L, Crijns H. Hemoptysis: Deja vu for cryoballoon use for pulmonary vein isolation for atrial fibrillation ablation. Chest. 2014;145:1435 Kumar N, Timmermans C, Das M, Pison L, Maessen J, Crijns H. Re: Ct imaging of complications of catheter ablation for atrial fibrillation. Clinical Radiology. 2014;69:e367-368

- $\quad$ Kumar N, Pison L, La Meir M, Maessen J, Crijns HJ. Hybrid approach to atrial fibrillation ablation using bipolar radiofrequency devices epicardially and cryoballoon endocardially.Interact CardioVasc Thorac Surg(2014) 19 (4): 590594.doi: 10.1093/icvts/ivu189

- $\quad$ Kumar N, Blaauw Y, Timmermans C, Pison L, Vernooy K, Crijns H. Adenosine testing after second-generation balloon devices (cryothermal and laser) mediated pulmonary vein ablation for atrial fibrillation. Journal of Interventional Cardiac Electrophysiology. 2014;41:91-97

- Kumar N, Phan K, Aksoy I, Pison L, Timmermans C, Maessen J, Crijns H. Management of pulmonary vein stenosis following catheter ablation of atrial fibrillation. Journal of Atrial Fibrillation. 08/2014;7:1

- Kumar N, Phan K, Pison L, Maessen J. (2014). Re: Clinical characteristics and prognostic significance of chronic obstructive pulmonary disease in patients with atrial fibrillation: results from a multicenter atrial fibrillation registry study. Journal of the American Medical Directors Association, doi:10.1016/j.jamda.2014.08.015.

- Kumar N, Timmermans C, Pison L, Crijns H. (2014). Hemoptysis After Cryoablation for Atrial Fibrillation Truth or Just a Myth? Chest. 2014;146(5):e173-e175. doi:10.1378/chest.14-1600.

- Kumar N, Phan K, Timmermans C, Pison L, Meir ML, Maessen J, et al. (2014). Catheter ablation of atrial fibrillation: The missing links. Eur Heart J. doi:10.1093/eurheartj/ehu291

- $\quad$ Phan K, Xie A, Tsai Y-C, Kumar N, La Meir M, Yan TD. Biatrial ablation vs. left atrial concomitant surgical ablation for treatment of atrial fibrillation: a meta-analysis. DOI: 10.1093/europace/euu220.

- $\quad$ Phan K, Xie A, Kumar N, Wong S, Medi C, La Meir M, Yan TD. Comparing energy sources for surgical ablation of atrial fibrillation: A Bayesian network meta- analysis of randomized controlled trials. Eur J Cardiothorac Surg. 2014 Nov 12. DOI:10.1093/ejcts/ezu408: ezu408. 
- $\quad$ Kumar N, Aksoy I, Phan K, Wainer J, Timmermans C. "Coronary spasm during cardiac electrophysiological study following isoproterenol infusion" for Interventional Medicine \& Applied Science. 6 (4), 183-186, doi:10.1556/IMAS.6.2014.4.7.

- $\quad$ Pison L, Peeters P, Blauw Y, Vernooy K, Kumar N, Philippens S, Crijns HJ, Jean SJ, Timmermans C. Headache during Balloon Cryoablation for Atrial Fibrillation. doi:10.1093/europace/euu321

- Kumar N, Dinh T, Phan K, Timmermans C, Das M, Dassen W, Phillippens S, Maessen J, Crijns $\mathrm{H}$. Adenosine Testing after Second generation Cryoballoon Ablation (ATSCA) study improves clinical success rate for atrial fibrillation. Europace; 10.1093/europace/euu352

- $\quad$ Kumar N, Bonizzi P, Mafi Rad M, Lankveld T. "Editorial - Left atrial dyssynchrony time measured by tissue Doppler imaging to predict atrial fibrillation recurrences after pulmonary vein isolation: Is this a mirage or the panacea?" Anadolu kardiyoloji dergisi: AKD = the Anatolian journal of cardiology 2015; 15:123-124.

- Kumar N, Pietro B, Pison L, Phan K, Lankveld T, Meir Mark La, Maesen B, Sandro G, Maessen J, Crijns $\mathrm{H}$. Impact of hybrid procedure on $\mathrm{P}$ wave duration for atrial fibrillation ablation. Journal of interventional cardiac electrophysiology. 2015. DOI: 10.1007/s10840-014-9969-9

- $\quad$ Bonizzi P, Kumar N, Zeemering SLM, Peeters R, Pison L. A novel P-wave modeling method to assess $\mathrm{P}$-wave duration impact after hybrid procedure for atrial fibrillation ablation. Conference: Computing in Cardiology 2014. DOI: $10.13140 / 2.1 .4089 .8882$

- $\quad$ Kumar N, Dinh T, Magdi Abbas M, Phan K, Phillippens S, Maessen J, Timmermans C. Not getting the suitable temperature during cryoballoon ablation: blame the refrigerant cylinder. Res Cardiovasc Med 03/2015; 4(1). DOI: 10.5812/cardiovascmed.25592

- Phan K, Wang N, Pison L, Kumar N, Hitos K, Thomas SP. Rivaroxaban versus warfarin or dabigatran in patients undergoing catheter ablation for atrial fibrillation: a meta-analysis. Int J Cardiol. 2015 Apr 15;185:209-13.DOI: 10.1016/j.ijcard.2015.03.102.

- Phan K, Wang N, Pison L, Kumar N, Hitos K, Thomas SP: Meta-analysis of dabigatran vs warfarin in patients undergoing catheter ablation for atrial fibrillation. International journal of cardiology 04/2015; DOI:10.1016/j.ijcard.2015.04.072

- $\quad$ Kumar N, Pison L, La Meir M, Maessen J, Crijns H. Pulmonary vein stenosis after laser balloon ablation for atrial fibrillation. Journal of American college of Cardiology: clinical electrophysiology.DOI:10.1016/j.jacep.2015.04.001

- Kumar N, Abbas M, Ter Bekke R, de Jong C, Choudhury R, Bisht O, Philippens S, Timmermans $C$. Maastricht experience with the second generation endoscopic laser balloon ablation system for the atrial fibrillation treatment. Netherlands heart journal. DOI: 10.1007/s12471-015-0703-8 [IF= 2.2]

- $\quad$ Kumar N, Lozekoot P. The Acute Effects of Adenosine Administration After Visually Guided Laser Balloon Ablation for Atrial Fibrillation Treatment and Follow-up. Europace. DOI: http://dx.doi.org/10.1093/europace/euv196 
- $\quad$ Kumar N, Pison L, La Meir M, Maessen J, Crijns HJ. The symbiotic use of a contact force catheter during hybrid ablation for atrial fibrillation ablation. Netherlands heart journal. DOI: 10.1007/s12471-015-0729-y

- Hakseem SKHa, Wang N, Wong S, Phan S, Liao J, Kumar N, Qian P, Yan TD, Phan K. Catheter ablation for atrial fibrillation in hypertrophic cardiomyopathy patients: a systematic review Journal of interventional cardiac electrophysiology. 2015. DOI: 10.1007/s10840-015-0047-8

- $\quad$ Kumar N, Pison L, Lozekoot P, La Meir M, Maessen J. We know what the cardiac surgeon did during last hybrid arrhythmia procedure. Innovations: Technology and Techniques in Cardiothoracic and Vascular Surgery. (Recently accepted) 